NATIONAL LABORATORY

\title{
Role for Distributed Energy Resources (DER) in the Digital Economy
}

\section{October 31, 2007}

Prepared by EPRI PEAC Corporation for ORNL Technical Manager: D. Tom Rizy

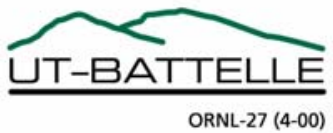




\title{
DOCUMENT AVAILABILITY
}

Reports produced after January 1, 1996, are generally available free via the U.S. Department of Energy (DOE) Information Bridge.

Web site http://www.osti.gov/bridge

Reports produced before January 1, 1996, may be purchased by members of the public from the following source.

\author{
National Technical Information Service \\ 5285 Port Royal Road \\ Springfield, VA 22161 \\ Telephone 703-605-6000 (1-800-553-6847) \\ TDD 703-487-4639 \\ Fax 703-605-6900 \\ E-mail info@ntis.gov \\ Web site http://www.ntis.gov/support/ordernowabout.htm
}

Reports are available to DOE employees, DOE contractors, Energy Technology Data Exchange (ETDE) representatives, and International Nuclear Information System (INIS) representatives from the following source.

Office of Scientific and Technical Information

P.O. Box 62

Oak Ridge, TN 37831

Telephone 865-576-8401

Fax 865-576-5728

E-mail reports@osti.gov

Web site http://www.osti.gov/contact.html

\begin{abstract}
This report was prepared as an account of work sponsored by an agency of the United States Government. Neither the United States Government nor any agency thereof, nor any of their employees, makes any warranty, express or implied, or assumes any legal liability or responsibility for the accuracy, completeness, or usefulness of any information, apparatus, product, or process disclosed, or represents that its use would not infringe privately owned rights. Reference herein to any specific commercial product, process, or service by trade name, trademark, manufacturer, or otherwise, does not necessarily constitute or imply its endorsement, recommendation, or favoring by the United States Government or any agency thereof. The views and opinions of authors expressed herein do not necessarily state or reflect those of the United States Government or any agency thereof.
\end{abstract}


Engineering Science and Technology Division

\section{Role for Distributed Energy Resources (DER) in the Digital Economy}

Prepared by EPRI PEAC Corporation

for ORNL

Technical Manager: D. Tom Rizy

Date Published: October 31, 2007

Prepared by

OAK RIDGE NATIONAL LABORATORY

Oak Ridge, Tennessee 37831-6283

managed by

UT-BATTELLE, LLC

for the

U.S. DEPARTMENT OF ENERGY

under contract DE-AC05-00OR22725 
The Power of Reliability ${ }^{\circledR}$

\title{
Role for Distributed Energy Resources (DER) in the Digital Economy
}

\section{Final Report: DER Opportunity and Feasibility} Assessments

Contract No. UT - Battelle, 4000008315

\author{
Prepared by: \\ EPRI PEAC Corporation \\ 942 Corridor Park Blvd \\ Knoxville, Tennessee 37932
}

\author{
Principal Investigators \\ Karen Forsten \\ Thomas S. Key \\ Lawrence C. Markel
}

Point to Contact: Thomas S. Key

Telephone: 865-218-8082

tkey@epri-peac.com

December 31, 2004 


\begin{abstract}
A large, and growing, part of the Nation's economy either serves or depends upon the information technology industry. These high-tech or "digital” enterprises are characterized by a dependence on electronic devices, need for completely reliable electric power supply, and intolerance to any power quality problems. In some cases these enterprises are densely populated with electronic loads and have very high energy usage per square foot. Serving these enterprises presents both electric power and equipment cooling challenges. Traditional electric utilities are often hard-pressed to deliver power that meets the stringent requirements of digital customers the economic and social consequences of a service quality or reliability problem can be large. New energy delivery and control options must be developed to effectively serve a digital economy. This report explores how distributed energy resources or DER, partnerships between the utility and the customer to share the responsibility for service quality, innovative facility designs, higher energy efficiencies and waste-heat utilization can be coupled to meet the needs of a growing digital economy.
\end{abstract}




\section{Table of Contents}

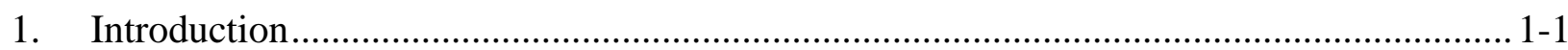

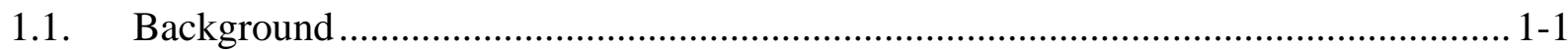

1.2. Project Objectives ............................................................................................ 1-2

1.3. The Pervasiveness of Digital Economy ………………............................................... 1-3

1.4. A Common Thread - The Microprocessor ………....................................................... 1-4

1.5. Trends in the Digital Sectors........................................................................... 1-5

1.5.1 Power Quality and Reliability Requirements ....................................................... 1-9

1.6. Issues and Concerns - Why Consider a DER Option? .................................................. 1-9

1.6.1 Distribution Power Quality and Reliability Studies............................................ 1-10

2. Digital-User Needs................................................................................................ 2-1

2.1. Understanding Needs of a Digital Economy .............................................................. 2-1

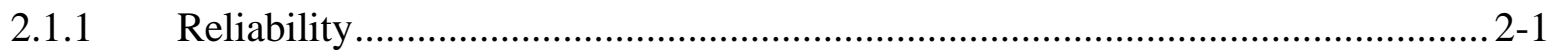

2.1.2 Availability ………………................................................................. 2-2

2.1.3 Availability as a Measure of Reliability …….................................................. 2-3

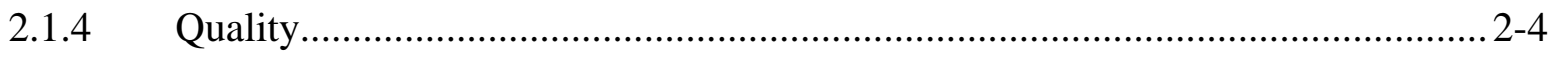

2.1.5 Power Quality Impact on Process Reliability …………….................................. 2-4

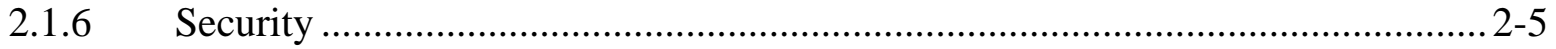

2.1.7 An Approach to Powering the Digital Economy ............................................... 2-6

2.2. Customer Segments and Drivers........................................................................... $2-8$

2.2.1 Concentrated Digital Loads (digital service industries)......................................2-9

2.2.2 High-Tech Manufacturing (digital process industries) ...................................... 2-10

2.2.3 Power Parks (multi-energy and power-quality) ................................................... 2-11

2.3. Digital Needs and Deregulated Utility Industry …................................................... 2-13

2.4. Power Delivery and Technology Gaps ................................................................... 2-14

3. DER Opportunity Assessment ................................................................................... 3-1

3.1. Options for Incorporating DER ………………................................................ $3-1$

3.1.1 Today’s DER Technologies and Systems ......................................................... 3-2

3.1.2 Future Utility Configurations and Systems........................................................ 3-4

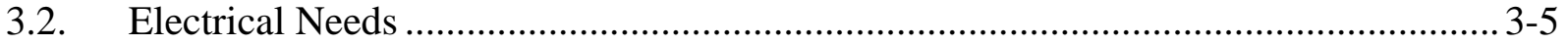

3.2.1 End-Use Equipment Susceptibility to Power Variations ........................................ 3-5

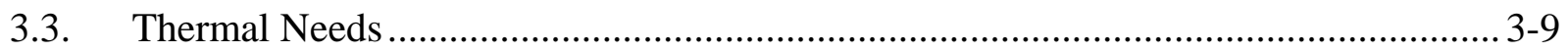


3.3.1 Present Practices for Cooling Digital Equipment ............................................... 3-10

3.3.2 Future Approaches - Opportunities for DER …………………..................... 3-11

3.4. DER for High-Tech Consumers............................................................................ 3-15

3.4.1 Value Proposition for DER in a Digital Economy.............................................. 3-20

3.4.2 Reliability of DER Compared to Conventional Power..................................... 3-22

3.4.3 Potential for Ancillary Services ....................................................................... 3-22

4. DER Feasibility Assessment....................................................................................

4.1. Potential DER Value Streams ........................................................................... 4-1

4.1.1 Screening DER for Digital End Use ............................................................. 4-5

4.1.2 Sizing of DER in Different Modes .............................................................. 4-10

4.1.3 Assessment of Efficiency Advantage …………...................................... 4-12

4.2. User-Owed DER for Digital Economy ……………............................................. 4-15

4.2.1 Feasibility for Premium Power from DER …………………………................ 4-22

4.2.2 Feasibility for CHP in High-Technology Facilities ............................................. 4-22

4.2.3 Most Likely Scenarios of End-User Owned DER ............................................ 4-26

4.2.4 Future Designs for High Technology Facilities................................................. 4-28

4.3. Utility-Owned DER for Digital Economy …………............................................. 4-30

4.3.1 Characteristics of Utility Supply Compared to DER ........................................ 4-31

4.3.2 Costs of Integrated DER Compared to Traditional T\&D Systems.................... 4-33

4.3.3 DER in Lieu of a Line Extension.................................................................... 4-36

4.3.4 Most Likely Scenarios of Utility-Owned DER................................................. 4-37

5. Conclusions and Recommendations ……………....................................................... 5 -1

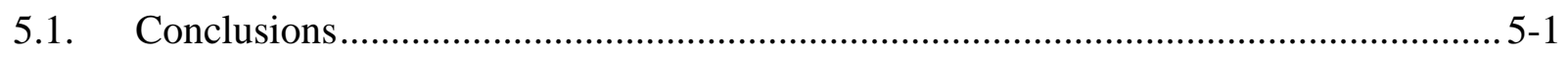

5.2. Recommendations for Future R\&D ...................................................................

5.2.1 Interconnection for DER-Compatible Distribution-System Architecture, and Control Methodologies ............................................................................................ 5-2

5.2.2 DER Compatible Distribution System Architecture ............................................. 5-2

5.2.3 Heat Recovery from Load Devices .................................................................. 5-2

5.2.4 Proof-of-Concept Designs, Modeling, and Lab Tests for DER based Premium

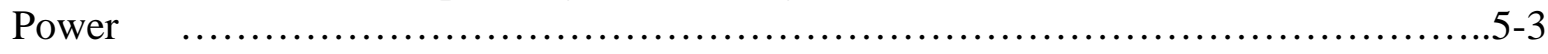

5.2.5 Detailed Economics DER ………………………............................................. 5-3

5.2.6 Power Equipment and Devices .................................................................... 5-3 


\section{List of Figures}

Figure 1-1 Sectors of Opportunity for DER in the Digital Economy …….................................. 1-3

Figure 1-2 The Pervasiveness of Digital Systems, Processes, and Enterprises ........................... 1-4

Figure 1-3 Application of Semiconductors: Percentage by End-use Sector (Source:

Semiconductor Industry Association)................................................................................

Figure 1-4 Balancing the Benefits and Costs of Microprocessor Technology ….........................1-6

Figure 1-5 Moore's Law of Digital Innovation ...................................................................... 1-7

Figure 1-6 Heat Density Trends for Information Technology Equipment ................................... 1-8

Figure 1-7 General Locations of Electric Utilities Participating in the EPRI Distribution

Power Quality Project .......................................................................................................... 1-10

Figure 1-8 Typical Interruption and Sag Rates as a Function of Voltage Magnitude ................1-12

Figure 1-9 Voltage Sags Below 70\% of Normal - $\mathrm{SARFI}_{70}$ Measurements at Study

Sites for EPRI Distribution Power Quality Study................................................................... 1-13

Figure 2-1 Average Hourly Costs of Computer Downtime for Various Business Types ........... 2-5

Figure 2-2 Area of DER Opportunities between Normal Operations and the Concern to

Reduce Costs and Emergency Operations and the Concern to Maintain Power and

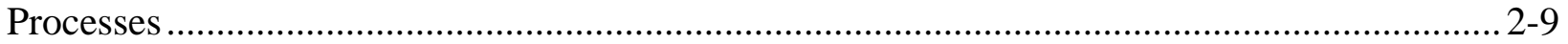

Figure 2-3 Elements of a Multi-Energy Approach include Various Distributed Generation, Heat Recovery, and Utilization Side Technologies

Figure 2-4 A Multi-Energy System Composed of Conventional Power Distribution,

Renewable and Fuel Cell Energy Sources Controlled by an Integrated Energy

Management System ............................................................................................................ 2-13

Figure 3-1 Value Proposition for DER is Often Based on Higher Costs and Benefits. ........... 3-20

Figure 3-2 Two Generators Each Rated to Carry the Entire Load Offer Contingency for a Single Unit Filter Providing Much Greater Reliability Then a Single Unit ............................ 3-23

Figure 4-1 Two Types of DER Operations: (a) Standalone and (b) Grid-Parallel ..................... 4-3

Figure 4-2 Faults in Power Systems Affect Voltage in the Vicinity (and these events are the most common cause of power-related end-user equipment disturbances).

Figure 4-3 A Generator That is Undersized to Supply the Total Islanded Building Load Can Still Carry the Critical Load if High-Speed Load Shedding is Used

Figure 4-4 If Operated as an Island, Generation Must be Sized to Handle Peak Load but Most of the Time it Operates at Average Load — This Leads to Highest Cost of Energy .......... 4-12

Figure 4-5 Combined Heat and Power Applications are the Best Route to High

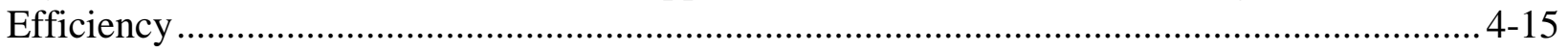

Figure 4-6 Size Ranges for Various Small Scale Generation Technologies …………….......... 4-17

Figure 4-7 Spectrum of DER and Premium Power Equipment and Configurations .................. 4-18 
Figure 4-8 Various Exposures, Potential Hazards and Miles of Power Delivery Equipment Lay Between the Typical Central Power and Load Centers then Between DER and Load.

Figure 4-9 Addition of Alternate Generator Source Enhances Power Availability.

Figure 4-10 Typical auxiliary equipment required to convert a standby source to premium power.

Figure 4-11 CFD image showing hot spot in raised-floor data center with no supplemental cooling Source [13]

Figure 4-12 CFD image showing same data center with supplemental cooling Source [13]

Figure 4-13 Distributed Resources Supplement Distribution System of the Future

Figure 4-14 Hypothetical Comparison between the Costs of Conventionally Delivered Power and Costs of a Low-Voltage Micro-Grid Application.....

Figure 4-15 Illustration of Cost Distribution of Utility Energy Cost Scenarios Overlaid on Possible DER Cost Scenarios

Figure 4-16 Distributed Generation Provides a Capacity Benefit Only if it is Available at the Time of Peak System Loading 4-38

Figure 4-17 Dispatchable DER can Operate with Renewable DER to Regulate Loading 4-39 


\section{List of Tables}

Table 1-1 Number of Annual Events by SARFI Levels for All Sites in the EPRI DPQ

Study $1-13$

Table 2-1 Relationship between Number of Nines and "Minutes Off” Supply ........................... 2-3

Table 2-2 Levels of Availability (Source: Sun Microsystems) .................................................. 2-10

Table 2-3 End-User Reasons for Using Digital Technologies (Source: U.S. Census

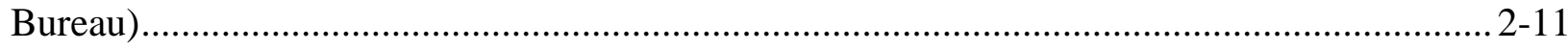

Table 2-4 Impacts of Electrical Supply Disturbances on Manufacturing Processes .................. 2-12

Table 3-1 Application of DER to Thermal Management of Concentrated Digital Load

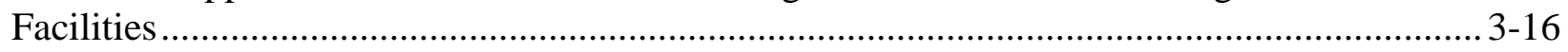

Table 3-2 Summary of Customer Needs and DER Applications .............................................. 3-18

Table 4-1 Inventory of different user values and related costs in DER applications. ................. 4-2

Table 4-2 Potential DER Benefits for Digital Facilities ............................................................ 4-16

Table 4-3 Performance Characteristics of a Standalone DER and a Utility Service

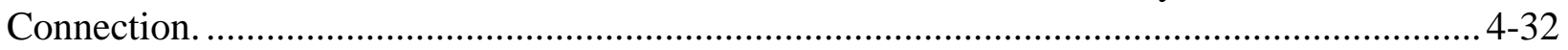

Table 4-4 The Generator Is Currently the Major Cost Contributor in Micro-Grid Systems ..... 4-35 


\section{Introduction}

A large, and growing, part of the Nation's economy serves and/or is dependent upon the information technology industry. These high-tech or "digital” enterprises are characterized by a dependence on electronic devices, need for completely reliable electric power supply, and intolerance to any power quality problems. In some cases these enterprises are densely populated with electronic loads and have very high energy usage per square foot. Serving these enterprises presents both electric power and equipment cooling challenges. Traditional electric utilities are often hard-pressed to deliver power that meets the stringent requirements of digital customers the economic and social consequences of a service quality or reliability problem can be large. New energy delivery and control options must be developed to effectively serve a digital economy.

This report explores how distributed energy resources, partnerships between the utility and the customer to share the responsibility for service quality, innovative facility designs, and energy efficiency and waste heat utilization can address these digital energy needs. Improving reliability and power quality (PQ) throughout the grid may not be technically or economically feasible. The needs of digital customers, and therefore the solutions, are localized. In applications where PQ and reliability are a premium, such as high-tech industrial processes, sensitive electronic equipment, or "smokestack" industries whose processes rely on computerized sensors and controls, one must determine the type and value of distributed energy resources (DER) and customer-side technologies to solve service quality problems. Consequently there is a need for an effective assessment tool that predicts whether DER is technically and financially viable for different installations and system scenarios, and for various DER options.

\subsection{Background}

To serve the new digital economy, the degree of electric power quality and reliability is being elevated to a new level, commonly described in "high 9's" of availability with zero defects. The new level of power quality, reliability and availability required to meet the stringent requirements of the digital economy is typically from 99.9999\% ("six nines") to as much as an unprecedented "nine nines", compared with the traditional "two to three nines" offered as standard utility service. The "high nines" characterization of reliability requirements does not adequately portray the requirements of a mission-critical facility, or the costs and damages resulting from a reliability or power quality problem. A more relevant model is the "zero failures" approach used, for example, by NASA. The focus is on redundant systems and recovery scenarios if an element fails, rather than simply trying to make the probability of a failure vanishingly small. DER thus becomes a back-up system to grid problems or failures.

Digital industries also use more electricity than "traditional" consumers. For example, a typical communications center or Internet server facility may have load densities (watts/sq. ft.) of 10 to 100 times greater than those of a typical office building.

In addition to increased energy consumption and demanding higher power quality and reliability, many digital-intense facilities, such as Internet Data Centers, are highly concentrated loads that are often located in areas already constrained by the electric transmission and distribution (T\&D) system. Not only do they demand higher quality and more reliable power for digital microprocessors and servers, but they also demand extensive cooling to remove heat from the 
equipment, in order to maintain their tightly specified operating environment (temperature and humidity). Because of these needs, concentrated digital load centers require special equipment to provide power conditioning, backup power, and space conditioning. For many utilities, serving such load concentrations, often in heavily congested urban areas, is a challenge both for retrofits and new construction. Providing the required high reliability and power quality using conventional power generation and distribution system technology is not often practical.

The emerging digital economy extends far beyond Internet hubs and data centers. Therefore before solutions can be designed or evaluated, we must clearly know with what we are dealing. This requires a better understanding of the impact of microprocessors and of the power and energy requirements for the digital technologies that they enable. Finding a practical and working definition of "digital technologies," identifying trends in electrical usage of end-use digital equipment, and characterizing their impact on the economy is critical before understanding what role distributed energy resources (DER) can ultimately play.

\subsection{Project Objectives}

With few exceptions the application of DER in digital installations has been limited. The newer generation of DER and energy storage technologies have the potential to play a more significant role in meeting the energy needs of a growing digital economy, since they can provide many of the same functions with improvement in power availability and response. Also, the successful integration of DER and combined cooling, heating, and power (CHP) into many new facilities offers several advantages compared with traditional powering methodologies:

- Onsite or nearby DER can be combined to meet both electrical and thermal requirements of digital loads, thereby increasing overall power plant efficiency

- DER can provide benefits to both the utility and customer by providing capacity relief, voltage support, and other ancillary services to the utility system and by providing increased reliability/quality to the customers

- $\quad$ Energy Management and DER controls can be integrated to provide optimal energy efficiency, power reliability and quality, and

- Alternatives to conventional battery-based energy-storage technologies (such as flywheels and ultra-capacitors), may reduce maintenance and improve operational reliability of these information data hubs.

Opportunities to harvest the increased power quality and reliability potential of DER will demand an expanded role for DER applications. DER can be integrated into CHP systems and drive thermally-activated technologies, such as desiccant dehumidification and absorptionchillers. Energy storage devices, such as batteries, flywheels and ultra-capacitors, may also be used to ride through transient events and to supply surge currents for motor starting and for other high-inrush loads, especially in the case of current limited inverter-based generation technologies.

This report will first summarize the opportunities for DER in serving the digital economy and assess the market for such applications. This is the first step in developing a DER technology roadmap for research, development and integration of DER into the digital economy. We will look in detail at specific types of digital equipment, digitally controlled processes, digitally enabled businesses, and digital facilities. We will look at their power quality and reliability 
needs, and forecast near-term technology and product developments that will harden these facilities or better structure them to maintain reliability standards and provide uninterrupted service to their customers. In particular the sectors of opportunity for DER that we will focus on are shown in Figure 1-1.

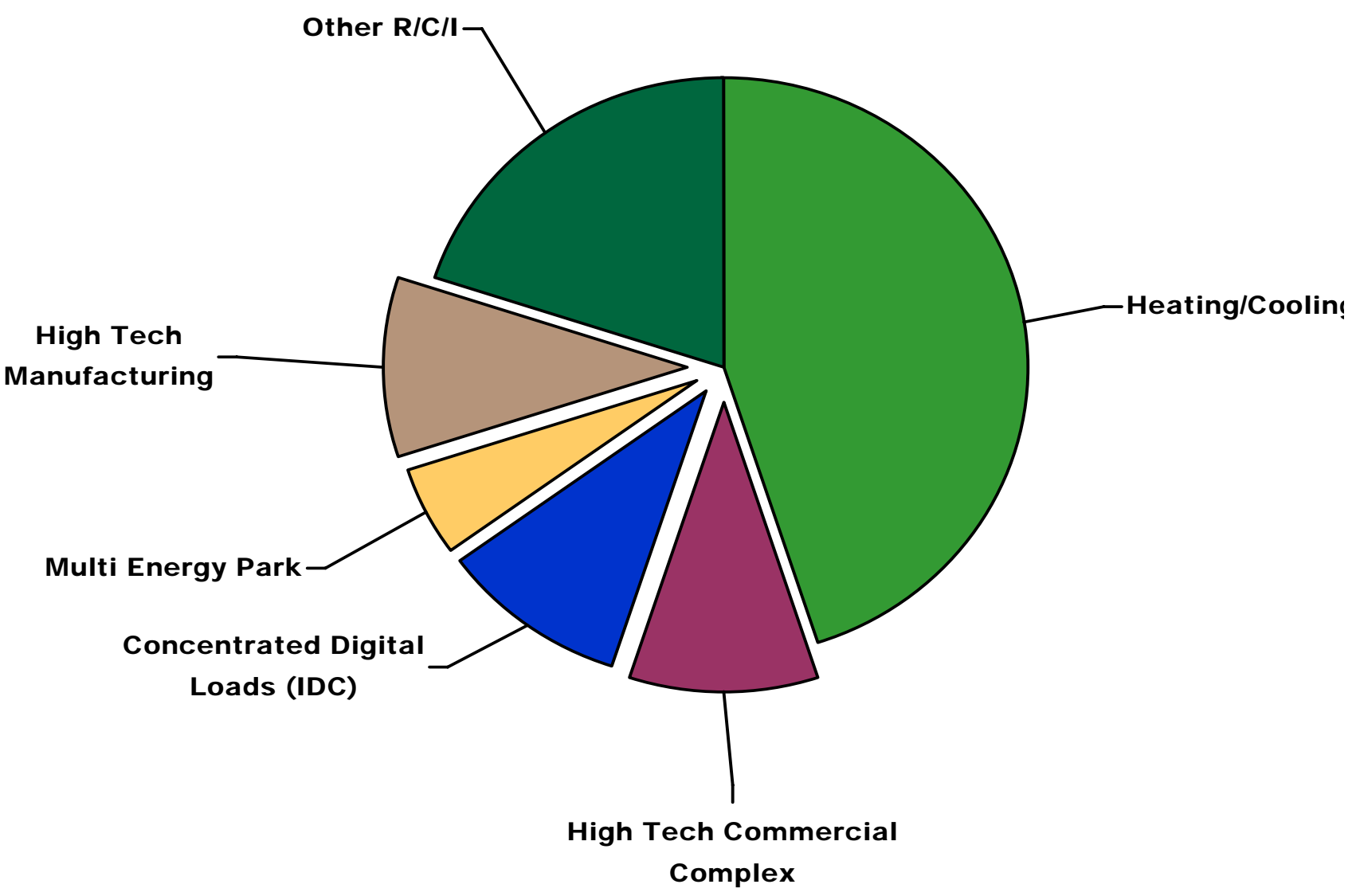

Figure 1-1

Sectors of Opportunity for DER in the Digital Economy

Secondly the report will provide a feasibility assessment for scenarios applying DER to digital facilities. This will serve to demonstrate a methodology for identifying and evaluating technology options and configurations - recognizing that technical and economic feasibility are a function of the characteristics and economics of the specific facility.

\subsection{The Pervasiveness of the Digital Economy}

Since the first personal computers in the 1980's, a technology revolution has been sweeping modern society, spawning a new era of economic and social change driven by microprocessors and the digitally-based technologies that these processors enable. As a result, our society has become the most highly automated and interconnected — creating and dependent on the smooth functioning of sophisticated devices and complex, interactive networks. This digital technology revolution has really just begun.

Digital technologies have a broad influence on modern society. The basic digital building blocks facilitate a wide range of applications - greatly influencing the residential, commercial, and 
industrial sectors. In turn, these capabilities support whole enterprises whose modern form is entirely based on digital technologies (see Figure 1-2).

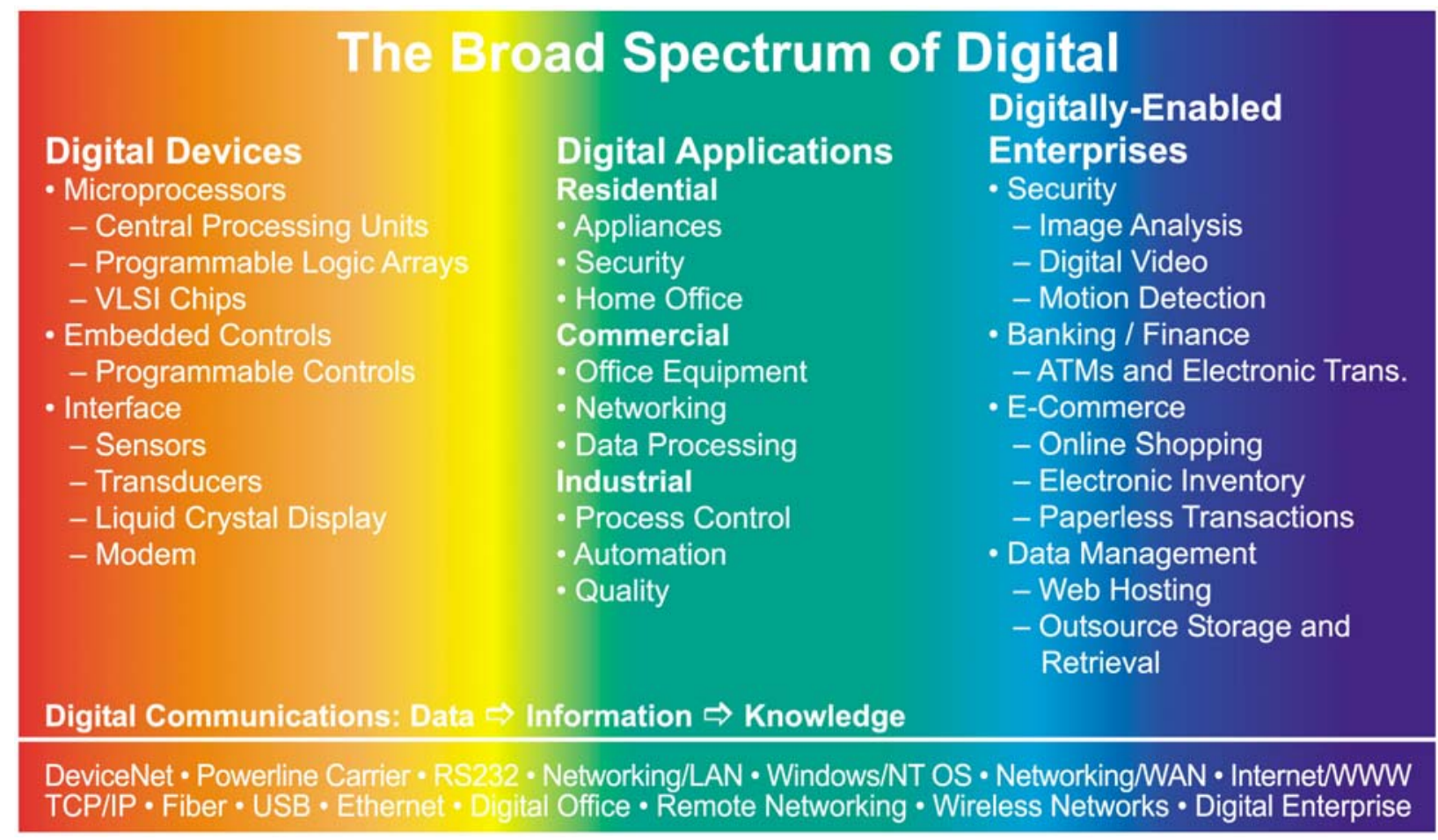

\section{Figure 1-2}

The Pervasiveness of Digital Systems, Processes, and Enterprises

In order to understand and quantify digital energy use and thereby opportunities for DER, digital equipment, digital processes, and digital businesses must be defined.

The electrical energy used by the digital economy, or “digital energy use,” can be defined to encompass four distinct classes:

1) Digital Equipment and Devices - microprocessors and computer-based equipment and appliances

2) Digitally Controlled Processes - enterprises and processes that rely on digital equipment, such as sensors and controls, to operate

3) Digitally-Enabled Enterprises - businesses, such as data processing facilities, integrated circuit manufacturers, or Internet service providers, whose basic product or service is to supply the digital economy

4) Digital-Enabling Loads and Processes - equipment or appliances without which digital equipment cannot operate, such as cooling systems and power conditioning

\subsection{A Common Thread - The Microprocessor}

The common thread among these four classes is the microprocessor. The microprocessor uses electric energy directly to provide a service, controls other energy-using equipment, or requires energy for fabrication or to maintain a suitable operating environment. 
It is difficult to underestimate the impact that microprocessors have had on our society, economy, and way of life. The sheer number of these devices already in existence and regularly entering society is already staggering, and all aspects of modern economies are affected (see Figure 1-3). Although computers are the most obvious application of microprocessors and other semiconductor chips, these comprise less than half of the applications. Consumer electronics and communications collectively use a third of semiconductor output. A large number, $10 \%$, goes to improving the productivity of industry.

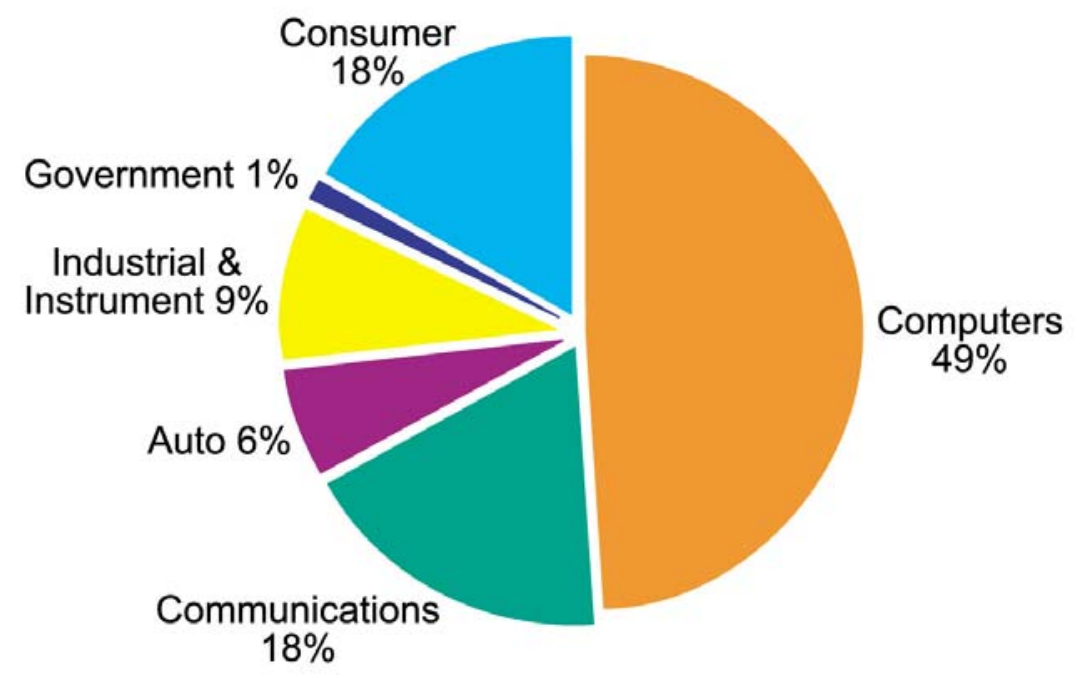

\section{Figure 1-3}

Application of Semiconductors: Percentage by End-use Sector (Source: Semiconductor Industry Association)

The microprocessor revolution has also enabled a host of innovative opportunities to improve energy efficiency, productivity, communications, and the quality of manufactured goods (see Figure 1-4). The revolutionary aspects of microprocessors offer both enhancements as well as challenges to the economy and standard of life. Although much has been made of the amount of energy microprocessors use, this same technology can offer energy savings opportunities that are far greater. While it is also true that microprocessors and the digital devices they enable can demand much higher performance from electrical supply systems, they also enable significant improvements in productivity.

\subsection{Trends in the Digital Sectors}

As the capability of computing technology has grown, the unique characteristics of such loads have evolved over time. An understanding of these trends in digital loads, the infrastructure that must support them, and the "conventional" loads that are controlled by them, is needed to evaluate the technologies - central utility, grid, DER and end-use - and the utility-customer configurations that might serve them. These trends include:

Miniaturization and packaging: Advances in fabrication technology for integrated circuits have resulted in larger, more powerful chips. Today's “chip” handles computational loads formerly relegated to tens or hundreds of individual components or computers. A large data processing room with several large computers may have been replaced by a "rack" holding dozens of data 
processing units, each of which has the computing power of the entire old mainframe computer room.

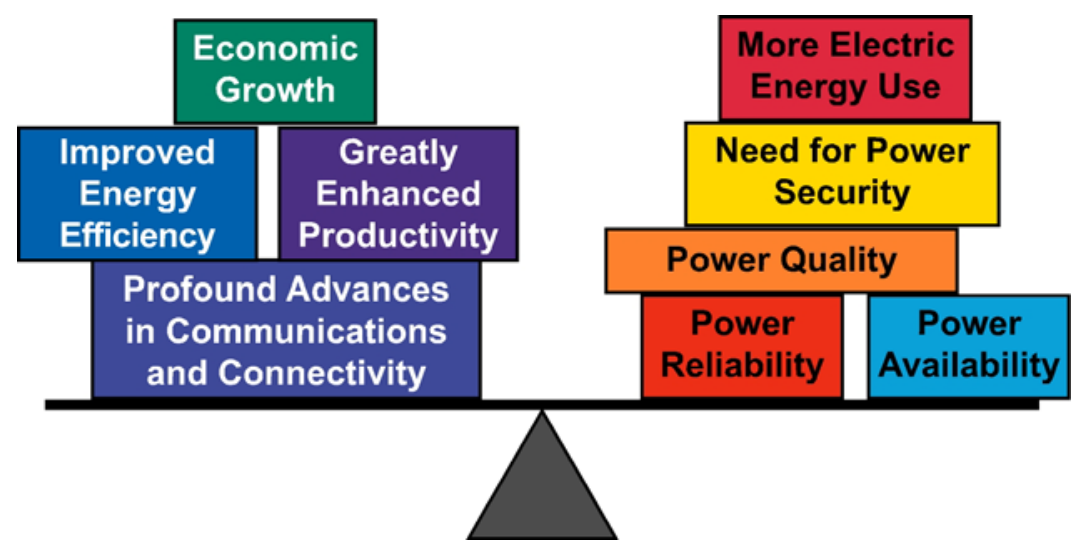

Figure 1-4

Balancing the Benefits and Costs of Microprocessor Technology

The pace of semiconductor innovation is fast and getting even faster. New technologies are now introduced every two years, one year faster than the traditional rate under "Moore's Law" (see Figure 1-5). Now, microprocessor speed doubles every four years. Every five years, manufacturers increase tenfold the number of bits, or units of memory, that are produced. Today's microcircuits routinely contain hundreds of millions of transistors per chip, connected by patterns that rival a street map of Earth in complexity. ${ }^{1}$

Electronics generate more heat: Along with the exponential growth in computing power and microchip density a corresponding growth in heat generated by the micro-circuits and related equipment has come. Figure 1-6 shows the heat density of modern equipment, growing from 300 to 500 watts/SF in 1992, to $15,000-30,000$ watts/sq. $\mathrm{ft}$. presently. This trend is expected to continue.

Sophisticated applications and higher computational overhead: Increased computational speed and capabilities at lower costs and size have led to sophisticated user interfaces, support of multiple functions with each transaction, simultaneous multi-user communications, greater transmission of data-intensive graphics, etc. As a result, more computational power is demanded for each transaction, communication, calculation and application. An analogy is the evolution of television from black and white to color; color television effectively utilized 3 black-and-whiteequivalent TV's in each console. Thus, advances in efficiency of television technology were somewhat offset by the increased "overhead" incorporated in the new, color televisions.

Concentration of resources: The miniaturization and cost reduction of computing technology, plus the growth of data and communications networks, have resulted in compact Data Centers (including Internet "hotels") that concentrate all of an enterprise's communications and information processing functions in one compact location. A problem is that the one location is no longer localized; it has the capability of crippling multiple networked companies and systems.

\footnotetext{
${ }^{1}$ Semiconductor Industry Association, “SIA 2001 Annual Report.”
} 


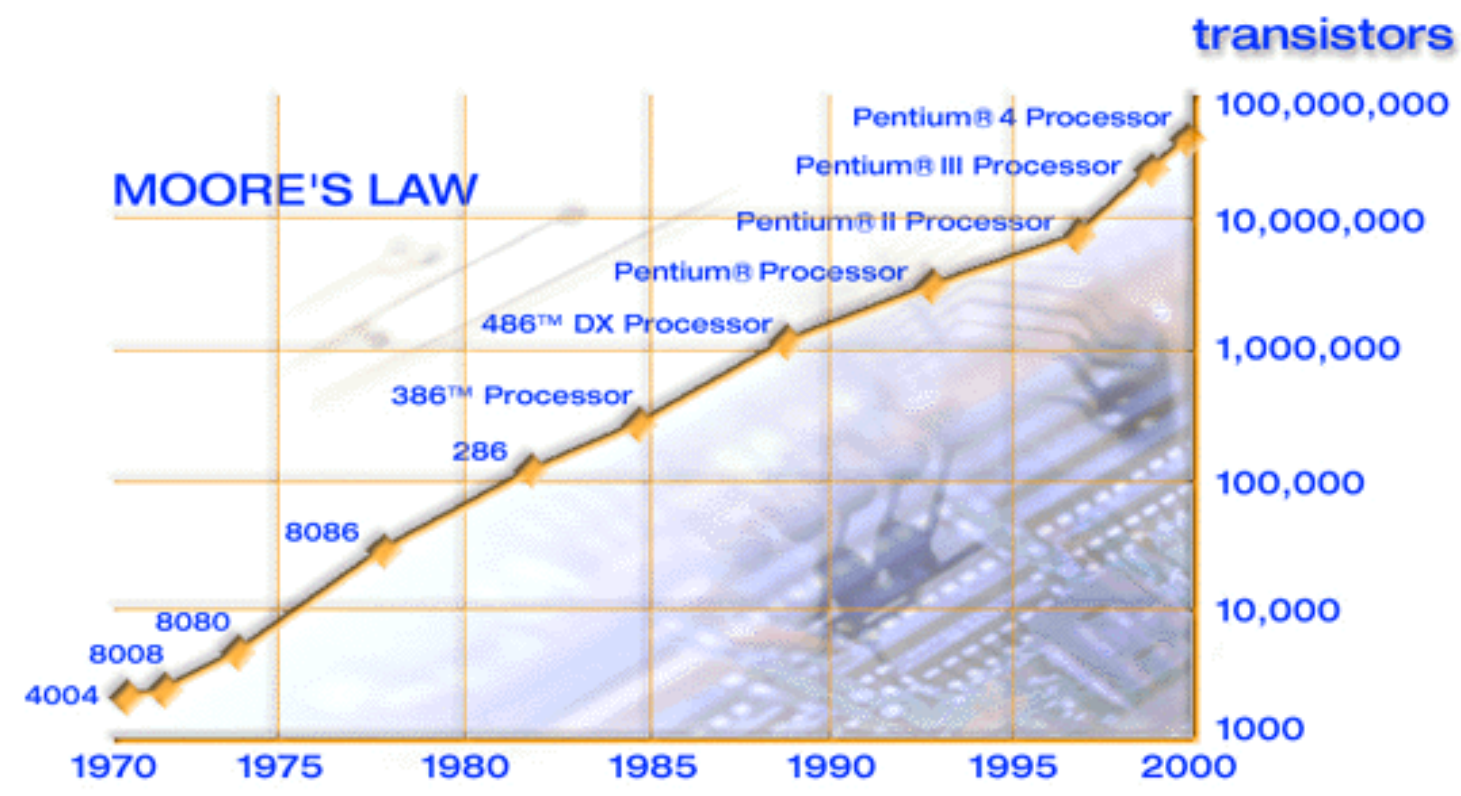

Figure 1-5

Moore's Law of Digital Innovation

Reliability requirements: Momentary disturbances are no longer tolerable. Therefore, uninterruptible power sources, power quality filters, and monitoring systems to anticipate and prevent disturbances are the rule. The cost of a problem has risen from a few thousand dollars to hundreds of thousands or millions of dollars per minute.

Communications as well as computation: The growth of and reliance on large networks has resulted in electronic communications resources - Internet, telecom, mobile telephone, GPS, etc. - being concentrated in the same location as the computational resources. Because so much of the value added of today's digital enterprise is electronic data and/or transactions, economic recovery from an outage may take hours, days or weeks, instead of minutes.

AC, DC multiple voltages: Converting grid-supplied AC power to the multiple voltage levels and micro-amperages ultimately demanded by the electronic circuits require rectifiers and transformers, all of which have power losses, generating heat.

The primary implications from an electrical perspective are:

- The utility must serve more electrical load within a facility or within a small spatial area. This often strains the local distribution system.

- The required quality and reliability of electric power is unprecedented. While there is much talk of "nine's" of reliability, in fact any interruption or voltage sag becomes intolerable, so traditional reliability models and indices (Loss of Load Probability, Mean-Time-BetweenFailures, System Average Interruption Duration Index, System Average Interruption Frequency Index, etc.) are not really relevant. A better model of the requirements of digital loads is the zero-failure mission-critical design approach of NASA. The utility power system - central generators and interconnected grid - is not capable of providing this degree of reliability and availability. 
- The enormous customer cost of an electrical supply problem means that the digital customer installs redundant equipment for processes and for power supply. These additional measures guard against interruptions, voltage sags and swells, and harmonic interference.

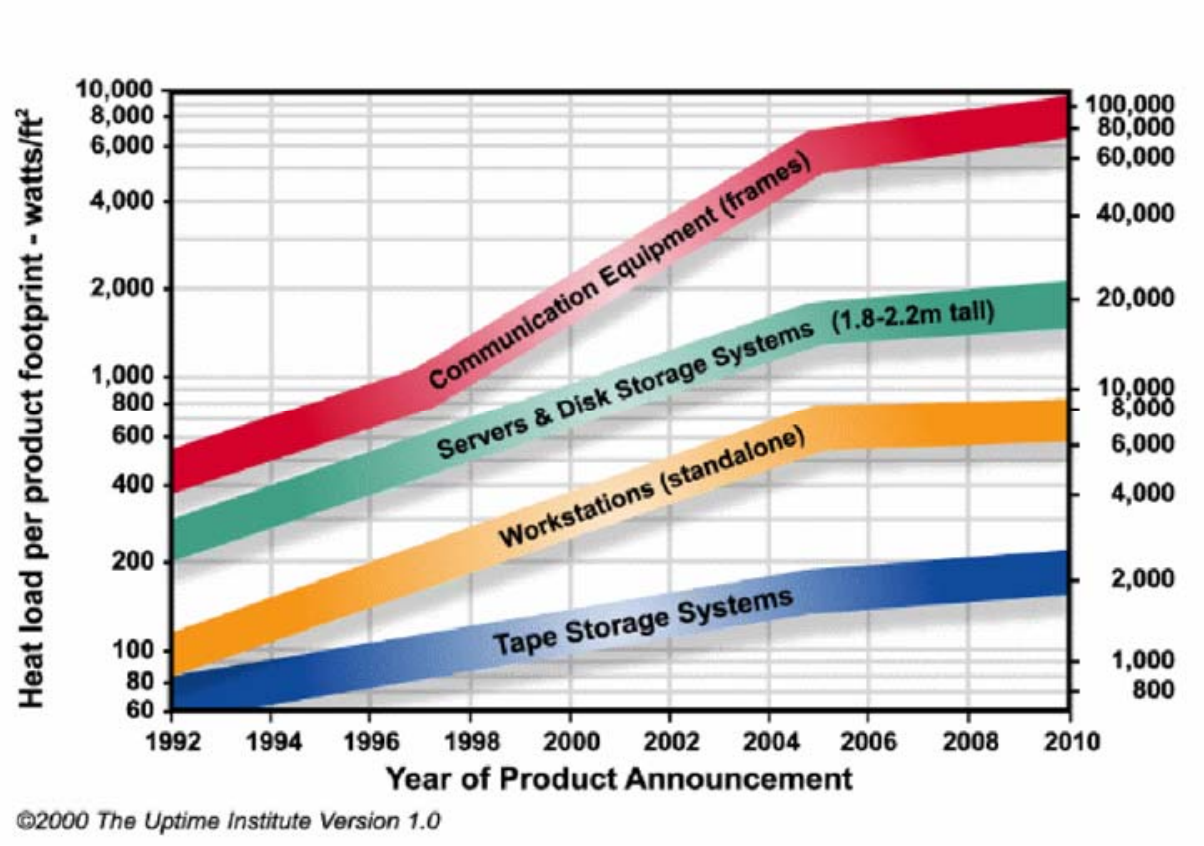

Thermal Management Consortium members

\begin{tabular}{|c|c|}
\hline 5 & $\begin{array}{l}\text { Amdahl } \\
\text { Cisco } \\
\text { Compaq } \\
\text { Cray } \\
\text { Dell } \\
\text { EMC } \\
\text { HP } \\
\text { IBM } \\
\text { Intel } \\
\text { Lucent } \\
\text { Motorola } \\
\text { Nokia } \\
\text { Nortel } \\
\text { Sun } \\
\text { Unisys }\end{array}$ \\
\hline
\end{tabular}

Figure 1-6

Heat Density Trends for Information Technology Equipment

The primary implications from the thermal perspective are:

- The electronic loads are tremendously concentrated. Integrated circuits have more computational power per square inch, the circuit boards are far more densely populated, and the boards are physically closer to each other. Electronic communications equipment is interspersed with information processing equipment.

- Electronic equipment is packaged in more compact enclosures or configurations that do not have the ventilation capacity per watt of older electronic equipment. It is more difficult to reject heat. A rack-mounted data processing unit may provide 10 times the computing power of an older technology server but require 30 times the airflow to cool it. A typical 84-inch cabinet can hold 40 new servers, each of which expels 250 watts of heat. The result is a 10,000-watt heat load in each cabinet, and an Internet "hotel" will have row upon row of such cabinets. ${ }^{2}$

- Reliability requirements necessitate uninterruptible power sources, power quality systems, status monitoring, and/or back-up systems that all consume power and generate heat.

- Today's electronic equipment is quickly and catastrophically vulnerable to heat build-up. Not only must there be back-up power for the facility, but the cooling system also requires redundancy.

\footnotetext{
${ }^{2}$ Koplin, Edwards C., “Data Center Cooling,” ASHRAE Journal, Vol. 45, No. 3, March 2003.
} 
For high-technology facility design:

- There is more heat generation.

- It is more difficult physically to circulate air to remove heat.

- Ancillary systems (cooling, communications, monitoring, protection, back-up power, etc.) generate significant amounts of heat.

- A large part of the facility's power requirements, and therefore its back-up power requirements, are for cooling.

\subsubsection{Power Quality and Reliability Requirements}

No part of the United States is immune from PQ events. An important part of understanding the quality of power that should be expected by end users is first to understand the average levels of quality delivered across the nation. Significant and important work has been done to document, with appropriate statistical methods, the level of PQ and reliability being delivered to users of electric power.

The EPRI Distribution Power Quality (DPQ) project measured PQ parameters (surges, sags, harmonics, etc.) on a significant number of feeders in the United States and calculated the average system performance, among other metrics. The project involved almost 300 distribution system sites at 24 different electric utilities across the United States as shown in Figure 1-7.

The results of monitoring 100 distribution feeders in the voltage range of $4 \mathrm{kV}$ to $33 \mathrm{kV}$ for two and a half years (from June 1993 to August 1995) were analyzed to develop benchmark statistics for the PQ performance of distribution systems across the nation. The data collected during the measurement period provided a statistically valid sample of the range of power quality events typically found in electrical distribution systems. ${ }^{3}$

\subsection{Issues and Concerns - Why Consider a DER Option?}

Today's power delivery grid is constrained in some areas and under-utilized in others. In many areas it is transmission bottlenecks rather than lack of generation that have led to regional and seasonal shortages. Indeed, a sharp decline in critical infrastructure investment over the last decade has left portions of the electric power system vulnerable to power quality-related service interruptions, market dislocations, and external threats, including natural disasters, terrorist and cyber attacks, and simultaneous threats.

Distributed energy resources (DER) must play an increasing role in enabling electricity providers to meet the electricity requirements of a digital society. These relatively small ( $<10 \mathrm{MW})$ generation and storage units could potentially benefit utilities, their customers, and the clients of those customers. To achieve these benefits, new types of service agreements and utility-customer partnerships must be developed that recognize that reliability and power quality are responsibilities shared by both utility and energy consumer. Proper allocation of costs, benefits and responsibility, and design of appropriate tariffs, requires a new approach to reliability - one that matches user-specific needs and costs with grid- and DER-technology-specific capabilities and costs.

\footnotetext{
${ }^{3}$ An Assessment of Distribution System Power Quality: Volumes 1-3; TR-106294-V1, TR-106294-V2, TR106294-V3, EPRI, Palo Alto, CA, 1995.
} 


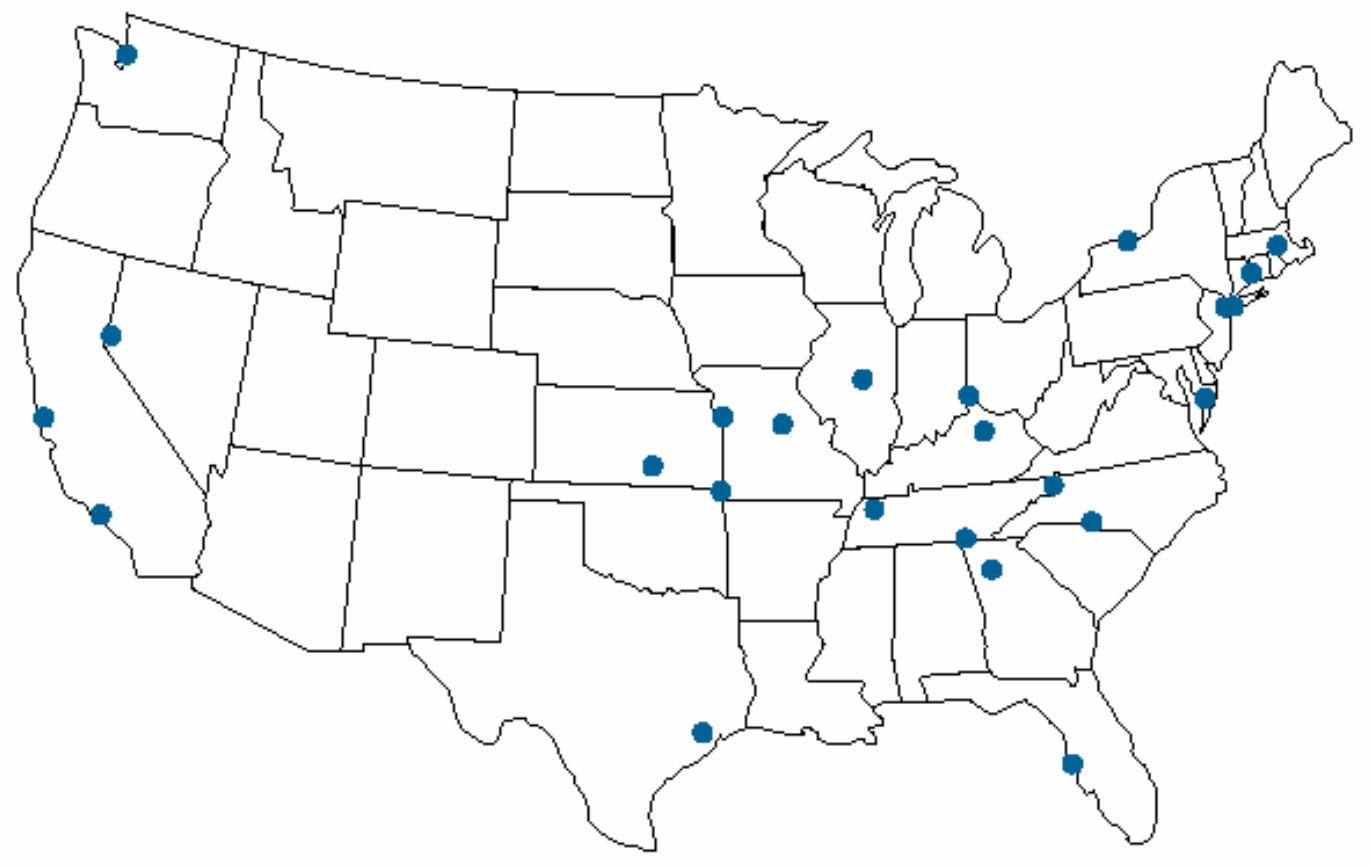

Figure 1-7

General Locations of Electric Utilities Participating in the EPRI Distribution Power Quality Project

Electricity consumers may use DER to achieve a lower cost of power and improved reliability along with additional security of supply. Electric utility "wires" companies may use DER to defer expansion of the transmission and distribution infrastructure, reduce power system losses, and enhance system reliability. Generation companies may elect to add renewable energy to their portfolio where it can offer emissions credits, fuel security, and enhanced marketing value. Energy service companies may install DER at customer sites and sell services such as reliability and heat (cogeneration) along with traditional electricity to create a new revenue stream. Finally, the society as a whole can benefit by having a diversified power system that is more resistant to natural and man-made disruptions. Furthermore, widespread deployment of fully integrated DER enables advanced operating concepts such as the self-healing grid, micro-grids and the virtual utility that benefit all energy users, not just the high-technology ones. Achieving such benefits requires an approach that evaluates who can - and should - provide energy and at what price.

\subsubsection{Distribution Power Quality and Reliability Studies}

Electric utility customers are exposed to power disturbances such as faults on distribution feeders and momentary, or sustained, loss of the primary power feed. Certain information technology equipment, as well as industrial programmable logic controls, relays, monitors and other control devices and switching equipment, may be affected by power disturbances and at the same time are critical to end user processes. The size of this critical load and the period that the disturbance and outage protection are required varies with end-user equipment and function.

The need for protecting equipment may vary from $100 \%$ to only a few percent of the total load at a customer location. This is evident when comparing a modern data processing center or Internet hotel that has nearly $100 \%$ critical load, to a factory where only motor controls, representing a 
few percent of the total load, are considered critical. On the other hand, some critical equipment are not sensitive to voltage variations and may therefore require less protection. Similarly, the required duration of the protection depends on the application and can range from a few minutes to several hours.

EPRI's distribution power quality study has quantified the number and duration of PQ events. Figure 1-8 shows typical interruption and sag occurrence rates based on the voltage magnitude of the sag from the study. ${ }^{4}$ These results are based on monitoring and recording 326,000 events at 277 locations for 28 months. Monitors were placed on utility feeders selected to be representative of typical power quality in the US. The average number of PQ events at each location was 74.6 per year.

The average number of events, per site, and per year, are given in 18 bins that represent the severity of the event. One-minute aggregation of data was used in determining the number of unique events. Events near zero voltage are on the left and events from 85 to $90 \%$ of normal voltage are shown in the vertical bar on the right. For example, the bin marked as 35 on the horizontal axis indicates that approximately one event per site per year occurred in the range of 35 to $40 \%$ of normal voltage, based on the site’s long-term average voltage.

The percentages on the right abscissa refer to the blue solid line on the graph and give a cumulative frequency for occurrence of all events 0 to $90 \%$ of normal voltage. This shows that about $10 \%$ of the events were classified as outages ( 0 to $10 \%$ voltage), and $90 \%$ of the events were voltage sags between $10 \%$ and $90 \%$ of normal voltage.

Another important set of data gathered by the EPRI DPQ project was an assessment of the number and severity of voltage sags on electric distribution systems. EPRI has developed a metric for measuring sags, "SARFI," stands for System Average RMS (Variation) Frequency Index Voltage $\left(\mathrm{SARFI}_{\mathrm{x}}\right)$, where the " $\mathrm{x}$ " refers to how deep the sag may be below nominal (normal) voltage. For example, $\mathrm{SARFI}_{0}$ would refer to voltage sags where the voltage dropped to a value of zero (that is, a complete power interruption). $\mathrm{SARFI}_{70}$ would refer to voltage sags that dipped below $70 \%$ of normal.

$\mathrm{SARFI}_{\mathrm{x}}$ was developed as part of an EPRI project designed to create a set of service quality metrics that included the effects of PQ variations such as voltage sags. SARFI and its versions have been documented in the IEEE literature and provide the basis of discussion for a proposed IEEE task force charged with standardizing PQ indices. Several US utilities are using SARFI for such applications as benchmarking, proactive maintenance planning, and premium service contract development. SARFI ${ }_{x}$ represents the average number of specified RMS voltage variation measurement events that occur over the assessment period per customer served. The specified variations are those whose RMS voltage magnitude drops below the threshold $x$ for sags or whose magnitude increases above $x$ for swells. The $70 \%$ threshold is the most common voltage level used for benchmarking with SARFI. Figure 1-9 below provides some results from the EPRI DPQ study to quantify the electrical environment based on the monitoring at 277 sites. The data shows the number of sags and interruptions counting in ranges of 5, from 0 to 210 . For each count the \% of sites in this range is given on the left vertical axis. From this data,

\footnotetext{
${ }^{4}$ An Assessment of Distribution System Power Quality, Volume 2: Statistical Summary Report, EPRI Palo Alto California, January 1996, Report TR-106294.
} 
representing distribution systems in the United States, the average number of voltage sags and interruptions below 70\% of normal voltage ( 0.7 per unit) was calculated to be approximately 17 .

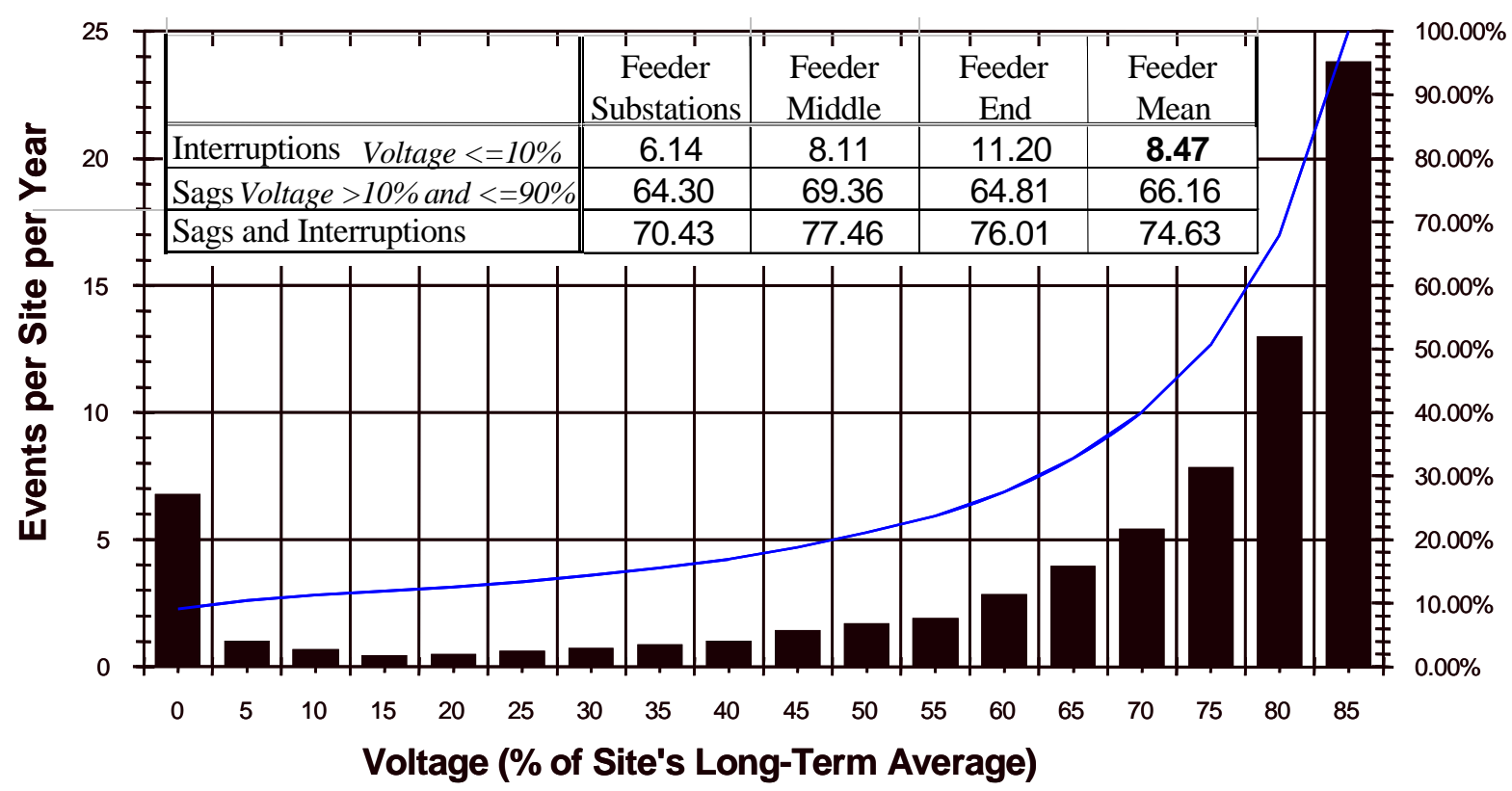

Figure 1-8

Typical Interruption and Sag Rates as a Function of Voltage Magnitude

This type of estimate is most useful when the threshold of upset of end-user equipment is known. For example if the equipment is expected to survive for momentary voltages sags above $70 \%$, then it can be expected that approximately 17 equipment upsets will occur at these sites per year. In practical cases equipment immunity is likely to be less predictable. The magnitude levels vary from as sensitive as tripping at the $90 \%$ level, to as rugged as surviving voltage sags to 45 or $50 \%$. Immunity to short duration events also depends on the duration of the event, where the device may withstand an outage for one or two cycles and trip at $80 \%$ voltage if the duration is 3 cycles. Immunity variations are also seen based on the operating mode of the equipment at the time of an event and based on secondary characteristics of events, such as initiation point on the waveform or phase shift during the event. The conclusion is that power system disturbances are generally better characterized than end use equipment immunity. However, some useful equipment and industry immunity characterizations are becoming available and will be discussed later.

Table 1-1 shows composite results for all DPQ study sites, including at utility substations and the feeders that deliver electric power to end users. As one would expect, the average annual number of shallow voltage sags $\left(\mathrm{SARFI}_{90}\right)$ is considerably greater than the deeper sags to 10,50 , and $70 \%$ of normal voltage. Electrical distribution feeders, on average, experience between four and five very deep voltage sags (or outages) per year, as reflected in SARFI 10 results.

Several lessons can be learned from these utility industry studies. First they show that any gridserved location has a significant probability of experiencing a reliability or power quality incident. Power system upgrades, such as adding alternate feeds and installing surge protection, 
will reduce but not eliminate this probability. Therefore, reinforcing the grid in the hopes of achieving acceptable quality of service for digital customers will not be an effective investment. The only feasible solution is to add local capability as a back-up system rather than grid reinforcement: on-site distributed energy generation or storage resources and/or facility/load hardening. The EPRI data help to specify what capabilities and capacity these local resources must have including: $\mathrm{kW}$ and $\mathrm{kWh}$ capacity, response time, voltage support, harmonic filtering, etc

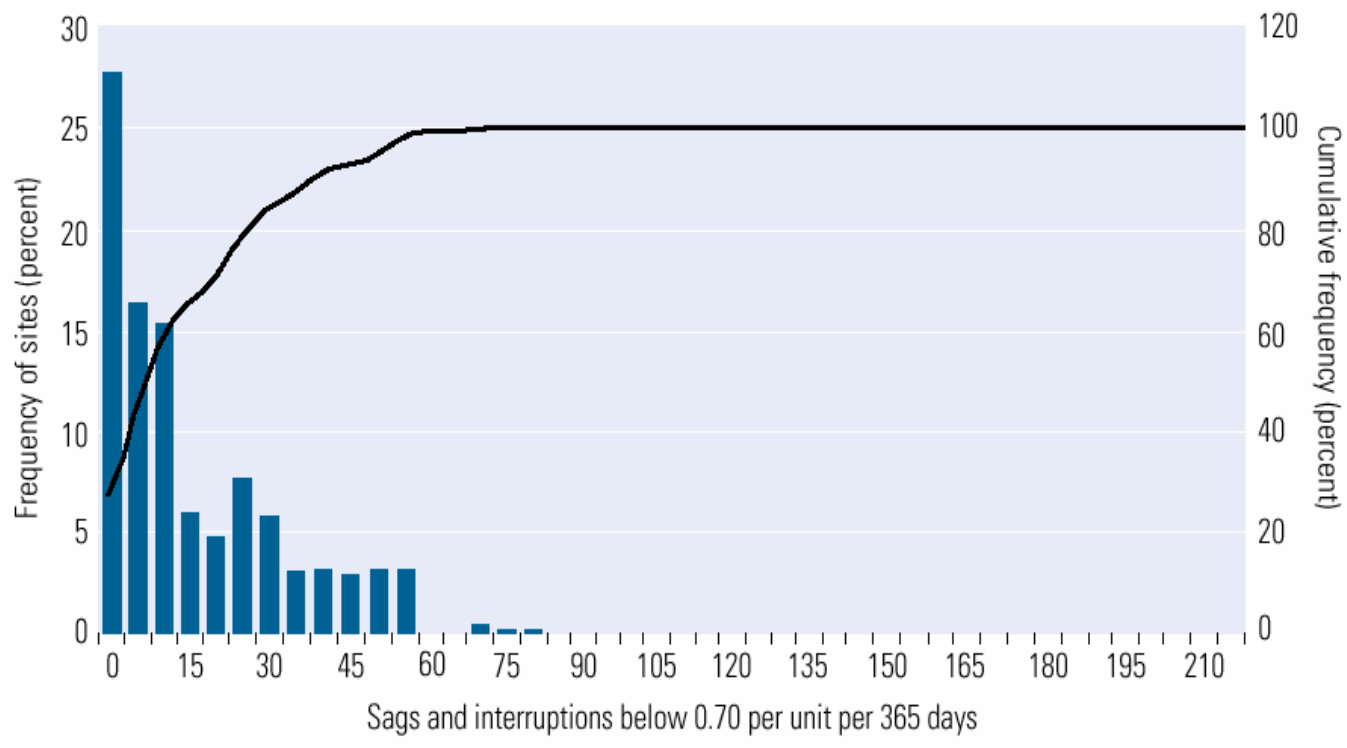

Figure 1-9

Voltage Sags Below 70\% of Normal - SARFI ${ }_{70}$ Measurements at Study Sites for EPRI Distribution Power Quality Study

Table 1-1

Number of Annual Events by SARFI Levels for All Sites in the EPRI DPQ Study

\begin{tabular}{|l|l|l|l|l|}
\hline \multicolumn{1}{|c|}{ Monitor Location } & \multicolumn{1}{|c|}{ SARFI $_{10}$} & \multicolumn{1}{|c|}{ SARFI $_{50}$} & \multicolumn{1}{c|}{ SARFI $_{70}$} & \multicolumn{1}{c|}{ SARFI $_{90}$} \\
\hline $\begin{array}{l}\text { Substation } \\
\text { average }\end{array}$ & 2.88 & 7.89 & 17.24 & 56.93 \\
\hline Feeder average & 4.67 & 12.07 & 20.64 & 54.63 \\
\hline
\end{tabular}




\section{Digital-User Needs}

With more than 12-billion microprocessors currently in use-a number that is expected to grow dramatically in the near future-utilities, industry, and government agencies must find ways to ensure the integration and compatibility of current and next-generation end-use devices.

Today's digital society demands a reliable, stable supply of high-quality electricity. EPRI estimates that between $8 \%$ and $10 \%$ of businesses require reliability to be at least "six nines," or 99.9999\%, and approximately 0.6\% requires reliability to “nine nines,” or $99.9999999 \%$.

Power quality problems are already costing industry billions of dollars each year. An EPRI report estimated the annual figure at between $\$ 118$ billion and $\$ 188$ billion. Outages due to the aging infrastructure and operating constraints are also costing industry. A 1998 Cal ISO study estimated that an eight-hour outage costs consumers between $\$ 95$ and $\$ 200$ per kW of lost load. ${ }^{5}$ According to a 1998 Sandia National Laboratories study, voltage sags cost industry \$114 billion annually.

As a result, a growing number of consumers are installing power conditioning and energy storage systems and devices. Total sales for power conditioning, energy storage, and distributed energy resources were between $\$ 5.3$ billion and $\$ 6.5$ billion in $2000 .{ }^{678}$ By 2005, sales of fuel cells and microturbines were projected to be $\$ 900$ million and $\$ 500$ million, respectively. ${ }^{9}$

Overall sales for power quality equipment were expected to grow by $11 \%$ per year, to $\$ 7.1$ billion, by $2006 .^{10}$

\subsection{Understanding Needs of a Digital Economy}

Ensuring the continued vibrancy of the Digital Revolution requires careful attention to ensuring its power quality, reliability, availability and even security requirements. This is particularly true in the area of the interface between electric power supply and digital systems, digital processes, digitally-enabled enterprises, and local or distributed energy generation, storage, transport, and utilization technologies (i.e., DER). This approach focuses on all aspects of the energy production, transport and use sector, from the generation of electric power to the connecting pins on semiconductor chips. Taking a closer look, we will start with Reliability.

\subsubsection{Reliability}

Power system reliability is the over arching objective of most digital enterprises. It encompasses the time an electric system is available, the frequency of failures, various types of failure, and contingencies that define operating margins or when single component failures may result in

\footnotetext{
${ }^{5}$ Cal ISO 1998 Transmission Reliability Report.

${ }^{6}$ Poised for Growth: DG \& Ride-Through Power, by Nathan Andrew, Power Quality, January 1, 2002.

${ }^{7}$ Renewable Energy Annual 2000, U.S. Department of Energy, Energy Information Association, March 2001.

${ }^{8}$ Business Communications Company, Inc., 25 Van Zant Street, Norwalk, CT 06855; Telephone: (203) 853-4266, ext. 309; Email: publisher@bccresearch.com; RE-083R-The Power Quality Equipment and Service Market: A 21st Century Growing Industry, October 2001.

${ }^{9}$ Poised for Growth: DG \& Ride-Through Power, by Nathan Andrew, Power Quality, January 1, 2002.

${ }^{10}$ Business Communications Company, Inc., 25 Van Zant Street, Norwalk, CT 06855; Telephone: (203) 853-4266, ext. 309; Email: publisher@bccresearch.com; RE-083R-The Power Quality Equipment and Service Market: A 21st Century Growing Industry, October 2001.
} 
system failures. The definition of a failure, and the probability that a failure will occur, are both key aspects of reliability.

One commonly accepted view on what system reliability should include is everything that may serve to reduce the probability that a failure will occur. Along the same line, high reliability should increase a power system's availability and reduce the number of failure events. However, these two measures are not necessarily improved in equal portions. For example, specific actions may significantly reduce the number of failures, while long repair times for remaining failure events may still result in poor system availability.

In the context of digital enterprise productivity we attempt to include the quality requirements of end-use equipment in defining power system reliability. Failures may be measured in equipment or process upsets and the restoration time may be how long it takes to restart the process irrespective of when power is restored. One challenge for today's electric power system is that the definition of a failure is expanding with the growth of high- tech end-user equipment and processes. And some power-quality related failure modes are impacting the customer's perception of power system reliability. One of the more common examples of this impact is when sensitive industrial and data processes fail due to very brief voltage interruptions or voltage quality problems. Similarly, power system security issues may increase the probability of a failure.

Along the same line, increasing reliability should also increase a power system's availability and reduce the number of failure events. However, these two measures are not necessarily improved in equal portions. For example, a specific action may significantly reduce the number of failures, while a long repair time of an infrequent failure event may still result in poor system availability. Also a large number of very brief power quality events may result in a high degree of power availability, while end-user equipment failures are frequent and power reliability is perceived as very low. So it is clear that reliability, availability, quality, and security all deserve some degree of consideration on an integrated basis.

Applied to the electric power supply, reliability is usually calculated as the total percent of time that voltage is present, and often expressed as the number of "nines" of reliability. For example, a power system that is down for 60 cumulative minutes each year would be said to be $99.98 \%$ reliable, or "three nines." The electric supply to sophisticated digital systems is often considered to require reliability of "six nines" or better, meaning less than 32 seconds of electric power outage allowed per year. Achieving this level of performance requires significant augmentation with new technologies and techniques.

\subsubsection{Availability}

As applied in electric power systems, the term availability simply means how much of the total time power is available. Availability is usually stated as a percentage. For example, a power system that is down for a total of 60 minutes each year would be said to have $99.98 \%$ availability. If the same power system failed 3 times in that year, then the mean-time betweenfailures would be 4 months. Availability and reliability are closely related in that each is a measure of time (or percentage of time) that a process is up and running. Availability, however, is more dependent on the time after a process is interrupted and reliability is more dependent on the time between process interruptions. 
Availability for sensitive digital processes acknowledges that there is a difference over the course of a year between a single one-hour electric power interruption and sixty one-minute interruptions. Since both of these scenarios have 60 minutes of cumulative outage, the calculation of power availability in both cases would be the same. However, the calculation of the process availability should consider the time required to affect repairs and get things up and running again. As a result, very high power availability may have poor reliability because of the number of upsets and poor process availability and cumulative time needed to restore the process after a large number of short time events.

\subsubsection{Availability as a Measure of Reliability}

In modern business today we often hear the metric Six-Sigma or 6 standard deviations from the mean as an important measure of process performance and quality. Many electric customers are striving for perfection in their business processes. The 6-sigma objective sets a target of 3.4 defects out of 1,000,000 results or opportunities. Higher sigma means fewer defects. And one of the most important concepts in achieving a high sigma success rate in a process is to reduce the process variance. Mathematically, variance is the square of standard deviation, so decreasing process variation reduces the number of defects and increases the process sigma.

In the power delivery industry availability, measured in terms of 9's, has become more or less an equivalent to the 6-sigma objective. And six-9's, or 99.9999\%, of power available is often cited as an objective for mission critical facilities. As shown in Table 2-1 the number of 9's is also equated to a number of minutes of off (no power) supply. In fact six-9's is actually better performance than 6-sigma since the deviation or failure rate is 1 part per million compared to 3.4 parts per million. The typical utility service in the US is approximately $99.95 \%$, which equates to a sigma of about 4.8. By this measure, the reliability of power delivery in the US is very good.

Table 2-1

Relationship between Number of Nines and "Minutes Off" Supply

\begin{tabular}{|l|l|c|}
\hline The Standard of Nines & The Number of Nines & Minutes Off Supply \\
\hline 0.99 & 2 Nines & 5256 \\
\hline 0.999 & 3 Nines & 525.6 \\
\hline 0.9999 & 4 Nines & 52.56 \\
\hline 0.99999 & 5 Nines & 5.256 \\
\hline 0.999999 & 6 Nines & 0.5256 \\
\hline 0.9999999 & 7 Nines & 0.05256 \\
\hline 0.99999999 & 8 Nines & 0.005256 \\
\hline 0.999999999 & 9 Nines & 0.000526 \\
\hline
\end{tabular}

The difference between the desired power availability for a particular site and the available power service at that site is one way to define opportunities for power system improvement. For example, if the desired power availability is 5 nines and the typical service availability is 3 nines, then on-site generation or energy storage is expected to have reliability value. 


\subsubsection{Quality}

Power quality (PQ) has proven to be a critical element of electric power delivery because many modern electrical devices and electronic equipment react to variations in quality. Just as availability takes reliability one step further, so with quality of power to digital systems. While both reliability and availability tend to focus on complete interruptions of power, power quality acknowledges that there are other characteristics of electric power supply that can impact the performance of sensitive digital systems. Examples of these include sags, swells, or transients in supply voltage as well as unbalanced voltages, poor electrical system grounding, and harmonics. Quality is influenced not just by power delivery systems, but also by end-user equipment and facilities.

In particular, continuous processes, from factory assembly lines to data processing, are vulnerable to quality variations. Upsets in even the smallest, and usually the most sensitive, equipment or device often results in downtime of an entire process or facility. The process outage usually occurs long after power is back to normal and often when electric service availability and reliability are relatively good. PQ related process outages are much more common than outage related event. However, traditional power system performance indices do not account for power quality variations.

Considering power quality properly is done by taking a step beyond the traditional measures of power continuity or the availability of power. It is well known that both reliability and availability tend to focus on complete interruptions of power while power quality acknowledges that there are other characteristics of electric power supply that can impact the performance of sensitive digital systems. Examples of these include sags, spikes, or transients in supply voltage, as well as unbalanced voltages, poor electrical system grounding, and harmonics. Quality at the point of end-use is influenced not just by the power delivery systems, but also by local wiring and neighboring end-user equipment and vulnerability of the electric system to external exposures.

\subsubsection{Power Quality Impact on Process Reliability}

The electric utility transmission and distribution system is a complex network intended to deliver the most reliable power to the majority of customers. Because of the way the system is protected, momentary disturbances are common. Every time a thunderstorm occurs, a tree or animal comes in contact with the power conductors, or some other abnormal fault event occurs, a certain number of electricity customers will experience a momentary interruption in power while many other customers will experience a momentary voltage reduction, called "voltage sag." This is simply a reduction in the voltage available from the power source while the fault current is flowing. As soon as the fault is cleared, the power goes back to normal. In the majority of cases, the entire event lasts less than a half second. Unfortunately for most customer process equipment, it doesn't matter because production has already stopped and a costly reset and or cleanup effort must be initiated.

In terms of utility power-system performance, everything has worked as intended and hopefully power is now restored for all customers. Therefore, from a reliability standpoint (that is, longterm interruption), no one was interrupted for an extended period of time. This is good for the reliability indices that the electric utility reports annually, but is terrible from a customer standpoint because there may be literally millions of dollars in losses if this event upsets process 
operations for a group of manufacturing or production facilities. Exactly how much does computer downtime and data loss cost businesses? The statistics are staggering. Figure 2-1 shows the average hourly cost for various businesses.

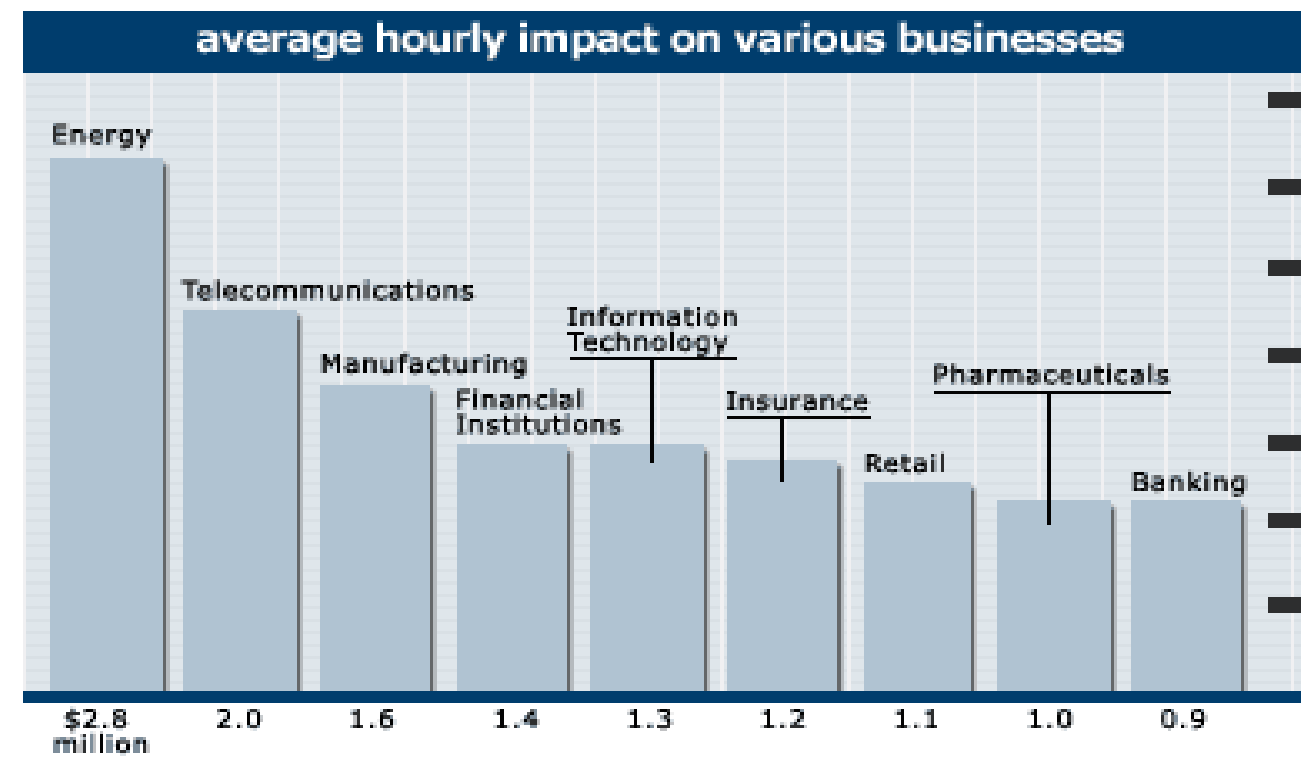

Figure 2-1 Average Hourly Costs of Computer Downtime for Various Business Types $^{11}$

Typically, the motors, pumps, compressors, and cooling systems and other support equipment are not sensitive to the momentary voltage sags, but the control circuitry is extremely sensitive and causes the production equipment to trip offline. Even if the power-system fault is many miles away, a few of the more sensitive process controls systems will trip while others may be unaffected. If the fault is within a few miles of the substation bus, the resulting sag will be more severe and everything in the plant is likely to trip offline. The bad news is that each event can cause costly process downtime.

\subsubsection{Security}

The role of security in serving digital enterprises is frequently talked about but has not yet evolved into any consistent set of definitions or measurement methods. Events that have occurred in recent years elevated the visibility and perceived importance of security in power system operations and protection of the electric infrastructure. Some of the complexities involved in protecting power systems and related infrastructures were identified by utility industry experts in response to the 9-11 terrorist attacks. In particular, this assessment identified three different kinds of threats that need to be considered:

- Attacks upon the power system. In this case, the electricity infrastructure itself is the primary target -- with ripple effects, in terms of outages, extending into the customer base.

112001 Cost of Downtime Survey Results, 2001. 
- Attacks by the power system. Here the ultimate target is the population, using parts of the electricity infrastructure as a weapon. Power plant cooling towers, for example, could be used to disperse chemical or biological agents.

- Attacks through the power system. Utility networks include multiple conduits for attacks on other infrastructures, including lines, underground cables and tunnels. An electromagnetic pulse, for example, could be coupled through the grid to damage both electricity and telecommunications networks.

Also the North America Electric Reliability Council (NERC) published security guidelines for the electric sector ${ }^{12}$ in 2002. These guidelines apply to critical facilities and operating assets. They provide one checklist and general description of power system security attributes. The DOE has designated NERC as the Sector Coordinator for the Electricity Sector and as the Sector Coordinator, has the responsibility to:

- assess sector vulnerabilities, develop a plan to reduce electric system vulnerabilities,

- propose a system for identifying and averting attacks,

- develop a plan to alert electricity sector participants and appropriate government agencies that an attack is imminent or in progress, and

- assist in reconstituting minimum essential electric system capabilities in the aftermath of an attack.

The idea of protecting the electric system infrastructure is not new. The electric grid is designed to ensure a reliable supply of electricity, even in the face of adverse conditions. Throughout its history, the industry has been able to restore service consistently and quickly after earthquakes, hurricanes, major floods, ice storms, and a variety of other natural and manmade disasters. Its experience in emergency management has prepared the industry to respond effectively to a "spectrum of threats" using its existing structure, resources, and plans. This spectrum ranges from simple trespassing, to vandalism, to civil disturbances, to dedicated acts of terror and sabotage. Perpetrators include "insiders" and "outsiders" whose actions may be cyber or physical in nature.

In looking at future needs of the electric industry, system security was identified as one of the top few "difficult challenges" for utility system operations. Indeed, if infrastructure security is not assured, even maintaining current levels of productivity and service will be jeopardized. Conversely deploying some of the advanced technologies needed to enhance security will also have a positive effect on efforts to improve grid reliability and coordinate power system operations with those of other energy infrastructures.

\subsubsection{An Approach to Powering the Digital Economy}

The characterization of electric service problems from reliability to availability, quality and security involves many types of power system disturbances, levels of equipment sensitivity, and criticality. As end use equipment becomes more complex, even less "serious” disturbances cause

\footnotetext{
12 "Security Guidelines for the Electricity Sector," Version 1.0, North American Electric Reliability Council, June 14,2002
} 
concern. Security failures or unavailability of electric power is often measured in hours or days that power is out - zero voltage - over the course of a year. For simple electric loads - lights, water heaters, space heaters, typewriters, calculators - the consequences could be measured in cumulative hours of inconvenience or lost productivity.

More sophisticated loads and instrumentation, such as power electronics and computercontrolled manufacturing processes, became susceptible to shorter outages or degraded service. Now outages of minutes or seconds matter, and voltage does not have to be zero - $50 \%$ or $75 \%$ voltage can cause equipment problems. This opened debate about what constitutes an outage: is it a 60-second or more interruption or a 10-second interruption or is one second sufficient? The time to recover from even a short outage became a factor in calculating the costs of a disturbance, so the concept of "availability” was used, with indices such as Frequency and Duration, SAFI, etc.

Presently, today's digital loads are susceptible to "quality" problems that may last from a fraction of a cycle (1/60 second) to a few seconds. A voltage dip of $5 \%$ to $10 \%$ or harmonic distortion of the sinusoidal power may be enough to stop a process or crash a computer.

As we have progressed from concerns about reliability to availability to quality:

- End use equipment has become more sophisticated and more "electronic."

- The time and magnitude of power system disturbances of concern has decreased

- Response to power "problems” must be quicker. (e.g., from flashlights to batteries to uninterruptible power supplies)

- The responsibility for reliable electric service is shared between utility and customer, with the customer having to take an ever-greater share of this responsibility

For example, 20 years ago a distribution feeder recloser could cause a momentary interruption to clear a fault. This was counted as a reliability improvement, since the barely noticeable flicker prevented an extended outage. Ten years ago, the recloser operation was regarded as an outage, as it interrupted electric clocks, VCRs, personal computers, etc. Now, as the consumer takes responsibility for implementing mitigating measures - appliances come equipped with "ride through" capacitors and more PCs are using uninterruptible power supplies - the recloser operation may soon be reclassified again as a "non-outage" For reliability of $21^{\text {st }}$ Century power systems, this has two implications:

- It may not be appropriate to require the utility alone to meet reliability and power quality criteria; the customer, too, must take some responsibility.

- The "reliability" of electric service is a function of the loads served as well as the characteristics of the electricity provided.

Characterizing the reliability requirements of the digital economy as a certain number of "nines" of reliability is a misleading over-simplification. A more balanced approach to serving the digital economy recognizes that reliability, availability, quality, and security must all be considered. Also the individual reliability of the generation, transmission, distribution and enduser facility systems all contribute to overall service quality. Reliability measurements, standards and costs are as dependent on the nature of the load as on the characteristics of the electric service at the meter. Thus, for the this report, we must examine the susceptibility of digital loads 
to power disturbances and, recognizing that the utility grid is at the point of rapidly diminishing returns as far as how much increased reliability any added investment in the grid will yield, we look at how distributed resources at or near the customer's facilities can provide required service quality. Implementing such DER options is often primarily the responsibility of the energy consumer, but there is also a role for the non-traditional utility.

\subsection{Customer Segments and Drivers}

Consumers are concerned with a number of issues regarding their electricity supply. Some of the most important drivers include:

- Cost of electricity

- Power quality and reliability

All digital customers have stringent needs for power quality and reliability. For digital service industries, such as data centers, the cost of electricity are a small part of the price of the services they provide. Interruptions in their processes will incur heavy financial losses, but more than that, the resulting problems in the reliability of the services they provide will damage their business reputation. Thus a power reliability problem has the potential to cripple its business base.

Power reliability problems at digital process industries, such as high-tech manufacturing plants, can also cause huge financial losses, as an entire batch of product may be ruined. However, the losses are limited to the product costs; future business and customer base will not be affected. Energy costs are often a significant part of the expenses of digital process industries, and reducing energy costs can help to make them more competitive.

Often a digital service company is concerned only with reliability, and doesn't bother to consider how DER can reduce its operating costs. Digital process industries are marginally less concerned with reliability - cost/benefit analysis of reliability improvements are fairly straightforward, as they don’t involve the “intangibles” of potential loss of market share. Losses from poor power quality or reliability translate into higher product costs, as do higher energy costs. For this reason, digital process industries are often more willing to look at DER options that can reduce energy cost and/or consumption.

Multi-energy parks (MEP) are installations where high power quality and reliability is provided to a diverse mix of digital customers - service and process industries. By focusing on "spot" reliability improvements instead of trying to increase reliability throughout the grid, a utility can make more efficient investments and provide better quality of service at lower costs. The diversity of customers at a multi-energy park offers more opportunities for reliability (sharing redundant facilities among the MEP residents), energy cost reduction (e.g., process industries can use waste heat from service industries' concentrated digital equipment), and facility capital cost reduction (sharing of costs of back-up power, local generation, alternate feeders, etc.).

Figure 2-2 portrays the primary concerns - after basic digital power quality and reliability standards are met - of digital customers. The figure also shows some of the DER technologies that can address those concerns. The MEP offers additional opportunities for DER technologies that address the needs of both service and process businesses. 


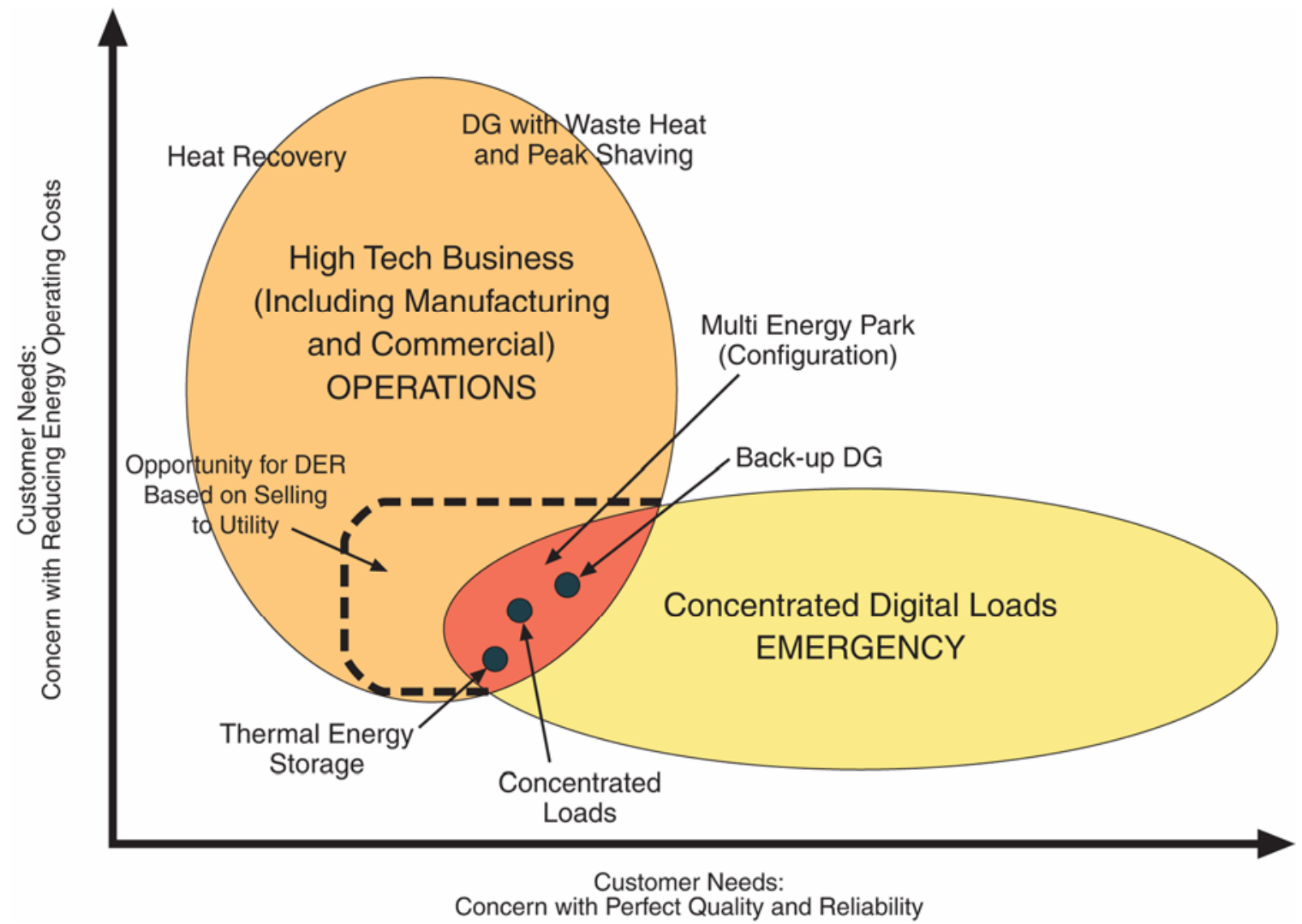

Figure 2-2

Area of DER Opportunities between Normal Operations and the Concern to Reduce Costs and Emergency Operations and the Concern to Maintain Power and Processes

\subsubsection{Concentrated Digital Loads (digital service industries)}

Highly concentrated digital loads such as data centers are very large "data warehouses" for critical business records and data storage. Data centers operate as a link and transport facility for mission-critical information and are designed to house the equipment that enables businesses to function efficiently in this digital age.

Due to the fact that the "new economy" depends on, and often demands, $24 \times 7$ availability of all computer and control systems, fail-safe backup and a disaster recovery system for data centers and facilities are now a business requirement. For mission critical database facilities and any other business where the primary product is the data stored on servers, when a company's digital processing system fails, the effects reach far beyond the boundaries of the data center. Downtime for information systems invariably translates into significant recovery costs, as well as lost revenue, angry customers, and a tarnished corporate image, all of which can be a great benefit to a company's competitors!

A major cause of data center downtime is electrical power failure. Providing alternatives or backups for the power supply is one method to insulate a company against external conditions that are beyond its ability to control. Interruptions in electrical power can result from a variety of factors, such as:

- Transformer failure or line damage. 
- Natural disasters and damage from severe weather.

- Utility company outages.

- Inadequate power-handling capacity in multi- or single-tenant buildings.

In addition to prolonged outages, most companies also confront a host of day-to-day powerrelated problems, including line dips and surges, transverse and common-mode interference or "noise," and in some areas, brownouts. All of these power disturbances can seriously damage computer equipment, destroy valuable data, and cause system downtime.

Various levels of power availability guidelines for concentrated digital loads or data-handling industry are shown in Table 2-2. Data centers usually aim to operate in the highly to ultra highly available range.

Table 2-2

Levels of Availability (Source: Sun Microsystems)

\begin{tabular}{|l|c|c|c|}
\hline \multicolumn{1}{|c|}{ System Type } & $\begin{array}{c}\text { Unavailability } \\
\text { (Minutes/Year) }\end{array}$ & $\begin{array}{c}\text { Availability } \\
\text { (Percent) }\end{array}$ & $\begin{array}{c}\text { Availability } \\
\text { Class }\end{array}$ \\
\hline Unmanaged & 50,000 & 90 & 1 \\
\hline Managed & 5,000 & 99 & 2 \\
\hline Well-Managed & 500 & 99.9 & 3 \\
\hline Fault Tolerant & 50 & 99.99 & 4 \\
\hline Highly Available & 5 & 99.999 & 5 \\
\hline Very Highly Available & 0.5 & 99.9999 & 6 \\
\hline Ultra Highly Available & 0.05 & 99.99999 & 7 \\
\hline
\end{tabular}

\subsubsection{High-Tech Manufacturing (digital process industries)}

Although manufacturing processes are not as glamorous as rooms full of Internet servers or smart, Web-enabled appliances, the digital revolution is at work at every level of the manufacturing sector. This sector is abundant with high-tech processes that are increasing digitally controlled. And programmable controls are covering wider areas of manufacturing operations from single assembly lines to an entire plant. Automated digital design and numerical control of part production, inventories, even the plant HVAC are digitally controlled and many specific manufacturing processes are entirely automated.

In 1993, the U.S. Census Bureau conducted a Survey of Manufacturing Technology, collecting information about the use of certain digital technologies and asking companies why they were installing the equipment. In particular, companies reported on the single most important reason for using a given technology. This study found that, not only are manufacturing businesses making aggressive use of digital technologies, they are also doing so primarily to improve quality and output-both important contributors to productivity (see Table 2-3). 
Table 2-3

End-User Reasons for Using Digital Technologies (Source: U.S. Census Bureau)

\begin{tabular}{|c|c|c|c|c|c|c|}
\hline \multirow{2}{*}{ Technology } & \multirow{2}{*}{$\begin{array}{l}\text { Percent of } \\
\text { Plants Using } \\
\text { Technology }\end{array}$} & \multicolumn{5}{|c|}{ Percent Distribution by Most Important Reason } \\
\hline & & $\begin{array}{l}\text { Improved } \\
\text { Quality }\end{array}$ & $\begin{array}{c}\text { Increased } \\
\text { Output }\end{array}$ & $\begin{array}{c}\text { Lower } \\
\text { Labor Cost }\end{array}$ & Other & $\begin{array}{c}\text { Not } \\
\text { Specified }\end{array}$ \\
\hline CAD/CAE & 57.9 & 24.9 & 24.7 & 3.1 & 3.0 & 2.1 \\
\hline CAD/CAM & 25.3 & 10.5 & 10.3 & 2.3 & 1.0 & 1.3 \\
\hline $\begin{array}{l}\text { Digital Data } \\
\text { Representation }\end{array}$ & 11.2 & 5.8 & 3.2 & 0.9 & 0.8 & 0.4 \\
\hline FMC/FMS & 12.6 & 3.5 & 5.0 & 2.5 & 0.8 & 0.8 \\
\hline $\mathrm{NC} / \mathrm{CNC}$ & 46.3 & 16.0 & 19.9 & 6.0 & 1.5 & 2.9 \\
\hline $\begin{array}{l}\text { Materials } \\
\text { Working } \\
\text { Lasers }\end{array}$ & 4.9 & 2.2 & 1.1 & 0.6 & 0.7 & 0.3 \\
\hline $\begin{array}{l}\text { Pick and Place } \\
\text { Robots }\end{array}$ & 8.5 & 1.5 & 3.3 & 2.9 & 0.3 & 0.5 \\
\hline Other Robots & 4.7 & 1.3 & 1.5 & 1.4 & 0.2 & 0.3 \\
\hline $\begin{array}{l}\text { Programmable } \\
\text { Controllers }\end{array}$ & 29.9 & 11.1 & 9.9 & 2.6 & 3.4 & 2.8 \\
\hline
\end{tabular}

Electric power delivery plays a pivotal role in the ability of digitally controlled processeswhether discrete or continuous - to deliver on the promise of improved productivity. In fact, as shown in Table 2-4, the presence of electrical disturbances can easily reduce the productivity of digitally controlled processes by 5 or $6 \%$ and as much as $9 \%{ }^{13}$

\subsubsection{Power Parks (multi-energy and power-quality)}

The Multi-Energy Park (MEP) concept is a coordinated approach for the delivery of specific electrical, mechanical, and thermal services_-both individually and in combination-from a menu of DG resources, energy control, power conditioning and efficiency technologies. This approach yields higher value for each kilowatt-hour or BTU delivered and higher efficiency and reduced environmental impacts for a given service. The MEP concept employs many technologies (see Figure 2-3) and covers a broad range of system integration and engineering issues relating to utilization side equipment, power generation equipment and power distribution systems.

\footnotetext{
${ }^{13}$ M. Howard, T. Key, R. Sawheny, "Evaluating Industry Specific Electrical Disturbances Using A Process Modeling and Simulation Tool,” EPRI PQA Conference, 1999.
} 
Table 2-4

Impacts of Electrical Supply Disturbances on Manufacturing Processes

\begin{tabular}{|lccc|}
\hline Manufacturing Metrics & $\begin{array}{l}\text { Production Results with } \\
\text { no Electrical Supply } \\
\text { Disturbances }\end{array}$ & $\begin{array}{l}\text { Production Results } \\
\text { with Electrical Supply } \\
\text { Disturbances }\end{array}$ & $\begin{array}{l}\text { Percent } \\
\text { Impact }\end{array}$ \\
\hline Number of Parts Produced & 66,644 & 65,111 & -2.3 \\
Average Time (min) in System & 10,012 & 10,802 & -7.9 \\
\hline Resource Utilization (\%) & & & \\
Stamping & 0.99 & 0.96 & -3.1 \\
Welding & 0.55 & 0.51 & -7.8 \\
Assembly & 0.86 & 0.8 & -7.5 \\
Painting & 0.55 & 0.52 & -5.7 \\
\hline Inventory Levels & & & -9.1 \\
Stamping & 6,648 & 7,257 & -8.6 \\
Welding & 0.23 & 0.25 & -7.9 \\
Assembly & 0.63 & 0.68 & \\
\hline
\end{tabular}

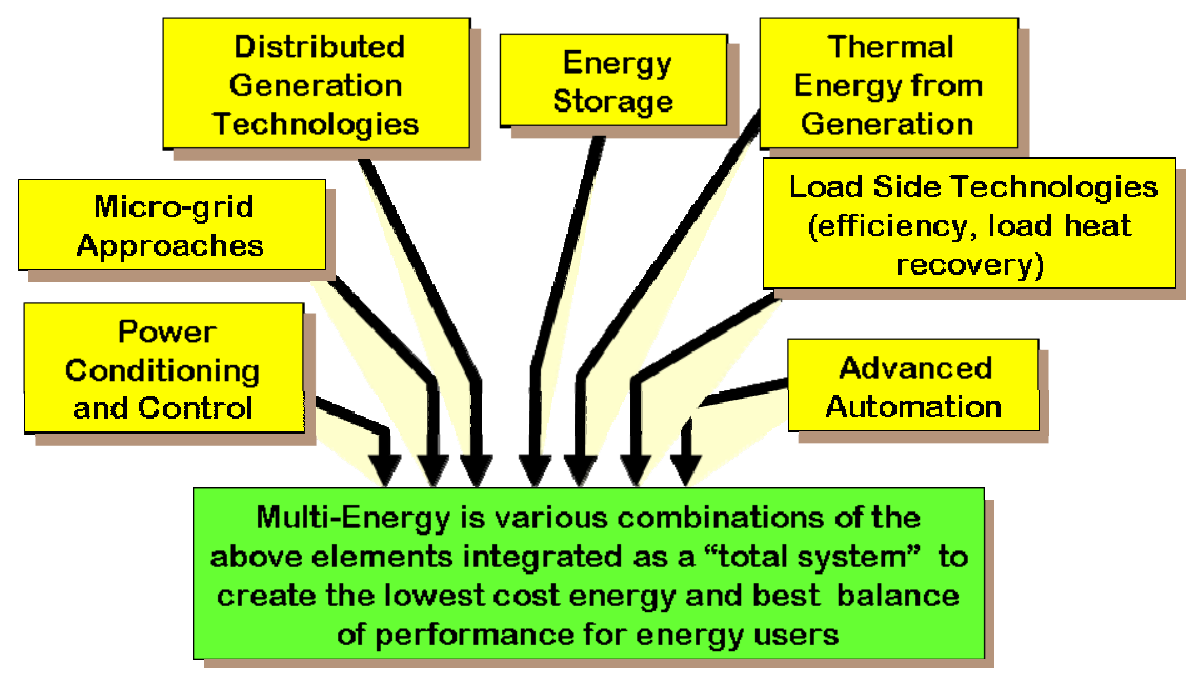

Figure 2-3

Elements of a Multi-Energy Approach include Various Distributed Generation, Heat Recovery, and Utilization Side Technologies

Advanced MEP systems may employ more than two generation source types, highly sophisticated energy management controls, energy storage, energy efficiency concepts, smartconservation approaches, and multiple uses for waste heat produced by the generators and loads. Advanced energy management controls can adjust the system load as needed to optimize the 
system performance in real time. In some applications, waste heat can be collected from the generators and also from the thermal exhaust of air-conditioners, motors, lights, and other loads. The recovered heat can then be used for space heating, hot water, and other applications to improve the overall system efficiency. In addition to distribution of electricity within a MEP, often a district energy system - distributing heat, cooling and/or process steam - is warranted. These types of energy schemes can be applied at a single facility, a small group of facilities, or within a larger "power park" that may have many energy customers. The size of a MEP system will generally fall into the DER size range (0-10 MW electrical demand) but may also be somewhat larger for certain industrial applications (perhaps up to $100 \mathrm{MW}$ ). Some MEP systems may be islanded to form a micro-grid that operates independently from the main utility system. Figure 2-4 is an example of an advanced MEP system employing a wind turbine, fuel cell, heat recovery, and advanced energy management controls.

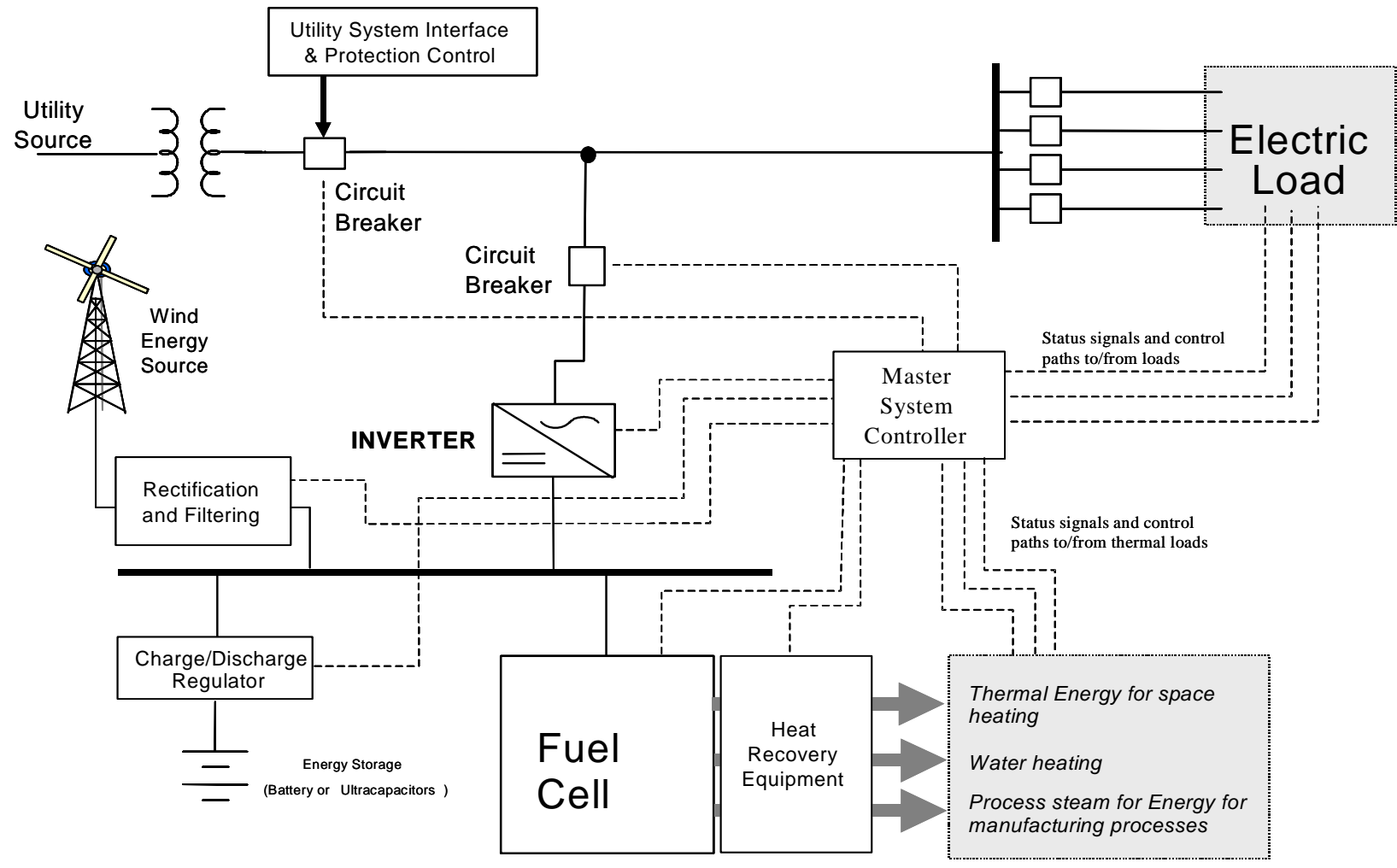

Figure 2-4

A Multi-Energy System Composed of Conventional Power Distribution, Renewable and Fuel Cell Energy Sources Controlled by an Integrated Energy Management System

\subsection{Digital Needs and Deregulated Utility Industry}

Utilities and service companies face tremendous hurdles in responding to the needs of the digital economy in an era of deregulation. Challenges include upgrading the aging infrastructure, adapting to regulatory and market changes, responding to society's use of complex digital devices, developing environmentally friendly components and materials, shifting to 
performance-based rates or other means to increase reliability and optimize returns on assets, mitigating operating risks, and ensuring continued security of the infrastructure.

The ultimate link between the consumer and the market-oriented power grid is the distribution or "wires" company. Distribution companies are under intense pressure to keep rates low, and they have divested much of the customer service capabilities the old, vertically-integrated monopoly utilities maintained. Often the utility customer service representatives have been assigned to an Energy Service Company (ESCo) set up as an unregulated subsidiary of the utility holding company.

This complicates the organizational and institutional picture for improving reliability and quality of electric service for digital enterprises. Because the reliability requirements of the digital economy are so rigorous, they cannot be met by blanket reinforcement of the grid; spot reinforcements or on-site generators - DER - are needed. Additionally, the extremely high load densities of digital enterprises often tax the distribution, sub-transmission, and substation transformer capacities of the local utility. The re-regulated utilities, especially the distribution companies, must avoid increasing costs for all customers in order to improve service for a particular customer class. Therefore, the best economic and technical alternatives to meet the power requirements of digital customers are often to locate groups of such customers in areas where the grid's capacity and reliability are high and where it is physically feasible to implement appropriate DER capabilities. Often this calls for new construction of power parks or multienergy parks offering premium energy services.

Another change in utility philosophy is a closer look at the service contract; customers must "pay as they go," and will be charged for special services and premium power. More and more it is recognized that the consumer must take a larger responsibility for its energy needs. This may be in the form of back-up or local generation, energy management systems, uninterruptible power supplies, power conditioning and filtering, etc. Thus, the DER options to provide power and reliability to digital enterprises may be owned by the utility, the customer, or a combination.

The most progressive utilities regard this as a business opportunity, either for their regulated or unregulated subsidiaries. Utilities are increasingly adopting the role of ESCos, sharing the costs and the resulting economic benefits of DER installations. This report explores the technical feasibility of various DER technologies to meet the requirements of digital facilities. The economic analysis considers overall costs and benefits, not necessarily differentiation between customer and utility costs/benefits. This is consistent with modern service contracts, performance-based rates, and ESCo-type initiatives. The measures to be implemented to achieve optimal economics and performance are first identified. Then the sharing of costs and revenues becomes a business negotiation, dependent upon the overall corporate and market management strategy of the utility. DER has become not only a non-traditional means of meeting customer service requirements, but also the basis for a non-traditional utility business model.

\subsection{Power Delivery and Technology Gaps}

Power delivery is not what it used to be. In fact, the electric power infrastructure that has served us so well in the past is now inadequate to meet the growing needs of consumers in today's digital economy. Delivering electricity has evolved from a rather direct transaction to a complex process, due to the exacting power requirements of digital technologies, and to the onset of competitive power markets, the implementation of self-generation, and the saturation of existing 
transmission and distribution (T\&D) capacity. Adding to the problem is the fact that load growth and new generation have outpaced investment in the electric system.

Substantial system upgrades are needed just to bring service back to the level of security, reliability, and quality already required and expected by consumers, and to allow markets to function efficiently so consumers can realize the benefits promised by industry restructuring. New technology is also necessary if society is to leverage the ever-expanding opportunities of communications with the natural connectivity of electric utilities and consumers. These developments will revolutionize both the role of a rapidly changing industry and the way consumers buy electricity in the future.

Today's power delivery grid is under tremendous strain. It is aging, constrained, underutilized, and inadequate to satisfy the growing needs of consumers and meet expectations for tomorrow's economy. It has become a patchwork of technologies and systems not really made to share data or applications.

Indeed, a sharp decline in critical infrastructure investment over the last decade has left portions of the electric power system vulnerable to power quality-related service interruptions, market dislocations, and external threats, including natural disasters, terrorist and cyber attacks, and simultaneous threats. The events of September 11, 2001 were especially significant to the energy sector, revealing vulnerabilities that must be addressed. These include public concerns about sharing information given the threat of cyber attacks, operations exposures, and cost recovery and rate regulations for unanticipated energy security costs.

Most of today's distribution systems are based on designs that originated in the 1950s. While these systems were adequate to serve the analog loads that predominated during the last halfcentury, the demands placed on distribution systems have increased dramatically in the last decade. Now, with consumers expecting greater reliability and higher-quality power, the leading challenge for distribution system owners/operators is to balance consumer needs with the cost of upgrading their systems, while also addressing regulatory and economic pressures to reduce operating costs.

Overhead distribution lines increasingly are being driven underground for reliability reasons and in response to demands from the public and local governments. Utilities are looking for lessinvasive under grounding technologies and methods to help address the conflicting demands for improved reliability and aesthetics, and lower costs for power.

Although many may argue whether industry restructuring will ever achieve its goals for expanded consumer choice and lower costs for electricity, it continues to have a tremendous impact on distribution utilities. Many have begun expanding their service offerings to include telecommunications, natural gas, and water, while others have turned to outsourcing traditional functions, such as customer service and billing, and offering premium power and other retail services to enhance revenues and build customer loyalty.

Finally, distributed energy resources (DER) have the potential to bring about the most significant changes to the distribution system in the past 50 years. Hailed as the technology with the greatest promise to improve distribution system reliability and security, DER also presents significant challenges. Chief among these are lack of control systems, grid integration complexities, lack of power quality standards, and high costs. 


\section{DER Opportunity Assessment}

Energy industry restructuring and improvements in distributed energy resources technology price and performance continue to increase interest in DER. A number of different current and potential applications for DER have emerged, and a diverse range of organizations sees DER as a possible business opportunity. To understand the scope of the potential DER markets, market research has been conducted to understand the primary drivers for end users and utilities who have expressed interest in DER. These include:

- Lowest cost of delivered energy to end-users (base load, cogeneration, CHP, and peaking),

- Premium power and disturbance protection,

- Using DER to balance supply and demand, and

- Applying DER to defer distribution system upgrades.

\subsection{Options for Incorporating DER}

The integration DER technologies within a power park development can provide additional benefits not currently being realized. These benefits include:

Energy self-sufficiency - combinations of DER units can serve the entire power park energy load during low-demand periods. Since demand for heating, cooling, or power is very seldom constant over time, the excess generation available during low-demand periods can be used to charge storage media in order to increase local capacity during high-demand, high cost periods. This results in better asset utilization as the load factor on the individual DER units will be increased. It is also helpful in negating high grid rates.

End-user power quality and reliability - combinations of DER units provide energy supply diversity and ensure against typical power interruptions. While single unit availability can be as high as 99\% (3.65 days of not being available), using a range of DER technologies can further improve energy quality by decreasing interruptions to under a second, as required by advanced manufacturing facilities, the "Dotcom's," and biotech companies.

Power system reliability - better load management reduces strain on existing constrained distribution systems.

Integration with infrastructure - operation of multiple DER units will be facilitated by infrastructure development in the power park. DER units can be joined by a mini-grid to synchronize operation and control, the latter through advanced wireless or fiber optic telecommunications. A district energy loop may be included to distribute thermal energy produced by CHP operations. Also, low and medium pressure natural gas lines can be provided.

Predictable energy costs - business and institutional operations need predictability in their annual cost of doing business. The power park scheme offers such operations long-term predictability of their power costs since the capital costs are known up front and can be allocated over a reasonable period of time. Long-term contracts for energy delivery can be determined and appropriately taken into account.

Environmental benefits - new energy technologies currently being deployed tend to be much more energy efficient and, therefore, use less fuel to create the same or a greater power supply. Release of greenhouse gases and other such emissions are thus substantially lowered. Some 
proven rates of efficiency range as high as $80-90 \%$ when a system is designed to capture and reuse waste heat, as in a CHP system. Lower emissions can mean less trouble siting and permitting at the local level as well.

Types of DER Technologies are described in the section following and include:

- Solar

- Wind

- Geothermal

- Biomass

- Electrical energy storage

- Engines

- Advanced turbines

- Microturbines

- Fuel cells - PEM fuel cells

- Non-electric chillers

- District energy systems

- Steam turbines

- Absorption chillers

- Absorption heat pumps

- Thermally activated desiccant systems

- Thermal energy storage

- Advanced thermal energy transport systems (e.g., heat pipes)

\subsubsection{Today's DER Technologies and Systems}

Solar - PV deployment in on-grid applications in congested areas offers the potential for effective load management, power quality and the opportunity for utilities to defer costly distribution upgrades. As more appliances become "smart" and require DC digital power, such DCPV systems will become ubiquitous in areas with a good solar resource. Solar thermal energy systems can provide hot water for domestic use or for hydronic space heating. A solar water heater provides about $3000 \mathrm{kWh}$ of energy annually, turning the roofs of buildings into distributed energy resources - even though they are less obtrusive than skylights. Hot water systems that use PV-powered pumps provide hot water when the grid is down. Some utilities are exploring the energy business opportunity of installing, owning, and operating solar water heaters on customers' roofs and billing them for the solar heated water.

Wind - Recent experience in Pennsylvania has shown that a location need not have an especially good wind resource for small $(<100 \mathrm{~kW})$ wind technologies to make economic sense. Wind turbines in the 3-10 kW size range (large residential/small commercial) now approach commercial fuel cells in installed costs. 
Geothermal - Geopower and direct heating technologies capture the earth's heat to warm and cool buildings, heat water, and generate electricity. Geothermal technologies include electric power generation, direct use for process and space heating, and ground-source heat pumps. Even though the smallest current geothermal electric project in the US is fairly large (700 kW), geothermal resources with high enough temperatures for electric generation fit in well with the power park concept of delivering both electricity and thermal services to nearby customers.

Biomass - Biomass power to date has been applied in larger, MW-scale baseload applications. Unlike many other renewables, it is not intermittent and is not limited to a particular geographic area. It can improve a community's economic self sufficiency and/or create rural jobs by creating markets for renewable "home-grown" energy crops.

Electrical energy storage - Energy storage will play a significant role in future power parks for both grid-tied and islanded systems. Energy storage serves an integrating role and provides unique capability for the power park. Storage can integrate the various generating or supply sources, creating a high quality, reliable power supply. For small- to medium-sized islanded systems with significant renewable resource generation, storage will smooth out the real time variability of the generation source. For hybrid systems, storage can follow the load peaks allowing the gas-driven devices to be sized for optimal efficiency, supporting the base load of the park.

Engines - (Including spark ignition, compression ignition and Stirling engines). Reciprocating internal combustion (IC) engines are reliable, efficient, have low first cost, and are easy to start. Power park engine applications are generally CHP. The two main types used for CHP are four cycle, spark-ignited (Otto cycle) and compression-ignited (diesel cycle) engines.

Advanced turbines - Gas combustion turbine development accelerated in the 1930s as a means of propulsion for jet aircraft. It was not until the early 1980s that the efficiency and reliability of gas turbines had progressed sufficiently to be widely adopted for stationary power applications.

Microturbines - A new class of small gas turbines called microturbines could jump start power park deployment. Microturbines are based on automobile turbo charger technology and thus are expected to be manufactured at very low cost. Due to their extremely high frequency power, microturbine output is first converted to DC then back to $60 \mathrm{~Hz}$ AC. Therefore, microturbines pose no energizing hazard in network type grids. They can also be used very efficiently in DC power applications.

Fuel cells - A fuel cell consists of a fuel reformer to generate hydrogen-rich gas, a power section where the electrochemical process occurs and a power conditioner to convert the direct current (DC) generated in the fuel cell into alternating current (AC). Fuel reforming "frees" the hydrogen in the fuel and removes other contaminants that would otherwise poison the catalytic electrodes. Fuel processing is usually performed at the point of use, eliminating storage of the hydrogen-rich mixture.

PEM fuel cells - Proton exchange membrane fuel cells (PEM FCs) operate on hydrogen and hydrogen-rich gases and are being commercialized at module sizes varying from 3 to $7 \mathrm{~kW}, 50$ $\mathrm{kW}$ and $250 \mathrm{~kW}$ to provide both power and heat for single-family planned residential and for industrial developments. PEM FCs are being manufactured by several companies and several small PEM FC systems will be commercial within a year or so. 
Non-electric chillers - This technology avoids the use of peak electric power and is therefore ideally suited for power parks. Absorption chillers, for instance, can use waste heat from CHP systems to produce chilled water. This application makes it possible to shift an electricity load to a thermal load, allowing for continuing use of CHP systems during the cooling season.

District energy systems - District energy is another key power park strategy, especially in combination with CHP. District energy systems distribute steam, hot water, and/or chilled water from a central plant to individual buildings through a network of pipes. District energy systems can provide space heating, air conditioning, domestic hot water, and industrial process heat. They can use a variety of thermal resources, including waste energy from CHP systems, industrial waste heat, geothermal heat, deep lake water (for cooling), or excess thermal capacity of individual pieces of equipment (e.g., transporting chilled water from one-building's chiller to another building's computer room when the computer room chiller is out of service).

Steam turbines - Turbines are one of the most versatile and oldest prime mover technologies used to drive a generator or mechanical machinery. This generation technology produces more than $80 \%$ of US electricity. A steam turbine does not directly convert a fuel source to electric energy but requires a source of high-pressure steam. The steam is usually produced in a boiler or heat recovery steam generator. Boiler fuels can include fossil fuels such as coal, oil and natural gas or renewable fuels such as wood or municipal waste or geothermal energy. Steam turbines are also widely used for CHP applications in the US and Europe. Because of their relatively low electric to thermal ratios at the smaller power park type sizes, steam turbines would mainly be used with district energy and/or a heat-powered cooling system in applications such as a power park.

\subsubsection{Future Utility Configurations and Systems}

Distribution automation, real-time communications, adaptive protection and control, micro grids and multi-energy applications are all part of the future distribution system. Together, these advances are expected to invite the use of DER and to enable achieving the full values of these resources in the future. For early DER applications in the digital economy advanced concepts are expect to begin at the user end of the system. One that is ready now is the multi-energy system concept.

The multi-energy (ME) system is a coordinated approach for the delivery of specific electrical, mechanical, and thermal services, both individually and in combination, from a menu of distributed-generation resources and technologies in energy control, power conditioning, and efficiency. This approach yields higher value for each kilowatt-hour or BTU delivered and higher efficiency and reduced environmental impacts for a given service. The concept of multienergy employs many technologies and therefore covers a broad range of system integration and engineering issues relating to utilization-side equipment, power generation equipment, and power distribution systems. ME is a newly evolved concept of distributed generation that reaches several steps beyond ordinary distributed generation and has the potential to improve the economics, efficiency, power quality, and reliability of distributed generation solutions.

A basic example of a multi-energy system is a combined heat and power (CHP) application with an integrated energy-management control to optimally balance heat production with electricity generation needs. Another example of a multi-energy-based system is a hybrid wind/photovoltaic system with energy storage. In this case, the use of two intermittent energy resources improves the energy-system availability due to the diversity of production of the two resources. Special 
energy-management controls would be used to coordinate the resources and loads of renewable energy production. More advanced multi-energy systems can employ more than two types of generation sources, very sophisticated energy management controls, energy storage, energyefficiency concepts, smart-conservation approaches, and multiple uses for waste heat produced by both generators and loads. Advanced energy-management controls can adjust the system load in large or fine increments or decrements as needed to optimize the system performance in real time. In some applications, waste heat can be collected not only from generators but also from the thermal exhaust of air-conditioners, motors, lights, and other loads and then be applied to useful functions to improve the overall system efficiency. These types of energy schemes can be applied at a single facility, a small group of facilities, or within a larger multi-energy park that may have many energy customers.

\subsection{Electrical Needs}

Whether in an Internet data center, a high tech office complex or in a high tech manufacturing facility, common issues are that digital equipment is becoming more sensitive, with more complex power conversion and power use requirements. A power supply for a programmable controller, a motor, and a start/stop relay are three electrically powered devices that have distinct differences in the way they utilize the voltage and current supplied by the power system. Each of these devices can have distinct differences in their sensitivity to electric power variations. The following section describes the typical equipment types found in commercial and industrial facilities and overviews the susceptibility of these equipment types.

\subsubsection{End-Use Equipment Susceptibility to Power Variations}

Relays, Starters and Contactors - These devices are typically found in the on/off control circuitry for most industrial processes as well as in the controls for HVAC systems, pumps, blowers and emergency stop circuits. The basic design concept is to energize a wire coil to magnetically change the state of (open or close) a set of contacts. The contacts act as the switch that turns off or on the device being controlled. The applied input voltage determines whether or not the coil will maintain enough magnetizing current to keep the contacts from changing state. Most coils can withstand steady state and momentary input voltage variations of plus/minus 20\% of nominal. Depending on the design, these devices can withstand complete interruption in power for only one or two electrical cycles. For momentary voltage sags, the sensitivity of these devices can be distinctly different.

Testing of these devices has shown that the sag sensitivity of relays and contactors can range from units that are susceptible if the voltage sags to $85 \%$ of the system nominal to units that are only susceptible if the voltage sags below $40 \%$ of the system nominal.

Information Technology Equipment (ITE) - Perhaps the best example of the machinery of a digital economy, IT equipment includes personal computers, servers, routers, fax and copy machines, telephone switching equipment, and printers. These devices are prevalent in both industrial and commercial office space. All of the mentioned devices utilize some variation of the "single-phase" switched mode power supply (SMPS) for input power. The SMPS input has a bridge rectifier and capacitor as the primary power converter to convert the AC line voltage to DC for power distribution at lower or higher DC levels as required. IT equipment is generally relatively immune to any line to neutral and line to line transients up to about 1000 volts peak, but may suffer from lockup or trip outs if a peak detection circuit is used to sense input voltage. 
SMPS testing indicates that these power supplies can withstand steady state input voltage variations of plus/minus $20 \%$ of nominal, can withstand variations of plus/minus $30 \%$ of nominal for a few seconds and can withstand complete interruption in power for one to thirty electrical cycles (depending on the loading condition and the size of the bulk storage capacitors used in the design).

Programmable Logic Controllers (PLC’s) - Programmable controllers are found in commercial and industrial process control settings ranging from elevators, to wastewater treatment, to automobile final assembly. The PLC is an industrial computer with capabilities to read input signals, make decisions based on a stored program and send corresponding signals to output devices. The power supply for the PLC is identical to that found in a computer (switched mode power supply), thus the electrical performance or susceptibility is similar. The PLC power supply will be relatively immune to any line to neutral and line to line transients up to about 1000 volts peak, but may suffer from lockup or trip outs if a peak detection circuit is used to sense input voltage.

PLC testing indicates that these power supplies can withstand steady state input voltage variations of plus/minus $20 \%$ of nominal, can withstand variations of plus/minus $30 \%$ of nominal for a few seconds and can withstand complete interruption in power for five to thirty electrical cycles. When evaluating PLC sag performance, it is important to look at more than just the power supply. Many PLC's monitor input voltage and will shut down if the voltage peak is reduced more that 20 percent below the nameplate specification. All of the devices controlled by the PLC input and output cards are potentially susceptible to voltage variations, and most of them are at least as sensitive or more sensitive than the PLC power supply.

Lighting - Keeping the lights on is a personnel safety objective as well as a required power quality (PQ) performance objective. It does no good to improve the PQ immunity of a process if the lights don't stay on. Therefore lighting and other process support aspects such as compressed air, heating, cooling, steam etc. are the primary objectives. The susceptibility of the lights to power variations is very different depending on the type of lighting used. The following discussion categorizes the lighting by the four most common lighting types and describes the PQ susceptibility of each type of light.

Incandescent Lighting: These are the most common of all lighting technologies. The bulb filament heats up and glows to illuminate the immediate area surrounding the bulb. The luminance of the filament is directly proportional to the voltage applied and even a 2 percent change in voltage is perceptible. This makes the incandescent lamp extremely sensitive to voltage flicker. In addition, these lights will prematurely fail if the steady state voltage exceeds 110 percent of the voltage rating of the bulb. Sensitivity to $P Q$ variations are primarily flicker and overvoltage related.

High Intensity Discharge (HID) Lighting: HID lighting includes both metal-halide, as well as, high and low pressure sodium lamps. The HID light is an arc discharge technology where a current arc is discharged across a gas filled tube very close to the peak voltage of every half cycle of the AC sinewave. A magnetic ballast will control the current discharge and the arc extinguishes close to the zero crossing of each half cycle. Once the tube is heated up, the arc will provide full light output, but even a one half cycle drop in voltage to less than about 80 percent of the system nominal will cause the lamp to extinguish, and a period of three to eight minutes of no light output will follow until the temperature and the pressure of the gas tube 
gets to a point where the arc discharge can resume. Sensitivity to $P Q$ variations is primarily related to voltage sags and momentary interruptions, where a nuisance dropout of the lights is the result.

Magnetic Ballasted Fluorescent: This type of lamp is the common four or eight foot fluorescent type where current is passed through a gas tube, rendering a luminance to the area surrounding the tube. These lamps will re-strike immediately following a sag or momentary interruption, thus the primary PQ concern with this light type is related to voltage flicker.

Electronic Ballasted Fluorescent: These lamps are identical to the magnetic ballasted fluorescents with the exception of the ballast type. The electronic ballast used in this type of lighting is very similar to a switched mode power supply and will restart immediately after voltage sag or a momentary voltage interruption and can withstand steady state variations of plus/minus 15 or 20 percent. The primary PQ concern with this light type is related to voltage flicker and to transients above 5 or 6 hundred volts peak that can damage the ballast.

HVAC Equipment - Heating, Ventilation, Air Conditioning equipment includes both single and three-phase products. Overall, the HVAC system is a process that includes a number of the elements described in this section such as relays, contactors, compressor motors, blower motors and so on. The primary PQ concerns can be correlated to the specific items described under each component description. Overall, the primary PQ concerns for HVAC systems are sensitivity to voltage sags, momentary voltage interruptions and voltage unbalance.

Air Compressors - Almost every industrial plant, from machine shops to pulp and paper mills, have some type of compressed air system. Plant air compressor systems can vary in size from a small unit of 5 horsepower (hp) to systems with over 50,000 hp. Similar to keeping the lights on, compressed air is many times one of the critical support aspects required to keep process operations running; thus priority should be placed on immunizing the compressors to better withstand PQ variations. The compressor itself will be sensitive to voltage (and corresponding current unbalance) and will usually have a programmable trip setting that may be adjusted somewhat to improve PQ performance. In addition a processor or a control board (similar to a PLC) is used to monitor a number of inputs and make decisions based on the states of the various inputs.

The PQ concerns for air compressors are sensitivity to voltage sags, momentary voltage interruptions and voltage unbalance

Chillers - Cooling is another one of the critical support processes for many applications. A number of sub-components such as relay contactors, compressors, blower and so on will be integrated into the chiller system. This makes the chiller very susceptible to PQ variations. Similar to the air compressor.

The PQ concerns for chillers are sensitivity to voltage sags, momentary voltage interruptions and voltage unbalance

AC induction motors - AC induction motors find uses in nearly every industrial and commercial facility and are said to be part of over $50 \%$ of the electric power utilization throughout the world. The induction motor has no power supply, but uses an insulated wire wound around a steel core to magnetically induce rotation in the motor shaft. Overall, the induction motors PQ concern are primarily steady state related issues such as voltage unbalance, single-phasing, and steady state voltage requirements within plus/minus ten percent of the 
equipment nameplate. For voltage sags and momentary voltage interruptions, it is usually the motor control circuit and the associated relays and contactors that cause any nuisance-tripping problems. In fact, holding induction motors in for ten to twenty electrical cycles during voltage sags and even during momentary interruptions is a process design objective for many petrochemical facilities.

To summarize the PQ concerns for induction motors, the AC induction motors are sensitive to voltage unbalance, single-phasing, and steady state over or undervoltage.

PWM Variable Frequency Drives - Pulse width modulated variable frequency drives comprise the majority of motor control applications. The basic PWM drive utilizes a three-phase bridge rectifier and capacitor to convert the input $\mathrm{AC}$ to a DC value equal to the peak voltage of the AC power source. The DC is then switched (or pulsed) to control the speed of an AC induction motor. Any time precision process control, variable motor speed or increased process efficiency is desirable, the PWM drive is likely to be found. The power supply for a PWM drive is essentially a three-phase switch mode power supply. There are a number of PQ concerns with PWM drives from both an emissions and an immunity standpoint. Regarding emissions, the PWM drives generate harmonic currents and high frequency switching transients that in turn propagate back into the electric power system. Regarding PQ immunity, EPRI PQ Test Facility results indicate that the PWM drive is sensitive to over and undervoltages as well as to short duration sags, swells and momentary interruptions. Another common problem for these drives is that utility capacitor switching can cause nuisance tripping of the drive due to DC bus overvoltage conditions. There are differences in sensitivity levels depending upon the manufacturer and the programmed setting of the drive. In addition the drive control circuit can sometimes be the weak link that causes process stoppage.

To summarize the PQ concerns for AC variable frequency drives, they are sensitive to virtually all PQ variations when the voltage goes outside a plus/minus twenty percent window around the drives' nominal nameplate voltage rating. In addition, $A C$ drives can generate transient noise and harmonic currents that propagate back into the power system.

DC drives - DC motor drives are used in a variety of commercial and industrial applications ranging from rolling mills to printing presses to elevators. The primary considerations for using DC drives center around those applications where there is a need for either high torque or precision speed control. In addition, with many "mature" processes, the designers and system integrators are much more comfortable and familiar with the use of DC motors and their attractive "first costs of implementation." In terms of PQ performance, the DC drive presents a unique set of challenges that makes the technology one of the most difficult to protect against electrical variations. The most common version of the DC drive uses a silicon controlled rectifier (SCR) converter type input power supply and a DC field winding power supply. Both of these sources must be able to ride-through electrical disturbances during normal operation as well as during regenerative operation. In addition, many DC drives use a second SCR package to dump energy back into the power system in order to quickly slow down, or perform what is commonly referred to as "regenerative braking." Overall, each of the PQ concerns described for the AC variable frequency drives are also the same for the DC drive. The notable difference is that the DC drive is usually a little more sensitive than a similarly sized AC drive.

To summarize the PQ concerns for DC drives, they are sensitive to virtually all $P Q$ variations when the voltage goes outside a plus/minus ten percent window around the drives' nominal 
nameplate voltage rating. In addition, DC drives can generate transient noise and harmonic currents that propagate back into the power system.

Sensor Control Units - Sensor control units are the power sources and watchdog or monitoring circuits for various process parameters such as gas flow sensors, flame detectors, pressure transducers, optical sensors and so on. The control unit usually supplies the power to the sensors, thus the PQ concerns are usually related to the control unit's susceptibility to voltage variations.

Most of these control units are immune to steady state PQ variations of plus/minus 20 percent and are immune to voltage sags and swells of plus/minus 30 percent of the nominal nameplate voltage. Some units can withstand greater variations, but test facility characterizations indicate that the sensitivity thresholds vary with different manufacturers.

Resistance Heating and Drying - Many processes contain resistance heaters or dryers as a component of the process. Examples include laser printers, copiers, aluminum melting and so on. There are usually not too many PQ concerns with the resistance process, but the control circuitry may contain relays and contactors that have extreme sensitivity to sags and momentary interruptions. Overall the resistance elements are not in need of power conditioning, thus the major challenge is separating this typically large portion of the electrical load from the more sensitive portions of the process. Occasionally, when more precise temperature control is required, the heating components will be controlled by silicon controlled rectifiers or other semi conductor control devices.

When these control devices are used, harmonic emissions back into the power system can become a concern.

\subsection{Thermal Needs}

The primary implications from the thermal perspective are:

- Today’s electronic loads are tremendously concentrated. Integrated circuits have more computational power per square inch, the circuit boards are far more densely populated, and the boards are physically closer to each other. Electronic communications equipment is interspersed with information processing equipment.

- Electronic equipment is packaged in compact enclosures or configurations that do not have the ventilation capacity per watt of older electronic equipment. It is more difficult to reject heat. A rack-mounted data processing unit may provide 10 times the computing power of an older technology's server but require 30 times the airflow to cool it. A typical 84 inch cabinet can hold 40 new servers, each of which expels $250 \mathrm{~W}$ of heat. The result is a 10,000 Watt heat load in each cabinet; an Internet "hotel" will have row upon row of such cabinets. ${ }^{14}$

- Reliability requirements necessitate uninterruptible power sources, power quality systems, status monitoring, and/or back-up systems that all consume power and generate heat.

- Today's electronic equipment is quickly and catastrophically vulnerable to heat build-up. Not only must there be back-up power for the facility, but the cooling system requires redundancy.

\footnotetext{
${ }^{14}$ Koplin, op. cit.
} 
For high-technology facility design:

- There is more heat generation.

- It is more difficult physically to circulate air to remove heat.

- Ancillary systems (cooling, communications, monitoring, protection, back-up power, etc.) generate significant amounts of heat.

- A large part of the facility's power requirements, and therefore its back-up power requirements, are for cooling.

\subsubsection{Present Practices for Cooling Digital Equipment}

Standard practice for computer rooms is to locate multiple electric-powered computer room air conditioners (CRAC) underneath an elevated floor. Cool air enters the room through floor diffusers or perforated floor tiles. Power and communications cables are also routed under the floor.

The ASHRAE Handbook originally published guidelines for cooling data centers in its 1987 Systems and Applications volume. The HVAC systems were designed to cool loads of 10 to 15 W/square foot; that guideline has yet to be updated in the Handbook (the 1999 Applications volume). To cope with increasing power/heat density, additional under-floor CRAC units are usually added to legacy cooling systems. These additional units, plus the increased cabling for power and communications, constrain airflow under the flooring. As a result, most data center HVAC systems do not have adequate static pressure under the floor to cool the room well. ${ }^{15}$

It is often said that digital loads require multiple "9's" of power reliability. They also require extremely high reliability of cooling systems. The HVAC control systems must be designed to be fault-tolerant, so some cooling is operating even during a control system failure. ${ }^{16}$ All mechanical components of the HVAC system must also have redundancy. Current practice is to build $\mathrm{N}+1$ redundancy, to cover failure of an individual component. However, the high heat density in the computer room and the physical constraints on under-floor air flow mean that each "grouping" of CRAC units requires $\mathrm{N}+1$ redundancy. Typically, an additional CRAC is installed for every grouping of 6 units. ${ }^{17}$

Computer room cooling system design practices encourage placing air outlets (e.g., perforated tile) from under-floor CRAC close to the air conditioner and locating high heat density loads close to the air outlet. Such practices actually result in inadequate cooling by isolating the cooling plumes from each CRAC, preventing mixing of the cool air streams. As the computing and heat load grows, adding additional CRAC to the legacy cooling system in this manner will make the problem worse. ${ }^{18}$

The objective of this approach is to prevent equipment overheating by cooling ambient air in the computer room. Looking at the "end-users" of the cool air - the rack-mounted servers - suggests that might not be adequate. Older computer room cooling system designs tended to address the 2-dimensional problem of locating computing equipment and cooling outlets on or under the

\footnotetext{
${ }^{15}$ Koplin, Ibid.

${ }^{16}$ Lawrence, Matt, “Controls for Critical Cooling,” ASHRAE Journal, Volume 45, No. 1, January 2003

${ }^{17}$ Sheehan, Timothy, “The Quick chill,” Engineered Systems, Volume 19, No. 9, September 2002.

${ }^{18}$ Koplin, op. cit.
} 
floor. Despite the increasing height of the digital equipment racks and enclosures, cooling system designs did not rigorously address third dimension - heating loads and cooling capabilities at varying heights above the floor. ${ }^{19}$ Better control of the air stream - "channel or duct cool air to the equipment, and provide a path for the heated air to leave" - will deliver more effective cooling more efficiently. ${ }^{20}$

The standard "solutions" to overheating problems of growing digital loads are inefficient: continue to add additional under-floor CRAC, and/or install an in-room spot cooling unit to cool the ambient air near the particular equipment that is overheating. Additional CRAC may further constrain airflow and impede mixing. Spot coolers reject heat into the computer room, local cooling of the ambient air may not be sufficient to relieve the spot overheating problem, and the local cooling may cause a condensation problem if the humidity is not well-regulated.

\subsubsection{Future Approaches - Opportunities for DER}

As the power density - and density of heat generation - continues to increase in concentrated digital load (CDL) facilities, present cooling system design practices will prove more inefficient and inadequate. The previous section presents a case for developing better methods for digital facility design. Under-floor cool air distribution is likely to remain the prevalent way to provide computer room cooling, but specific improvements are needed:

- Better placement of CRAC, cool air outlets, and electronic equipment, alternating "hot” and “cool” aisles.

- Vertical control of airflow, to deliver cool air and remove heated air.

ASHRAE's Guideline HDEC: Thermal Guidelines for Data Centers and Other Data Processing Environments, was published in early 2004. Recognizing the environment-related rates of failures for modern electronic equipment, the Guideline significantly tightens the recommended environmental parameters. Industry experience is that:

- The number of failures doubles when indoor ambient temperatures rise from 20 to 30 degrees Celsius.

- Recorded failures of electronic equipment can be attributed 55\% to temperature-related causes, $19 \%$ to humidity conditions (e.g., conductor anodic failures), and 19\% to hygroscopic dust.

The Guideline recommends temperatures in the 20 to 25 degrees Celsius range and relative humidity in the 40 to 55\% range. This will require much more precise environmental monitoring and controls in data processing facilities. The susceptibility of electronics to dust-caused failures means that outside make-up air is not used, as most filtration systems are not effective enough. Therefore, existing air must be filtered and reconditioned; outside air can be used to help cool internal air with air-to-air heat exchangers. This means that much of the heat build-up from ancillary equipment (e.g., CRAC) and the hot air "exhausted" from the computer room must be

\footnotetext{
${ }^{19}$ Koplin, Ibid.

${ }^{20}$ Mordick, Brian L., “How To Eliminate Heat From Enclosures,” Control Solutions, Volume 76, PennWell Publications, February 2003
} 
cooled. The result of these updated guidelines and practices is that the energy needed to properly condition mission-critical digital facilities will significantly increase.

Distributed energy resources (DER) offer capabilities to meet the stringent electrical and environmental requirements of digital loads - reliability, power quality, load density, cooling, humidity control - that the conventional power grid cannot. DER also offer opportunities to more efficiently meet the thermal requirements of these CDL facilities by:

- Reducing the cooling loads

- Spot cooling electronic equipment

- Controlling humidity to reduce latent heat (reduce cooling requirement) and prevent condensation

- Removing heat from the computer room

- Reducing the amount of back-up power generation needed

- Decreasing energy bills for the facility

- Improving reliability of the cooling systems

DER technologies offer two complementary strategies to improve thermal management of concentrated digital loads. First, better facility design and use of DER can improve the rejection of heat from electronic equipment and computer rooms, and use this heat plus waste heat from distributed generators or on-site industrial processes to provide cooling and dehumidification. Second, DER technologies of thermal storage and fuel switching can provide thermal reserves, reduce electric back-up generator capacity, and reduce peak load operating costs. Four types of DER applications are relevant:

- "Harvesting” waste heat

- Concentrating waste heat

- Using waste heat

- Delivering cooling

The following discussion presents an idealized scenario for DER technologies. Obviously, not all these DER applications or technologies will be technically feasible, economically justified, or even relevant in every CDL installation.

\section{"Harvesting” waste heat.}

Potential sources of waste heat in a digital facility are:

- Heat generated by the electronic equipment

- Heat from distributed generators

- Heat from on-site industrial processes in some facilities

The DER Program has helped develop, improve or publicize a variety of techniques for obtaining such waste heat in usable form. 
One of the improvements needed in the design of CDL facilities is to better direct cool air to the electronic equipment and reject warm air after cooling. Such active ventilation management reduces the cooling energy needed by more efficiently delivering cooling to the "hot" spots, and exhausting the warmed air keeps the ambient temperature of the computer room low. However, such a design also provides an airflow that is a source of low-grade heat.

Distributed Generation (DG) -micro-turbines, fuel cells, etc. - all generate high temperature waste heat. The exception is reciprocating engines; the waste heat given off by them really is not high temperature. Their waste heat is mixed between the exhaust and the cooling water - but those temperatures are low. In some CDL facilities, the DG may operate continually in a gridparallel mode, serving some of the facility's electrical needs on a regular basis for reliability improvements or operating cost reductions. Such installations provide a high-grade heat source that has combined cooling, heating and power (CHP) applications. In most digital facilities, however, the DG is limited to back-up status for reliability. Where DG is operated rarely or intermittently, it will probably not be economically justified to seek to extract and utilize its waste heat.

Concentrated digital loads may also be located in a facility or be close to a facility with other heat-generating processes. (E.g., proximity to light industry in a power park, restaurants or hospitals in an urban area) Such heat sources may be useable in CHP or district energy applications.

\section{Concentrating Waste Heat}

Typically heat must be at least 80 to 90 degrees Celsius to be useable. The exhaust air from a computer room or other CDL facility is much less (about 40 degrees). The DOE DER program sponsored development and application of thermally-activated absorption heat pumps (TAHP) to concentrate - and use - low-grade heat. (The GAX heat pump - gas-absorber heat exchange cycle - is one example.) TAHP can produce useable heat, or their output can be directly applied to gas-fired air conditioners.

\section{Using Waste Heat}

The primary DER technologies utilizing waste heat for space conditioning are thermally activated absorption chillers and thermally-activated desiccant dehumidifiers.

Desiccant dehumidifiers apply available heat to recharge a desiccant wheel. By dehumidifying the space, this DER technology reduces the latent heat load, thus requiring less energy to cool the ambient air. In CDL facilities where spot cooling is needed, condensation is a potential problem when the spot cooler reduces the ambient air temperature to below its dew point. Lower humidity reduces the risk of condensation.

Absorption chillers provide cooling by using heat; high-grade waste heat and/or heat generated by the combustion of natural gas. Although absorption chillers typically cost 2 to 3 times more than electric chillers, this DER technology still has the potential to markedly reduce CDL facility costs and improve reliability. Typical absorption chiller applications trade off lower operating costs against their higher capital costs. The strategy is for a facility with hybrid capability - both electric- and gas-fired chillers - to operate the absorption chiller during times of high electric 
prices (time of use or real-time pricing) or to use it to lower the facility's peak electrical load. ${ }^{21}$ This analysis applies to a CDL facility, where the absorption chiller can be operated to reduce facility peak electric demand and/or substitute for electric chillers during the peak period of time of use rates or high real-time prices. (Most digital facilities have some form of back-up generator because of their requirement for highly reliable power, so a source of natural gas is likely to be available.) For a CDL facility, where a "free” heat source is available, the absorption chiller's operating costs can be even lower than if it is entirely gas-fired.

For CDL facilities, absorption chillers can also improve reliability and reduce back-up generation costs. HVAC system design for digital facilities calls for a redundant ( $\mathrm{N}+1$ back-up) air conditioner for every grouping of under-floor computer room air handlers. ${ }^{22}$ A typical CDL facility may require 4 to 12 such redundant units; if these are linked to an absorption chiller, then the facility has a fuel switching capability for its cooling system: Back-up generator capacity can be reduced by the electrical load the absorption chiller and air handlers can supplant.

\section{Delivering Cooling}

Several DER technologies can cool digital loads. Thermally-activated absorption heat pumps and thermally-activated absorption chillers have already been discussed. Three other relevant DER technologies are:

- Advanced thermal transport, such as heat pipes

- $\quad$ Thermal Energy Storage (TES)

- District energy systems

DER's Thermally Activated Technologies Program is promoting research, development and applications of advanced heat transport technologies. Heat pipes are designed to electronically deliver or remove heat from a spot location. A heat pipe applied to an integrated circuit, for example, can provide local cooling to the chip without heating the ambient air. (The "output" of the pipe is heat that can be "harvested" using other DER techniques.) This technology addresses the growing problem of effectively cooling densely populated server racks with limited air flow. ${ }^{23}$

Thermal energy storage (TES) technology can provide back-up cooling during a power interruption or reduce peak electric demand by replacing some of the output of the primary chiller. Chilled water and ice storage are the most common TES technologies for cooling. For CDL facilities, rapid deployment of cooling "back-up" is needed, and the design outage is typically 5 minutes to 2 hours. In this case, a rapid discharge capability is called for; advanced ice slurry systems may be best suited to this application. (e.g., Thermetica's IStorm system uses a fluorinated hydrocarbon in the ice slurry mix to enable rapid discharge - up to $100 \%$ discharge in 30 minutes is possible, compared to $15 \%$ per hour for conventional ice systems.) Discharging TES and operating absorption chillers at the same time can deliver significant cooling without using electrical chillers. This reduces the amount of back-up generation needed as well as being

\footnotetext{
21 Smith, Brian, “Economic Analysis of Hybrid Chiller Plants,” ASHRAE Journal, Volume 44, No. 7, July 2002

22 Sheehan, Timothy, “The Quick Chill,” Engineered Systems, Volume 19, No. 9, September 2002

${ }^{23}$ Mordick, op. cit.
} 
able to reduce peak electric operating costs by providing a proven, reliable on-peak alternative to electric air conditioning.

District energy systems circulate thermal energy throughout a facility or among several buildings by piping a fluid transport medium - steam, water, or other fluid. District energy allows a central chiller or heat plant to supply thermal energy to remote facilities. By having the capability to transport thermal energy throughout digital facilities, it is possible to utilize waste heat, thermal energy storage, and reserve or redundant chiller capacity available at one point but needed at another location. Applying district energy technology in this manner has the potential to reduce operating (energy) costs (by using the least expensive cooling energy anywhere in the facility), reduce capital costs (by sharing reserve capacity of different chillers, storage media, heat pumps, etc. throughout the facility), and improve reliability (sharing redundant or reserve equipment).

Table 3-1 summarizes these technologies, applications and potential benefits.

\subsection{DER for High-Tech Consumers}

Based on the characteristics and needs of several digital economy sectors, DER is a viable opportunity for the following applications:

- Digital Services. High technology enterprises performing high-value transactions or services. Reliability is crucial - interruptions are extremely costly and may be devastating to the enterprise's ability to attract and retain customers. Energy costs are not a major part of the enterprise's cost of business. Examples are Internet Service Providers, financial transaction clearing houses, and mobile communications centers.

- Digital Processes. Manufacturing or fabricating materials using tightly-regulated computercontrolled manufacturing processes. Reliability is crucial, as a momentary interruption may disrupt the process, resulting in a ruined or low quality product batch. Energy costs may be a significant part of product costs. Examples are silicon chip or integrated circuit manufacturer, chemical or petroleum refinery, and steel mill.

- Multi-energy parks. It is difficult, if not impossible, to provide digital customers with required extremely high levels of electric reliability and power quality using the "conventional" utility configuration. One solution or application is the power park or multienergy (and multi-user) park, where diverse digital customers are concentrated. This allows the utility to make spot investments in high-technology reliability and power quality solutions, and charge the customers accordingly. The economics of a multi-energy park (MEP) are improved if there is a diversity of digital customers - characteristics, needs and benefits. Therefore a MEP will likely contain both digital service and digital process customers and economically justify more DER technologies and applications.

Table 3-2 summarizes these unique characteristics, customer needs and drivers, DER technology options and the overall benefits when applying DER for digital services and digital processes. 
Table 3-1

Application of DER to Thermal Management of Concentrated Digital Load Facilities

\begin{tabular}{|c|c|c|}
\hline Technology & Applications & Potential Benefits \\
\hline $\begin{array}{l}\text { Improved computer room air } \\
\text { modeling }(F D)\end{array}$ & $\begin{array}{l}\text { Optimize placement of computer room } \\
\text { air handlers and digital equipment to } \\
\text { improve distribution of cool air }\end{array}$ & $\begin{array}{l}\text { Reduce air conditioning load. } \\
\text { Fewer hot spots and less equipment overheating. } \\
\text { Better able to accommodate growth in facility's electronic } \\
\text { loads. }\end{array}$ \\
\hline $\begin{array}{l}\text { Improved server } \\
\text { rack/enclosure air flow }(F D)\end{array}$ & $\begin{array}{l}\text { Better channel cool air into enclosure } \\
\text { and remove heated air }\end{array}$ & $\begin{array}{l}\text { More effective cooling of electronics. } \\
\text { Reduce cooling load. } \\
\text { Provide a low-grade heat exhaust for thermally-activated } \\
\text { DER technologies. }\end{array}$ \\
\hline $\begin{array}{l}\text { Distributed generation \& } \\
\text { CHP: micro- turbines, } \\
\text { reciprocating engines, fuel } \\
\text { cells }\end{array}$ & $\begin{array}{l}\text { Back-up electric generators } \\
\text { Provide waste heat for CHP - heat } \\
\text { recovery techniques }\end{array}$ & $\begin{array}{l}\text { Provide reliable power. } \\
\text { Local generation may reduce distribution overloads or defer } \\
\text { feeder/transformer reinforcement. } \\
\text { Reduce electric charges during peak load periods. }\end{array}$ \\
\hline $\begin{array}{l}\text { Thermally-activated } \\
\text { absorption heat pumps }\end{array}$ & $\begin{array}{l}\text { Concentrate low-grade waste heat } \\
\text { Non-electric cooling }\end{array}$ & $\begin{array}{l}\text { Make use of low-grade waste heat. } \\
\text { Reduce on-peak electric load for cooling. } \\
\text { Reduce required capacity of back-up electric generators. }\end{array}$ \\
\hline $\begin{array}{l}\text { Thermally-activated } \\
\text { absorption chillers }\end{array}$ & $\begin{array}{l}\text { Use this technology for redundancy of } \\
\text { computer room air handlers - provides } \\
\text { non-electric cooling } \\
\text { Utilization of waste heat }\end{array}$ & $\begin{array}{l}\text { Utilize waste heat - reduce operating costs. } \\
\text { Fuel switching - improve cooling system reliability. } \\
\text { Reduce required capacity of back-up electric generators. }\end{array}$ \\
\hline Desiccant dehumidifiers & $\begin{array}{l}\text { Use waste heat to recharge desiccant } \\
\text { wheel } \\
\text { Dehumidify CDL facility }\end{array}$ & $\begin{array}{l}\text { Reduce latent heat content of air - lower cooling load } \\
\text { (reduced demand, energy, chiller capacity). } \\
\text { Reduce risk of condensation in digital facility. }\end{array}$ \\
\hline
\end{tabular}




\begin{tabular}{|l|l|l|}
\hline Technology & Applications & Potential Benefits \\
\hline District Energy System & $\begin{array}{l}\text { Distribute cooling or heating energy } \\
\text { throughout the facility or multi-energy } \\
\text { park }\end{array}$ & $\begin{array}{l}\text { More effectively utilize waste heat, thermal energy storage } \\
\text { and/or reserve capacity of heating or cooling equipment } \\
\text { within the facility }\end{array}$ \\
\hline Heat pipes & Spot cooling of integrated circuits & $\begin{array}{l}\text { More effectively cool hot spots without raising ambient } \\
\text { temperature. } \\
\text { Reduce required chiller capacity. }\end{array}$ \\
\hline $\begin{array}{l}\text { Thermal energy Storage - } \\
\text { ice slurry }\end{array}$ & $\begin{array}{l}\text { Provide back-up cooling (5 to 120 } \\
\text { minutes) during power interruptions. } \\
\text { Supplement direct cooling during } \\
\text { periods of peak electric rates. }\end{array}$ & $\begin{array}{l}\text { Improved thermal (cooling system) reliability. } \\
\text { Reduced electrical costs - responsive load, peak reduction, } \\
\text { load shifting. } \\
\text { Reduce required capacity of back-up electric generators. } \\
\text { Reduce required capacity of electric chillers. }\end{array}$ \\
\hline
\end{tabular}

Note: $F D$ = facility design technology/improvement rather than DER technology 
Table 3-2

Summary of Customer Needs and DER Applications

\begin{tabular}{|c|c|c|}
\hline & Digital Services & Digital Processes \\
\hline Needs/Drivers & $\begin{array}{l}\text { Absolute reliability - single cycle to } 120 \text { minutes } \\
\text { Absolute power quality - single cycle to } 120 \\
\text { minutes }\end{array}$ & $\begin{array}{l}\text { Absolute reliability - for duration of the batch process } \\
\text { (up to } 8 \text { hours) } \\
\text { Absolute power quality - protect computerized sensors } \\
\text { and control equipment }\end{array}$ \\
\hline $\begin{array}{l}\text { Characteristics } \\
\text { of the Facility }\end{array}$ & $\begin{array}{l}\text { High concentration of silicon load, } \\
\text { computer/server rooms: concentrated digital } \\
\text { loads. } \\
\text { High load factor: } 24 / 7 / 52 \\
\text { Energy costs are a small part of cost of service. } \\
\text { Need to eliminate heat (cool the electronics). } \\
\text { Availability of low-grade waste heat. } \\
\text { End-use DC at multiple voltages }\end{array}$ & $\begin{array}{l}\text { Computer-controlled batch process. } \\
\text { Possibility to schedule facility's production given } \\
\text { adequate notice. } \\
\text { Energy costs significantly affect cost of product. } \\
\text { Likelihood of high-grade waste heat from process } \\
\text { available on-site. } \\
\text { Possibly able to use waste heat for process. } \\
\text { Multi-energy loads, computers and controls need PQ } \\
\text { protection }\end{array}$ \\
\hline $\begin{array}{l}\text { DER Technology } \\
\text { Solutions } \\
\text { - Electrical }\end{array}$ & $\begin{array}{l}\text { Back-up generation - CT's, reciprocating } \\
\text { engines } \\
\text { Short-term electrical storage - ultra-capacitor, } \\
\text { flywheel, UPS (battery), SMES } \\
\text { Power electronics to ensure power quality. } \\
\text { Advanced inverters \& power supplies, universal } \\
\text { transformer, micro-grid }\end{array}$ & $\begin{array}{l}\text { Back-up power - UPS, reciprocating engines, turbines } \\
\text { Back-up heat sources } \\
\text { Power quality technology - UPS, filters, power } \\
\text { electronics }\end{array}$ \\
\hline $\begin{array}{l}\text { DER Technology } \\
\text { Solutions } \\
\text { - Thermal }\end{array}$ & $\begin{array}{l}\text { Back-up cooling - thermal energy storage } \\
\text { Desiccant dehumidification - reduce latent heat } \\
\text { Thermally-activated absorption chillers - reduce } \\
\text { electric cooling load }\end{array}$ & $\begin{array}{l}\text { Thermal energy storage (heat and/or cool) to reduce } \\
\text { production costs and/or chiller/boiler capacity } \\
\text { Fuel switching for cooling (thermally-activated } \\
\text { absorption chillers) }\end{array}$ \\
\hline
\end{tabular}




\begin{tabular}{|c|c|c|}
\hline & Digital Services & Digital Processes \\
\hline & $\begin{array}{l}\text { Thermally-activated absorption heat pumps - } \\
\text { concentrate low-grade waste heat } \\
\text { Spot cooling - heat transport/heat pipe } \\
\text { technology } \\
\text { Reduce thermal load - cabinet and computer } \\
\text { room design } \\
\text { District energy system }\end{array}$ & $\begin{array}{l}\text { Desiccant dehumidification to reduce cooling load } \\
\text { Use of waste heat (thermally-activated absorption heat } \\
\text { pumps) } \\
\text { District energy system }\end{array}$ \\
\hline DER Benefits & $\begin{array}{l}\text { Relieve T\&D overload, alternative to distribution } \\
\text { reinforcement } \\
\text { Back-up power - reliability } \\
\text { Power quality } \\
\text { Back-up cooling, greater HVAC reliability; } \\
\text { Diversified fuels increases reliability } \\
\text { Reduce capital cost for back-up generation } \\
\text { Improve computer room cooling and/or reduce } \\
\text { cooling load } \\
\text { Reduce condensation } \\
\text { Enables facility expansion }\end{array}$ & $\begin{array}{l}\text { Relieve T\&D overload, alternative to generation, } \\
\text { transmission or distribution reinforcement/investment } \\
\text { Back-up energy - reliability } \\
\text { Power quality } \\
\text { Reduced energy costs - use of waste heat, peak } \\
\text { shaving, time-of-use scheduling } \\
\text { Reduced facility capacity costs - back-up generation, } \\
\text { HVAC system capacity }\end{array}$ \\
\hline
\end{tabular}




\subsubsection{Value Proposition for DER in a Digital Economy}

Distributed resources can improve the performance, cost effectiveness, and reliability of electrical power at locations where they are installed. However, the higher generation cost for smaller scale and dispersed systems must be overcome by the additional benefits derived from operating near end-use loads. If we assume that the benefit of using electric energy produced locally is equal to the benefit of purchased electric energy than the higher cost needs to be overcome by other benefits. Other benefits as previously indicated, in addition the electrical energy produced, include reduced power system losses, deferral of T\&D investment cost, local peak shaving, and by products of local generation such as on-site heat energy, improved power reliability, etc.

Most of these additional benefits also have associated incremental costs that add to overall energy system cost and the unit cost of electricity. As shown graphically in Figure 3-1 the concept of higher system costs and more system benefits provides a reasonable value proposition for the future potential of DER.

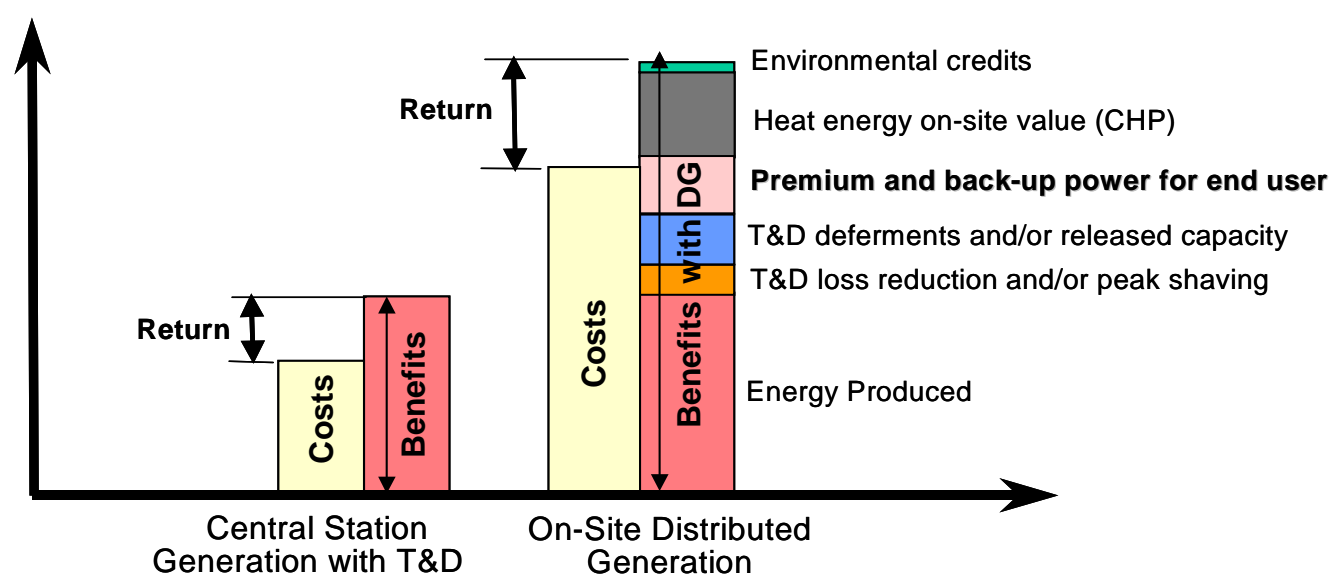

Figure 3-1

Value Proposition for DER is Often Based on Higher Costs and Benefits.

DER systems can offer greater value for the digital economy because of the combination of characteristics that can be achieved with a well-engineered system. These include improved reliability, better power quality, increased efficiency, and lower emissions.

Reliability: The reliability of the power system is a measure of its ability to deliver power in sufficient quantity and at the times demanded by electric customers to satisfy end-use needs. In recent years, there is an increasing need for more reliable power systems to serve commercial and industrial loads that have sensitive end-use loads or processes. These may include banks, Internet-server farms, automated production lines, microchip fabrication facilities, and many other loads. Reliability is generally measured by a variety of indexes that track the availability of power and the number of sustained interruptions (greater than 5 minutes) occurring at customer facilities. In recent years, short duration (or momentary interruptions less than 5 minutes) have also become an important issue and are commonly tracked. DER systems can improve the system reliability because they are based on the use of redundant and diverse energy resources that may offer less exposure to natural or man-made disasters than the traditional T\&D system. 
Like traditional standby generators, DER systems can be used as part of an integrated backup system that provides power during conventional system outages. However, DER systems may employ greater redundancy than traditional back up systems. Therefore, the reliability improvements may be greater and this reliability can have tremendous significant value for enduser processes in a digital economy.

Power Quality: Power quality is a term that can be interpreted fairly broadly depending on the context of the situation where it is applied. In general, power quality focuses on waveform anomalies and transient disturbances that exist on the power system, without any power outage. These include voltage sags, voltage swells, harmonic distortion, switching surges, lightning surges, and even steady-state voltage regulation. Depending on the context within which power quality is discussed, issues such as momentary interruptions are often included in the scope of power quality-related power disturbances. DER systems can improve power quality through the application of various power-conditioning and protection technologies that are associated with DER resources. For example, rapidly responding, inverter-based generation may be employed with static switches to offer rapid mitigation of voltage sags and other anomalies. The rapid response of power electronics use in inverters may also be used to dynamically correct voltage level and distortion, and mitigate flicker.

Increased Efficiency: A well-designed CHP application-as part of a DER approach—can offer greater efficiency than a conventional central station-T\&D approach. The most efficient central station technologies available (i.e., combined-cycle combustion turbine plants) are 55-60 percent efficient, while many other central station steam plants and single-cycle combustion turbines can be less than 40 percent efficient. In addition, nearly 10 percent of the central station power is lost in the T\&D process because of resistance in the wires and core losses in transformers. This means that conventional power system approaches deliver less than 40 percent of the total energy in the fuel to the customer, whereas a well-designed, DER-based CHP approach may be able to achieve 70-90 percent total system energy efficiency. This gain in system efficiency can be attributed primarily to the use of waste heat. Without heat recovery, the overall DER system efficiency might be lower than the central station approach. DER approaches also offer the potential to improve efficiency on the load side through the use of more efficient loads and by heat recovery from loads.

Conservation: Non-invasive energy conservation is possible using energy management controls even in high-tech facilities. The use of sleep states in personal computers is a good example. This type of technology —if carefully applied — can reduce the use of energy without degrading the quality of lifestyle or productivity. Examples include smart lighting systems that adjust light output and operation according to needs, HVAC systems that employ special sensors to sense the need for heating or air-conditioning, and a variety of other types of controls and improvements to end-use load devices. These functions can all be integrated as part of a DER-based approach perhaps reducing energy usage by 25 percent or more and reducing the required capacity of power generation and delivery infrastructure.

Emissions: In some cases the use of DER can reduce emissions compared to a central station approach, if clean renewable resources (e.g., wind, photovoltaic) are employed. High efficiency, in conjunction with heat recovery and the latest emission controls will provide lower emission levels per unit of primary fuel consumed. Note that there is no guarantee that lower emissions will be achieved for some forms of DER. For example, a diesel generator used for DER will 
typically generate far more pollutants per kilowatt-hour of energy generated than a central station power plant using a combustion turbine.

T\&D Benefits: The use of DER systems may also bring a variety of potential benefits to the local distribution company. These benefits include (1) potential deferments in T\&D infrastructure upgrades or additions, (2) reduced power losses on the T\&D system, (3) greater security of the power system, (4) scalability that better matches load growth, and, (5) easier siting and permitting of generators than conventional larger-scale power system infrastructure.

\subsubsection{Reliability of DER Compared to Conventional Power}

The reliability of average power distribution circuits in the United States is about 99.98\%, which means that power is available for $99.98 \%$ of the year or there are about 2 hours of cumulative interruption time each year. This is far better than typical individual distributed generators such as internal combustion engine (ICE) units or combustion turbine (CT) units, which have availability in the range of 95 to $98 \%$, depending on how they are maintained and operated. To achieve 99.98\% with ICE units requires more than one unit, and they need to be sized so that if one should fail, the others can pick up the load.

As an example, if a micro-grid has a load of $1 \mathrm{MW}$ and two $1 \mathrm{MW}$ ICE generators are employed to support the island, then this is an $\mathrm{N}-1$ design contingency-meaning that if one unit fails, then we can still carry the micro-grid load (see Figure 3-2). If each generator in our example has a reliability of $97 \%$, then two in parallel (assuming their failures are independent) have a reliability of $99.91 \%$. This is much better than one generator but still several times worse than the average conventional power distribution feeder. If full-time micro-grids are to have reasonable reliability, then they must be designed for the $\mathrm{N}-1$ contingency or even $\mathrm{N}-2$. Using the utility system as a backup source is one possibility that avoids the need for redundant generation capacity, but from a cost perspective, there may be standby charges that are assessed to the DER operator that seriously impact the system economics.

If redundant generation is used, then usually units are broken down into clusters of 3 to 5 units as opposed to the 2 units in our example because this allows less overcapacity. The important point here is that the reliability in a stand-alone micro-grid can be increased to that of a typical distribution system if an $\mathrm{N}-1$ or $\mathrm{N}-2$ design is employed given the typical availability of standby generators. This design redundancy does come with cost and performance penalties because there is always some underutilized generation capacity.

Standalone systems, because they are not connected to the bulk supply and/or because they can quickly isolate themselves from the bulk supply, will have less effective exposure to bulk system disturbances. Thus, while generation reliability is an issue for DER, operating stand alone, they do have the advantages of fewer faults and voltage sags due to their limited exposure.

\subsubsection{Potential for Ancillary Services}

DER offers the potential for ancillary services that may be able to generate a revenue stream for the owners/operators. In this case both heat and power can be considered such as thermal energy in a district heating system and electrical services for the local power system. These services really cannot be offered with a conventional power system because generation is located a longdistance from loads and because it is very difficult to have targeted high-power quality/reliability on the conventional system. So these are service areas where the DER has a definite location 


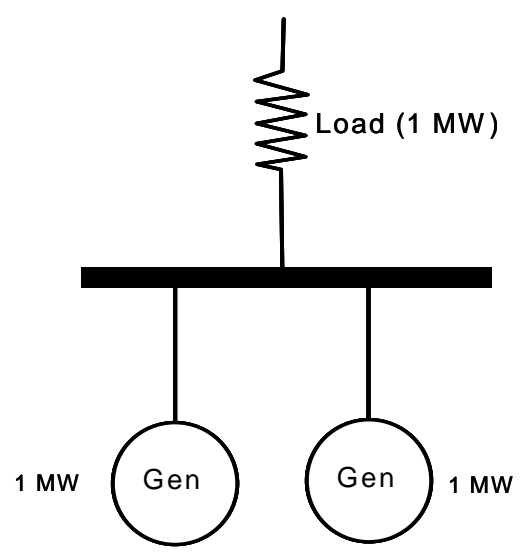

Figure 3-2

Two Generators Each Rated to Carry the Entire Load Offer Contingency for a Single Unit Failure Providing Much Greater Reliability Then a Single Unit

advantage over a conventional power system. Consider the benefit of heat production and its sale as a product. If the DER is established at a single customer site, business park or even industrial facility, heat can be recovered from the generation systems and distributed throughout the area for various purposes. Some basic services that can be provided with heat include:

- Space and water heating

- Digital equipment cooling or refrigeration (via chiller systems)

- Process heat for a manufacturing, food industry, or agricultural process

To understand the value of waste heat from the generation process, let's consider how much heat is produced each time a kilowatt-hour of electricity is created. First consider that natural gas costs in the range $\$ 4 \mathrm{GJ}$ (note $1 \mathrm{GJ}=278 \mathrm{kWh}$ ). This is equivalent to about 1.4 cents per $\mathrm{kWh}$. If generation is $40 \%$ efficient, then for each kilowatt-hour of electricity produced, $1.67 \mathrm{kWh}$ of heat is produced. Thus the value of heat is about 1.4 cents x 1.67 or about 2.33 cents per kilowatthour of electricity produced. Of course not all of this can be recovered or used, but if $85 \%$ could be recovered and used, then at current gas prices this thermal energy offsets the need to burn about 2 cents of natural gas for each kilowatt-hour of electricity produced. The heat could be sold to customers as an added service that would generate revenue for the operator of the DER.

Electrical ancillary services that may be available at the distribution level are:

- Reactive power and voltage control

- Spinning or non-spinning reserve generation

- Black start capability.

Although reliability is often a key benefit that the digital end user derives from DER it is also another service that could be sold. Customers might be willing to pay some fraction of the cost they would otherwise spend on UPS equipment to mitigate their power quality/reliability problems if they were located on a conventional system. Revenue obtainable from such "reliability service" could be estimated by considering the annual carrying cost of UPS equipment that the DER user has deferred, then charging a fee that is less than that so that both the customer is happy and the micro-grid operator gets some revenue. 


\section{DER Feasibility Assessment}

The feasibility and acceptance of DER in digital economy applications depends on clear demonstration of value added services. Prior DOE and EPRI studies have detailed a number of the concerns of electric distribution engineers regarding adverse results from adding DER to the power system. Many of these issues have been addressed by both the DER technology and the interconnection and integration efforts. However, in applying DER to digital facilities, one must not only focus on the need to avoid PQ- and reliability-related problems of DER, but to actually gain a performance advantage from DER. This section of the report addresses the critical question of how a decentralized electric power system can perform better for digital users than the "traditional" vertically integrated centralized generation and control utility.

\subsection{Potential DER Value Streams}

To answer the question of how DER will either improve the local power system's performance requires system details such as the relative sizes and characteristics of the involved loads and the size and types of installed DER. In applications where power quality and reliability are given premium value, such as high-tech industrial processes or sensitive electronic equipment, this will be the main value of a DER installation.

One challenge in comparing investment alternatives with independent costs and benefits is to correctly assign which costs and benefits are fully, or marginally, involved in the decision. For example, if a generator is already in place at a site for premium power, only the marginal cost of adding DER functions needs to be included in the DER investment case analysis. Another challenge is to realize all the values when there is more than one party involved in both the costs and benefits. An inventory of different user values and related costs that need to be considered in potential DER applications are provided Table 4-1.

An example of the need to properly allocate cost and benefits is illustrated in the case of a new installation where generators are planned for reliability purposes. Here the incremental costs and benefits of adding DER functionality and operating capability must be identified for an appropriate evaluation. Because local generation equipment is likely to be already cost justified for reliability value, adding DER capabilities should be considered to further improve the cost to benefit ratio of these installations. In any specific case, the unique operational requirements of the particular industry and the unique needs of the local utility power system will determine the incremental value of adding DER capabilities.

There are interesting opportunities for digital economy applications where both utility DER and premium power benefits can be obtained. The main idea is that much of the same generation and storage equipment is used for both premium power and for utility system support. When this synergy is achieved, additional benefits are derived with marginal additional investment cost. And the business case for on-site energy production is likely enhanced when premium power value can be included along with other benefits such as heat recovery, demand reduction, and utility grid support. 
Table 4-1

Inventory of different user values and related costs in $\mathrm{DER}^{24}$ applications.

\begin{tabular}{|c|c|}
\hline \begin{tabular}{ll}
\multicolumn{1}{c}{ Value to Utility } \\
- & Loss Reduction \\
- & Peak Shaving \\
- & T\&D deferments and other released \\
- & capacity \\
- & Load factor, quality and reliability \\
- & Other such as environmental credits
\end{tabular} & \begin{tabular}{ll} 
& \multicolumn{1}{c}{ Value to End User } \\
- & Full-time electric power \\
- & Part-time electric power and low \\
interruptible rates \\
- & Power reliability and quality benefits \\
- & Heat recovery \\
- & Demand charge reduction \\
- & Other such as emergency power
\end{tabular} \\
\hline $\begin{array}{ll} & \text { DR Equipment-Related Costs } \\
\text { - } & \text { DR Planning and installation } \\
\text { - } & \text { Permits and connection fees } \\
\text { - } & \text { DR equipment first cost } \\
\text { - } & \text { DR life cycle costs } \\
\text { - } & \text { Maintenance and operation } \\
\text { - } & \text { Repair and replacements } \\
\end{array}$ & $\begin{array}{ll} & \text { Application-Related Costs } \\
\text { - } & \text { CHP related equipment } \\
\text { - } & \text { Paralleling switch gear and controls } \\
\text { - } & \text { Electronic switching and interrupt } \\
\text { devices } \\
\text { - } \\
\text { - } & \text { Senerator fuel } \\
\end{array}$ \\
\hline
\end{tabular}

\section{Grid-Parallel or Standalone Operating Modes}

Two types of DER operating modes can be considered to evaluate PQ and reliability improvement feasibility: standalone and grid-parallel DER. A standalone operating mode is an independent island and as such must provide voltage and frequency regulation within the island (see Figure 4-1a). Stand-alone DER must be able to follow and support various loading conditions while maintaining acceptable PQ. Loading conditions may include load steps, motor starts, inrush current, load nonlinearity, reactive power needs, unbalances, and periodic load fluctuations. The standalone generator must be reliable because it is the only source of power available. The standalone application is usually more demanding and costly than grid-parallel because it is designed with greater redundancy and imposes more requirements on the generator. This usually means that it is difficult to optimally size, from a capital investment perspective, and to optimally operate, from an efficiency perspective.

The other type of operating configuration is the grid-parallel system (see Figure 4-1b). DER connected in parallel with the utility system operates as an additional source of energy, feeding the grid. It is usually very small with respect to the total power system and has no significant impact on power system frequency. It may supply most or all of the energy to the local customer load, but the customer site can rely upon the utility system source should the distributed generator fail. This means that reliability of the DER is not crucial as it would be for a standalone system. Grid-parallel DER is normally operated in a voltage-following mode, which means the machine operates at close to unity power factor and does not attempt to directly regulate voltage with reactive power.

${ }^{24}$ DER is identified as DR in the table. 
(a) Stand-alone DG

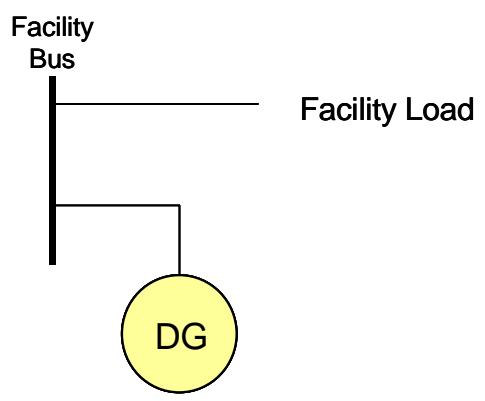

(b) DG in Parallel with Utility

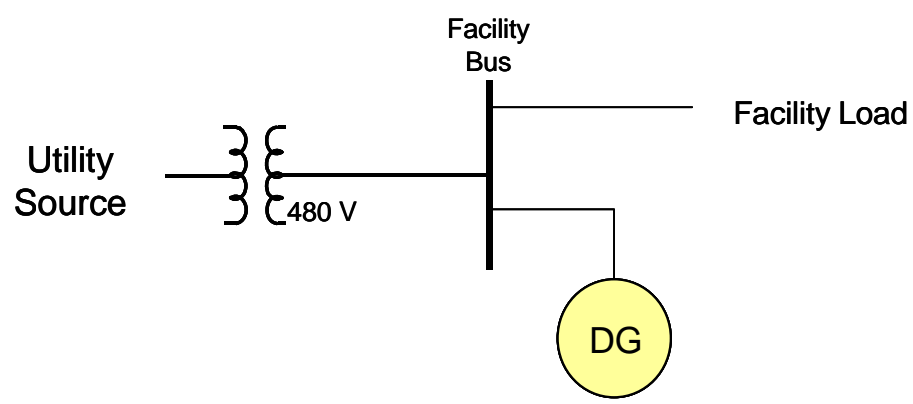

\section{Figure 4-1}

Two Types of DER Operations: (a) Standalone and (b) Grid-Parallel

The grid parallel system has the advantage that the utility system can provide the reactive power for the load, handle load-step transitions and motor starts, and deal with nonlinear load currents. This may allow downsizing of the plant capacity somewhat compared to standalone approaches. Grid-parallel DER does not usually load-follow but instead is operated at constant full load to provide the best efficiency and maximum return on capital investment. In general, a generator designed for grid-parallel operation can forego redundancy and capacity and will operate in a more economical fashion even when standby charges in the electricity tariff are factored in.

Even when the generation or storage is designed to be operated in grid parallel mode, its primary function is improving reliability of electric service to the digital facility. Thus, the generator must be designed to operate in stand-alone mode, at least to serve critical processes, with the attendant load following and frequency regulation requirements. Most of the on-site generators at digital user sites are provided as back up power systems, and are designed to operate standalone with a specified load. Most commercial and industrial CHP systems are operating as grid-parallel, to achieve better performance.

\section{Power Quality Costs Define the Main Value Potential}

The realities of electric power generation, transmission, and distribution in the United States show that an average utility customer will experience several power disruptions in any particular year - including voltage sags, interruptions, transients, and other phenomena. Significant and important work has been performed to understand the level of electric service quality, continuity, 
and reliability delivered to users of electric power - much of this work conducted by EPRI and its family of companies. Monitoring data, site investigations and case histories have documented occasional end use equipment and electric power compatibility problems in all business sectors and electric system types.

Utility reported experience and field data have shown that the single most potent cause of end user PQ problems is low voltage or voltage sags. As shown in Figure 4-2, a single fault in the transmission or distribution system will affect voltage for miles around, and, depending on the location and severity, can affect hundreds or thousands of end users. Statistics show transmission faults occur less often than distribution; however, they are likely to affect more end users. Severity of voltage sags is measured by the percent loss of voltage (sag magnitude reduction) and the time the voltage is outside normal limits (sag duration) as illustrated in the graphic.
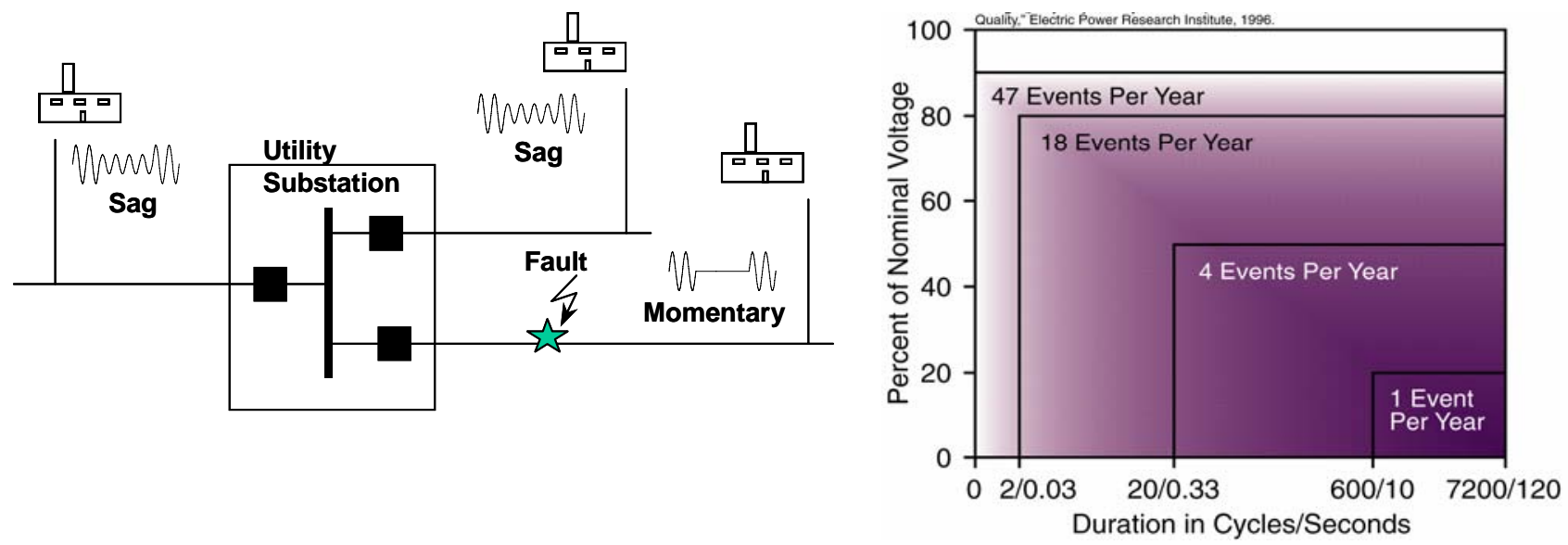

\section{Figure 4-2}

Faults in Power Systems Affect Voltage in the Vicinity (and these events are the most common cause of power-related end-user equipment disturbances)

These measures help to predict if end-use equipment will be disrupted. The typical number of disruptive voltage sag events occurring annually at any one location is more than 10 . Although power system exposure to faults remains fairly constant, the growth of the "digital economy" proliferation of microprocessors and power electronics in commercial and industrial facilities has greatly increased the economic losses to businesses caused by these power disturbances.

Most industry experts believe that tens of billions of dollars are lost each year in the US alone due to inattention to these power quality problems. Studies conducted by EPRI ${ }^{25}$ have demonstrated that, on average, a typical electric power distribution feeder will experience approximately 17 significant voltage sags or outages in any given year. Furthermore, nationwide business losses attributable to PQ and reliability issues amount to approximately $\$ 119$ billion per year, and may be as high as $\$ 164$ billion per year. ${ }^{26}$ Of all the states, California has the highest costs for both outages and PQ phenomena (between $\$ 13.2$ billion and $\$ 20.4$ billion), followed by Texas ( $\$ 8.3$ billion to $\$ 13.2$ billion) and New York ( $\$ 8.0$ billion to $\$ 12.6$ billion).

\footnotetext{
${ }^{25}$ EPRI DPQ Report - Final, EPRI TR-106294-V2, Palo Alto, CA, May 1996

26 “The Cost of Power Disturbances to Industrial and Digital Economy Companies,” E2I CEIDS (June 2001).
} 
Little doubt exists that PQ and reliability issues are costly to U.S. businesses. It has been documented that the costs to fix an incompatible system after installation are many times greater than when addressing PQ in the planning stage This advantage also applies when considering DER for premium power applications. But what form do these losses take, how sensitive are they to outage duration and where does DER fit in? Digital economy business losses can be segregated into five categories:

1. Damaged plant equipment

2. Spoiled or off-specification product; "product” may include information, data, or communications services

3. Extra maintenance and operating costs

4. Cost for repair of failed components

5. Reduced throughput and lower efficiency and productivity

\subsubsection{Screening DER for Digital End Use}

DER applications compete as an alternative to traditional energy delivery approaches. These applications must be screened during the design phase to identify the combination of generation technologies, energy management controls, and efficiency approaches that can perform better than traditional energy delivery approaches. If a significant cost savings or other performance enhancement cannot be realized, then moving forward with DER does not make sense. Every proposed DER application will not be economically superior to the traditional solution. The objective of screening is to identify which applications make sense and to determine the best mix of technologies to optimize performance.

Some key steps in screening include:

1. Identify the objectives for applying DER.

2. Identify characteristics of energy loads to be served (Examples: electrical, thermal, mechanical, reliability and power quality needs).

3. Identify physical layout of facility as it pertains to DER application.

4. Determine the number of customers served. (Is it a DER Park or just a single customer?)

5. Identify suitable technologies and equipment for DER-based solution.

6. Check for barriers that may hinder successful deployment (Examples: interconnection issues, lack of fuel delivery infrastructure, emissions limits, zoning).

7. Determine the cost of traditional energy delivery service at desired performance level

8. Compare costs and benefits of the proposed DER-based solution

Each of the above screening steps is described in further detail as follows:

\section{Step 1 - List Objectives for DER Service}

The first step in the screening process is to identify the objectives of the planned DER project. The objectives of applying DER are typically going to be one of the following or a combination of the following: 
- Reduce the cost of energy

- Improve the reliability/power quality (thereby increasing productivity)

- Promote green power and efficiency for marketing, regulatory, or political reasons

- Establish greater security of the power system through use of distributed generation

The first two objectives—reducing the cost of energy and improving reliability-have historically been the main reasons why customers adopt DER approaches. The third objectivepromoting greener more efficient power-is starting to play a role in many new applications, given public demands for clean power and government incentives for it. With the terrorist attacks that occurred in New York and Washington in 2001, a new awareness exists for "energy security.” Thus, the fourth objective is becoming another focus of industry and government. DER-based approaches—-because they use local distributed generation—can be much more secure than the bulk power system if they are implemented correctly.

Identifying which of these objectives is the driving motivation behind a proposed project is crucial to the screening process because these objectives determine the benefits that are the project focus and the types of equipment that will be required to complete the project. For example, green power projects would typically employ fuel cells, photo-voltaic (PV), or wind energy. Whereas, low-cost energy projects would likely employ internal combustion engines with CHP since they probably have the best economics in most applications. Reliability-oriented projects would use a high level of on-site generation redundancy coupled with power conditioning equipment such as uninterruptible power supply (UPS) systems. Energy security projects would be similar to reliability projects but would have the added focus on assisting the power grid as a whole and not just the local customer during national emergencies. Of course, various combinations of these objectives can exist and that would result in some complex equipment arrangements with features borrowed from all the different design options. These objectives need to be quantified in screening as to the cost target $(\$ / y r)$ and/or reliability target (outages/year) so that system designers can develop designs to meet the objectives and compare options.

\section{Step 2- Identify Size and Types of Loads to be Served}

The second step of the screening process is to review the loads to determine the mix of thermal, electrical and mechanical loads at the facility. This review should consider the following elements:

$+$

- Peak facility electrical demand,

- Daily electrical demand cycle and load factor,

- Peak facility thermal energy demand and thermal load characterization (daily cycle and needed temperatures and uses),

- Relative locations of thermal and electrical loads in facilities,

- Mechanical energy requirements (if any), 
- Load types (Examples: synchronous motors, induction motors, lighting systems, resistive heating, heat pumps, adjustable speed drives (ASDs), arc furnaces, office equipment, special manufacturing),

- Electrical load transient starting characteristics,

- Facility requirements for power quality and reliability,

- Loads and processes that can be potential heat sources for other processes,

- Load blocks that can be segregated if necessary, and

- The end-use energy form(s) in the facility processes.

The information above is reviewed from the perspective of establishing the capacity of generation equipment that will be needed and the types of combined heat and power equipment that can work effectively with the thermal and electrical loads. For example, if 700 degree Fahrenheit heat is required, then only higher temperature generation devices are appropriate. Ideally, the demand cycles for the electrical and thermal loads should be coincident to insure a good match for CHP purposes. A poor coincidence may mean that thermal or electrical energy storage must be applied to make CHP viable. The reliability and power quality needs of the facility must also be determined. Key questions include: (1) What is the needed reliability level and how sensitive to disturbances are the factory processes, and (2) Can the critical processes be isolated to reduce the amount of load requiring high-grade power? These and other questions must be answered to identify the ratings and types of generation and other conditioning equipment needed for the DER project.

\section{Step 3- Identify Physical Size and Layout of Area to be Served}

This step is highly important because the physical layout of the facility (or facilities) will to a significant degree determine the design for the DER system. This step involves reviewing various aspects of the building design and layout from an electrical, thermal, and structural perspective. For example, the physical locations of major loads and industrial processes should be identified with respect to the key electrical distribution within the facility so as to determine potential locations for on-site generation and ability of the wiring systems to handle on-site generation. The locations of thermal loads too are evaluated to determine which locations are ideal for CHP equipment and to identify how piping may be routed to carry thermal energy. Additions of any needed electrical distribution infrastructure also should be considered. The infrastructure for fuel delivery (natural gas) or other fuels needs to be considered.

At this point, note that if the facility is a brand new building - a so called clean sheet designthen much flexibility exist for selecting the types of motors, lighting, HVAC, and other facility load equipment such that the it can be the most efficient and highly compatible in a DER design scheme. The architectural design of the building (examples: insulation levels, window placement) plays a role in making the building more energy efficient and compatible for DER approaches. Architectural and building mechanical design issues should be considered for any clean sheet design.

The size of the area to be served is critical in laying out the design for the DER system components. DER systems may be applied at a broad range of facility sizes ranging from approximately $100 \mathrm{~m}^{2}$ up to more than $10 \mathrm{~km}^{2}$. This size range includes everything from a single 
residential customer, to a commercial office building, to factories and industrial facilities, andin the largest case - a massive DER park that may serve as much as $100 \mathrm{MW}$ of load and the area equivalent to that served by a large, conventional distribution substation. The types of electric power distribution equipment, protection, voltage regulation control, generation placement, heat recovery systems, thermal energy delivery systems and other components needed for these applications are determined in part by the area served. A DER application of 2 MW or less serving any single building can be performed using low-voltage power delivery infrastructure within the building (i.e., 208 or 480 volts). In this application, heat transfer distances are short (distances are $100 \mathrm{~m}$ long or less) so thermal losses can be more easily dealt with. Air-ducting and other types of limited-distance heat transfer systems can play a major role in these smaller DER applications.

For low-voltage systems, power quality- and reliability-enhancing equipment such as UPS systems and other power conditioners can be of the type that are designed to work within small to midsize facilities and there won't be any usage of high-voltage, custom power equipment. If the facility is large, such as a large industrial facility (larger than $0.5 \mathrm{~km}^{2}$ ) or a distribution feeder system converted to DER-park, then the whole nature of the system design changes. Now the design must consider high-voltage power delivery infrastructure as well as secondary distribution at the various buildings within the park. The more scattered nature of the system means that longer distance heat transfer options (such as district heating technologies) may need to be employed. These options are designed with higher temperature transmission and improved insulations to extend their reach to greater distances.

The power quality and reliability of the distribution system may be enhanced not only locally with in-building power conditioning devices, but also through the use of custom power devices on the high voltage interconnecting distribution infrastructure. Unlike a small DER system that would island just a single building, the large DER Park concept may be configured (depending on needs) to island the entire DER Park facility during loss of bulk supply from the utility company. This would require special controls on the generators and other devices. The system would need to be configured as a networked power system suitable for multiple generation inputs at scattered locations. Overall, it is clear that evaluating the size of the DER application is crucial to select the appropriate system design.

\section{Step 4 - Identify Suitable Technologies for DER-Based Solution}

Based upon the screening outcome and data collected in the first three steps of the screening process, the system planner/designer can identify the basic configuration of DER system that would be suitable for the application. The design will include a specific list of DER devices, heat recovery, load management, and energy efficiency technologies composing the DER system. Supporting infrastructure requirements are also identified such as fuel delivery needs, heat piping and power delivery equipment. All of this information is used to eventually develop a preliminary system design and expected cost for the proposed DER solution.

\section{Step 5 - Determine the Cost of Traditional Energy Service}

Based upon the cost, reliability, emissions, and security performance criteria outlined in Step 1 of the screening process, determine the cost of meeting these objectives using a traditional central station approach with a T\&D system. The cost should include any special T\&D system upgrades required to meet the objectives. For example, if the facility where DER is being considered is currently served by a radial distribution line and the reliability needs to be 
upgraded to meet the objective, then what are the distribution system enhancements that need to be made and how much do they cost. These enhancements could be custom power type of enhancements or more traditional feeder configuration upgrades (such as adding auto-loop, changing to a primary selective system and reducing lightning or tree faults). The cost of the conventional system that can meet these operational objectives will be compared with the cost of the DER approach in Step 7.

\section{Step 6 - Check for Barriers to Successful Deployment}

This step can be extremely crucial because everything up through Step 5 may be positive for an DER application, but an unexpected barriers can arise that prevents the completion of the project in a timely and economical fashion-thus making it non-viable. These barriers may be because of power system interconnection issues, lack of fuel delivery infrastructure, and emissions regulations or zoning restrictions that prohibit the usage of certain forms of generation and equipment. In the case of interconnection, a wide range of possible problems can occur. These problems are discussed later in this section. Some interconnection problems could add sufficient cost to the installation that it is no longer justified. From the perspective of fuel delivery infrastructure, the lack of a natural gas delivery pipeline or insufficient gas capacity could force the use of more expensive fuels (such as propane) or higher emission fuels (such as diesel) that cost too much or pollute too much to work within the framework of the proposed DER system.

Upgrading the gas infrastructure may prove too costly in some situations. The Environmental Protection Agency (EPA) and various state air quality management boards limit emissions from generators. Some generators, such as standard un-permitted diesels, are only allowed to operate a few hundred hours per year without needing a special permit. An emission permit will be required in most locations where DER is applied if the generators are not solar, wind, or fuel cells and if they are reasonably large (larger than $100 \mathrm{~kW}$ ). Noise ordinances and aestheticsbased zoning restrictions can prevent wind turbines and other generation plant infrastructure from receiving a site permit. Any restrictions need to be identified and the cost and time delays associated with mitigating them should be included in the cost analysis.

\section{Step 7 - Compare Cost and Benefits of DER-Based Solution}

In this final step, the costs and benefits of applying DER should be evaluated and compared with the costs of achieving the same performance using more conventional T\&D solutions. A full range of options needs to be considered; starting at the option of doing nothing (i.e., living with existing power system cost and performance levels) and leading up to the option of implementing a fully deployed DER-based system with the maximum possible features and capabilities. Various intermediate options exist that involve only partial implementation of the DER approaches. These intermediate approaches are sometimes viable when the full implementation is not. Note that in most applications where an existing bulk power system connection is in place or is closely available, DER approaches are not considered as a substitute to such connections but rather are performed in concert with the bulk system supply. This is because DER applications tend to achieve the best economics when they are operated in parallel with the bulk supply - this allows them to be sized for optimal economics as opposed to serving an islanded load all of the time. The DER applications that would not be in parallel with the utility system are usually those that are remote from the T\&D system where the cost to extend the line is prohibitive. 


\subsubsection{Sizing of DER in Different Modes}

Generation for DER applications must be sized to operate satisfactorily from both a cost and electrical performance perspective. The optimal sizing of generation will depend on the intended modes of operation, the types of loads being served, and whether or not the generator is coupled to a CHP application. To start, let's consider a non-CHP application where we only need to worry about electrical output of the generation system. For this type of application, some possible modes of generator operation are:

- Operation in parallel with the utility system

- Operation as an islanded micro-grid during utility outages

- Operation as a full time or part time micro-grid for extended periods

Each of these three modes is discussed in detail below:

\section{Mode 1- Operation in Parallel with the Utility System}

If the unit is never intended to operate without a parallel utility connection, then the generator does not need to carry the load in an islanded fashion. Therefore, it does not need to quickly load follow or to perform motor starting because the utility system connection is always available to help with any significant load steps. In this type of operation, the unit can be sized to operate at its ideal efficiency point. The ideal efficiency point for most generation systems will be between 50 and 100 percent of the rated output. The cost of operation is not just in the efficiency, however, it is also dependent on the effective capital cost, which is spread-out over the total energy generated by the machine. The more kilowatt-hours the machine produces in its lifetime, the lower the capital cost per kilowatt-hour. So, the best economics occur when the machine is operated fairly close to its rated power (90-100 percent) as much of the time as is possible.

Sizing of the generator in this type of operating mode is simply a matter of selecting the size of the load you want to carry with the generator and purchasing a unit with a continuous duty rating able to handle that requirement - then you simply operate it at that level for as many hours as possible to get the best economics. The rating of the generator would generally not be larger than the facility load, otherwise the machine would export power back to the utility system and that is generally not very attractive since the utility company would pay only 3-4 cents per kilowatthour for the surplus.

One complicating factor is that the load at the facility may not stay constant but would have a daily cycle. In that case the machine might be sized for the minimum daily facility load so that it could operate at full power all the time. Or, it could be sized for larger than minimum load but throttled to track facility demand so as to never export. In most applications, there are several machines operating in parallel that are switched on/off in stages with one machine load following and the others running full load. The best economic operating points for complex demand cycles and multiple machines depend on a lot of factors including fuel costs, load factor, machine characteristics and other factors. The more heavily loaded the machines are without actually exporting power; generally, the better are the economics.

\section{Mode 2 - Operation as an Islanded Micro-Grid during Utility System Outages}

If the generator is to be operated in parallel with the utility system during normal conditions (just like Mode 1) but then islanded as a micro grid during utility system outages, the generator will 
need to be able to follow load and handle load steps during islanded conditions. If the loads include large motors that must be started, then this will place an added burden on the generator and it may need to be oversized to provide reliable backup power for these conditions. This forces the generator sizing to be focused less on the optimum economic operation point and more on the technical requirements for driving islanded loads. To avoid having to significantly oversize the generator, there are a number of possibilities. First, consider that it may be possible to avoid placement of motor loads or large step-loads on the generator-supplied circuits. If this is not possible, consider that the loads may be controlled in a manner that limits starting inrush during island conditions. Another approach is the use of high-speed, load-shedding equipment to trip unnecessary loads when the generator becomes islanded (see Figure 4-3). With the highspeed load-shedding scheme, the generator may actually be able to be undersized relative to the total facility load but still able to carry the critical load circuits during the islanded conditions. If high-speed, load-shedding can’t be used and the generator still must island significant-sized motor loads, then, as a rule of thumb, the rating will need to be at least twice as large as the single largest motor load on the circuit and some sort of reduced inrush current starting method should be employed on the motor.

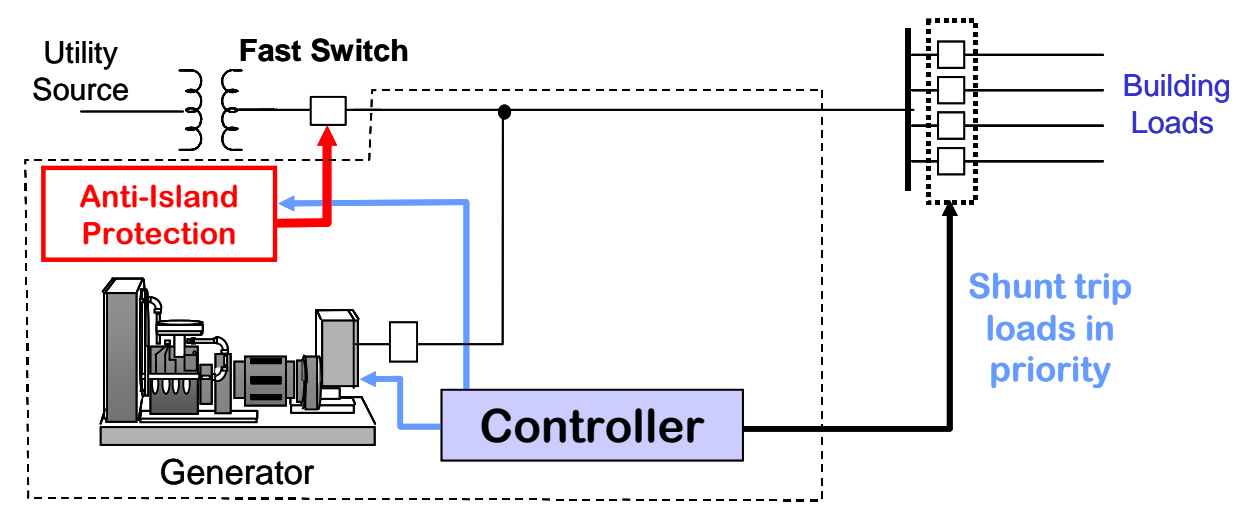

Figure 4-3 A Generator That is Undersized to Supply the Total Islanded Building Load Can Still Carry the Critical Load if High-Speed Load Shedding is Used

Mode 3- Operation as a Full-Time or Part-Time Resource for Extended Periods

If the DER system is operated independent of the utility system for extended periods of time, then it is a full-time or part-time micro-grid application. This type of operation requires that the generation should be able to handle a variety of loading conditions including:

- Cold-load pickup and black starting of the system;

- Daily demand cycles;

- Motor starting inrush;

- Unbalances, harmonics, etc.; and

- Load growth on the DER system.

These conditions can make it difficult to maintain good economics because they lead to underutilized capital investment (generators larger than needed during most operation conditions) and poor running efficiency of generators (because generators may be lightly 
loaded). This all translates into a much higher cost of electricity, which is why it is often necessary to operate DER in parallel with the utility system and not as an island. Figure 4-4 shows the dilemma. Here a generator must be sized to handle brief peaks of $50 \mathrm{~kW}$ each day, but the average load would only be approximately $10 \mathrm{~kW}$. This extreme example is described for illustration purpose, but it clearly identifies the issue. In small DER applications that are standalone (like a residence), not much diversity of load exists and so the load factor (which is the average load divided by peak load) can be 0.1 or less, which is actually worse than Figure 4-4. For a large DER park, the load factor would be much better because of diversity and may be 0.3-0.5 depending on the mix of loads. Clearly, a DER park makes a lot more sense to operate as a full-time micro-grid than a single residence from a load factor perspective.

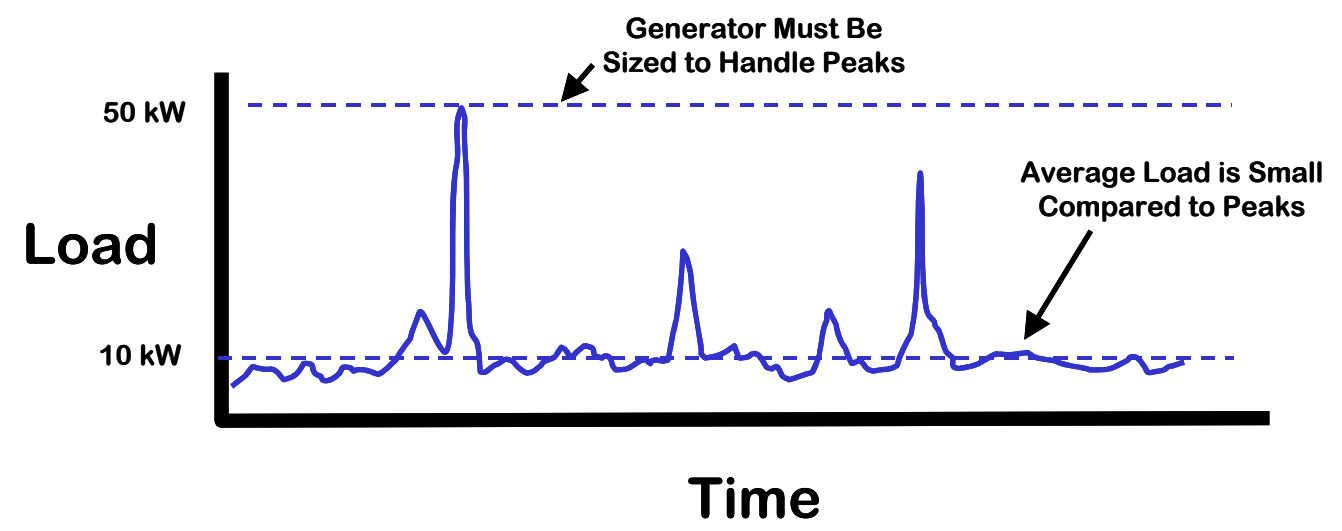

Figure 4-4 If Operated as an Island, Generation Must be Sized to Handle Peak Load but Most of the Time it Operates at Average Load-This Leads to Highest Cost of Energy

Another issue with a micro-grid type application is when grid collapses and needs to be restarted, then how is it restarted? The answer is simple, for a small operation that has just one generator — just restart and close the switch. But for a large DER park with many generators—none of which have the capacity needed to restart the entire system —-the system must be restarted piece by piece and brought back together in stages. This is no different than the way the bulk power system would be restarted following a major system blackout.

Another issue with a micro-grid application is that during normal operation, the system needs to have some form of central controller that (1) controls dispatch of the individual generators, (2) provides for reactive power support, frequency control, voltage control and (3) generally manages load following so that all of the contributing generators are operating efficiently and contributing appropriate amounts of power. Overall, for generators operating on DER-based micro-grid systems, it is clear that the whole system needs to be sized and controlled much like its larger counterpart - the bulk utility system. This will be a key technical challenge of the DERdigital power park arrangement.

\subsubsection{Assessment of Efficiency Advantage}

There are two sides to the distributed generation efficiency argument. One school of thought considers that distributed generation, with less delivery loss and the potential for heat recovery is the most efficient system. Another considers that small systems are characteristically less 
efficient than a modern central-station power plant. To determine which argument is correct, let's consider both arguments.

\section{The Case for DER Efficiency}

If you were building a new facility, you could choose from a variety of off-the-shelf distributed generation technologies that have peak electrical efficiencies ranging from about $25 \%$ up to more than $42 \%$ efficiency. These would include combustion turbine units, internal combustion engine (ICE) technologies, and microturbines. There are also commercial phosphoric acid fuel cells available that are about 38 to $40 \%$ efficient. The efficiency of all these distributed generation products are not particularly high compared with new central-station combined-cycle power plants that can be up to 55 to $60 \%$ efficient. However, if heat recovery from the distributed generators is performed and if it is used effectively, then the total energy efficiency of the process can be as great as about $70 \%$ to $90 \%$ in a very-well designed CHP application.

This level of efficiency far exceeds that of a central-station plant that does not have heat recovery. Furthermore, the central station plant will lose some additional power in the transmission and distribution process (about 8 to 10\% on average). Therefore, for a new combined cycle plant, the net efficiency (power delivered to load) is perhaps about 50 to 55\% in the best case. Most applications with properly designed heat recovery have better than 50 to 55\% efficiency. Some people also consider that the "fleet" average of utility power plants, which include many older steam-fired plants and simple cycle plants, is more on the order of 35 to $40 \%$. When T\&D losses are factored in, only about $1 / 3^{\text {rd }}$ of the energy in the utility company fuel input actually reaches the load as electricity. On the other hand, with distributed generation in a combined heat and power configuration, up to $90 \%$ of the energy in the fuel is usually utilized.

Even more promising is the fact that existing DER technologies are steadily improving in their electrical efficiency, and new emerging products will soon be available. For example, conventional distributed-scale combustion turbine and reciprocating engine products are expected to approach about 50\% efficiency by the end of this decade due to improvements in designs and materials. In the next 5 to 10 years, high-temperature fuel-cell technologies such as the solid oxide and molten carbonate fuel cells are expected to be fully commercialized and should have electrical efficiencies from 55 to 60\%. Manufacturers of fuel cells are also working to develop fuel-cell/combustion turbine hybrid systems, where the electrical efficiencies may reach $70 \%$ or better.

With electrical efficiency levels this good coming in the near future, it would seem that the case for the efficiency of distributed or on-site generation compared with conventional power systems is quite strong and getting stronger. However, let's now look at the case against the efficiency of distributed generation.

\section{The Case against DER Efficiency}

Many power system engineers rightfully argue that DER efficiency may often be less than the bulk power system efficiency. First of all, if the distributed generation application does not employ heat recovery, then its peak efficiency will be about equivalent to the utility centralstation "fleet" average efficiencies or even a bit lower for many of the current technologies. This does not sound too bad until one recognizes that comparisons to the "fleet" average is not a very meaningful comparison because the argument for micro-grids is always a comparison with 
investing in new central power plants. It may not be reasonable to compare existing fleet plants to the latest state-of-the-art DER.

Another flaw in the argument is that the efficiencies cited for distributed generators are often peak efficiencies that occur at only the optimal loading point (near rated load). In many microgrid applications, it will not always be possible to keep all generators loaded at their peak efficiency point because the load factors on the micro-grid are much less than 1 and because it is always necessary for some of the generation to be load following and oversized slightly to handle load steps and so on. As a result, the efficiencies obtained in practical operating conditions can be many percentage points lower than the stated peak DER efficiency (such as $25 \%$ instead of $30 \%$ ). Ancillary equipment such as gas compressors for boosting gas pressure and other devices can cut back a few more percent on the overall system efficiency. Finally, even when CHP is used, if the heat is poorly recovered or cannot be fully utilized because of a mismatch between heat demand and electrical production, then CHP efficiency may actually not add that much to the overall efficiency. Looking at this total argument, it is clear that poorly designed micro-grid applications could actually have lower total efficiency than installing new central station plants.

\section{DER Efficiency Conclusions}

The efficiency of distributed generation can certainly be greater than the bulk power system, but it is important to recognize that this is not universally guaranteed for all applications. Many applications are less efficient when they do not employ the correct elements needed for efficiency success! Micro-grid distributed generator applications that are sure to outperform combined-cycle central-station options by a wide margin are those that satisfy both of the following:

- They are operated at very high capacity factors that will ensure that they are near the most efficient operating state most of the time

- They employ heat recovery whereby most of the recovered heat can be used for useful purposes (see Figure 4-5)

If the above two conditions are not satisfied, then the DER application may not be as efficient as a central-station combined-cycle application and it will need to be studied closely to see if there is an advantage in this category.

Distributed generation applications that meet the following two conditions will likely be less efficient than even the utility "fleet" average:

- DER applications that do not have heat recovery

- DER applications with generators that have less than 35\% peak-rated efficiency and are operated at less than $50 \%$ capacity factor 


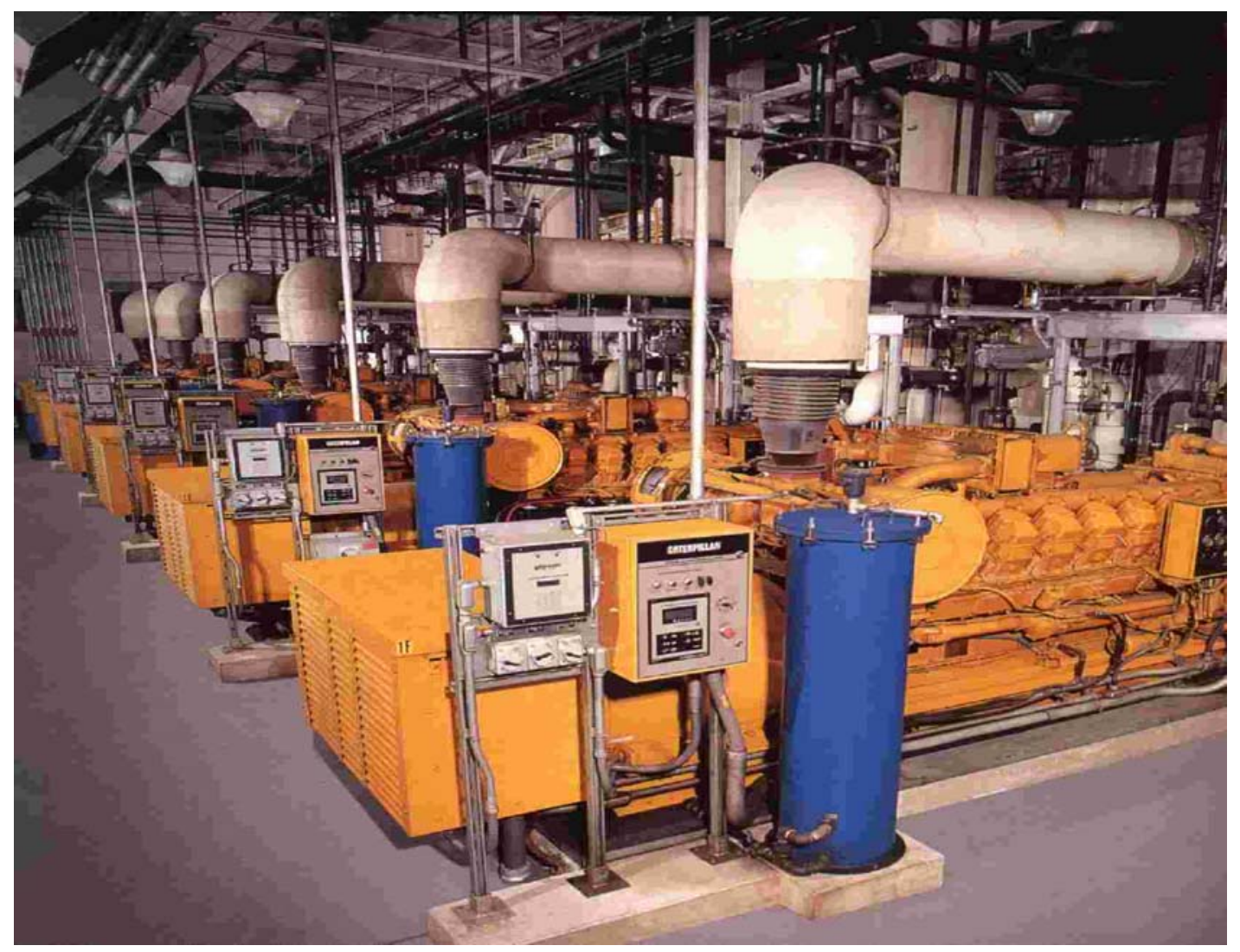

\section{Figure 4-5}

Combined Heat and Power Applications are the Best Route to High Efficiency

\subsection{User-Owed DER for Digital Economy}

Tables 3-1 and 3-2 presented the scope of applications of DER to high-tech "digital” facilities. Acceptance of DER technologies in these application areas will depend on the perceived added benefits of DER. These benefits for the end user include reduced operating and capital costs, increased reliability, and power quality protection. Table 4-2 summarizes the types of DER technologies applicable to digital facilities, and the potential benefits each can provide.

Typically, for digital facilities the cost of electricity, even the capital cost to provide the electricity (at required power quality and reliability levels), is dwarfed by the value-added of the business conducted in the facility. That means that even though electricity and electric facility costs may be high, the primary need of digital facilities is to guard against work stoppage due to transients, sags or interruptions in electric supply. The "traditional" central station-supplied grid is simply not, mathematically, able to provide the needed quality and reliability of power. Therefore, to determine the "value stream" of DER for the digital economy, one must first determine how DER can provide the necessary electric reliability, and then investigate whether variations in the DER paradigm can result in lower capital or operating costs, or further protect against possible but unlikely outage scenarios. One approach is to define the "value streams" of DER benefits and then see how DER installed for customer reliability and power quality could also provide value to the utility and additional economic value to the digital facility. 
Table 4-2

Potential DER Benefits for Digital Facilities

\begin{tabular}{|c|c|c|c|c|c|c|c|c|c|}
\hline DER Technology & 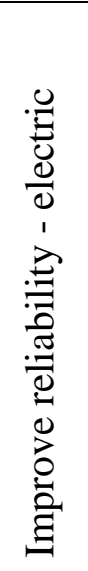 & 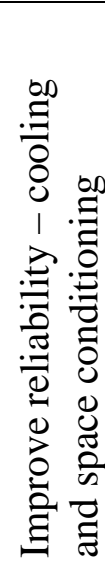 & 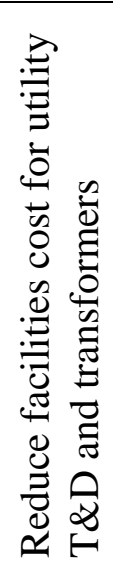 & 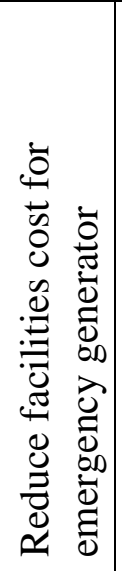 & 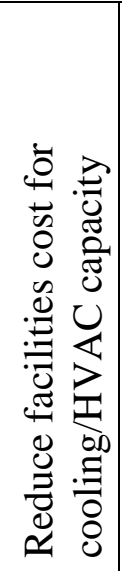 & 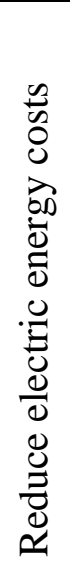 & 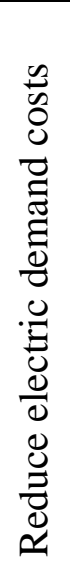 & 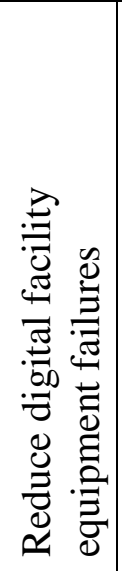 & 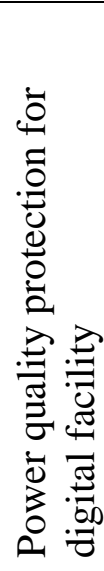 \\
\hline Local power generation & $x$ & & $\mathrm{x}$ & & & $\mathrm{x}$ & $x$ & & $\mathrm{x}$ \\
\hline $\begin{array}{l}\text { Electric Storage - Long } \\
\text { term }\end{array}$ & $x$ & & $x$ & $x$ & & $x$ & $x$ & & \\
\hline $\begin{array}{l}\text { Electric Storage - Short } \\
\text { term }\end{array}$ & $x$ & & & & & & & & $x$ \\
\hline Thermal Energy Storage & & $x$ & $x$ & $x$ & & $x$ & $x$ & & \\
\hline Absorption Cooling & & $\mathrm{x}$ & $\mathrm{x}$ & & & $\mathrm{x}$ & $x$ & $x$ & \\
\hline Waste Heat Utilization & & & & & $\mathrm{x}$ & $x$ & $x$ & $x$ & \\
\hline Power Quality Systems & $x$ & & & & & & & $x$ & $x$ \\
\hline Micro-grid (energy park) & $\mathrm{x}$ & $\mathrm{x}$ & $\mathrm{x}$ & $\mathrm{x}$ & $\mathrm{x}$ & $\mathrm{x}$ & $\mathrm{x}$ & & $\mathrm{x}$ \\
\hline
\end{tabular}

When do DER-based solutions make economic sense for a digital user, and which of myriad DER technologies offer optimal solutions? Among the many types of distributed generators size is a key factor. As shown in Figure 4-6, the practical size range varies from one DER technology to another. Likewise the premium power requirement of various end users will be size-specific and in most cases will not include the entire facility load. Matching end-user premium power needs with the best size for other DER functions and benefits is a key part of any application. For example, if for a given application the DER is relatively large, on the order of megawatts, for the most economic production of electricity and heat, but the premium power requirements are in the kilowatts, than the value of combining these two benefits will need to be discounted.

Also inherent to the different DER technologies are major differences in system availability and response times, both keys to success in premium power applications. For example, depending on weather, solar and wind systems will have availabilities from 20 to 40\%, which, without energy storage, will not support premium power. Diesel-fueled internal combustion engines will be limited in the hours available per year based on environmental constraints and by the size of the fuel tank in longer duration applications for back up generation. Fuel cells and microturbines, unless outfitted with energy storage, will have limited overload capability and slower response times, which must be considered in most premium power applications. For example the inverter 
output of these DER technologies are limited to one or two times rated current and require minutes to start up or to transition from one operation mode to another. Figure 4-7 also shows some of the likely combinations of distributed generation and storage elements to provide premium power systems.

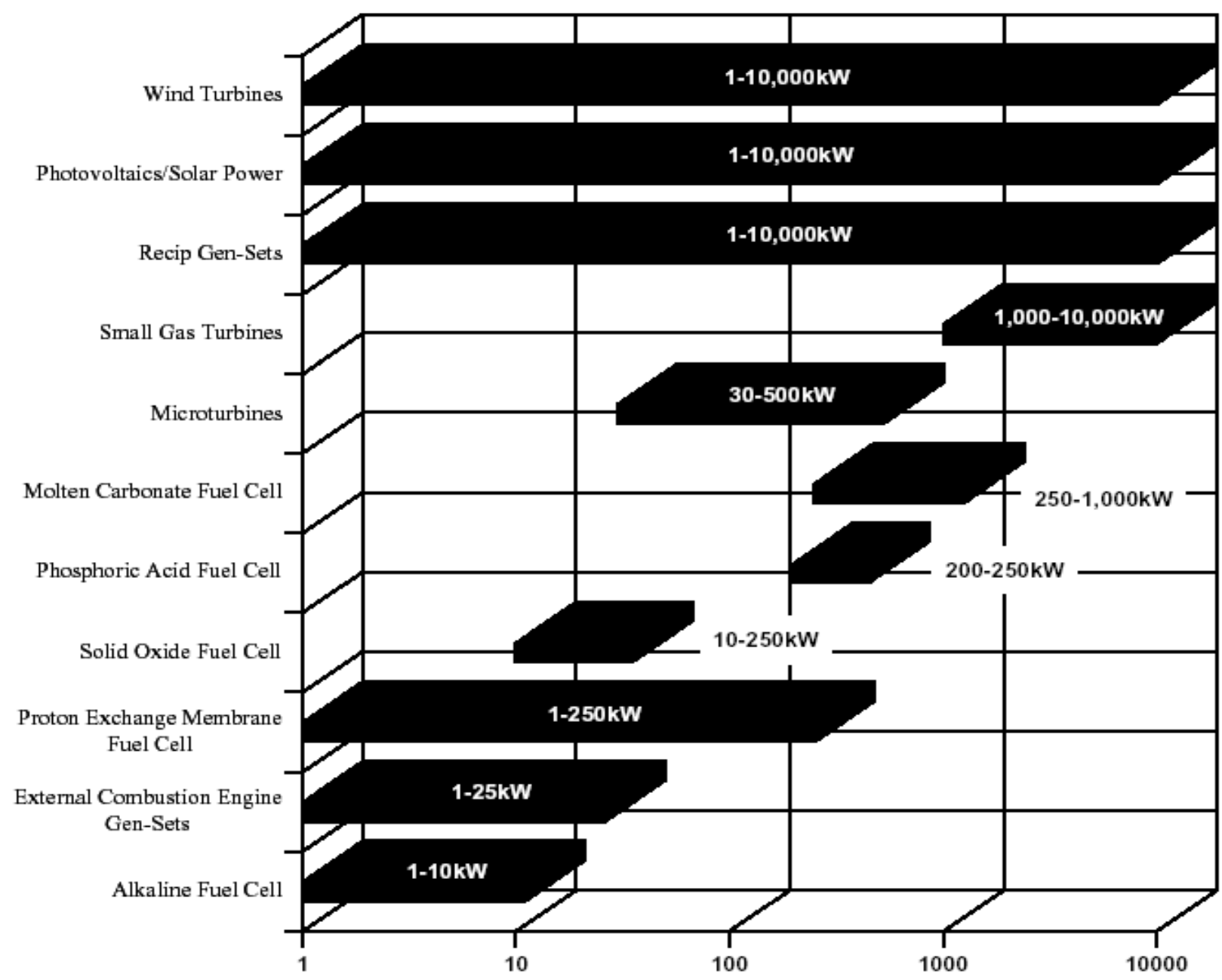

Figure 4-6

Size Ranges for Various Small Scale Generation Technologies

Another challenge in applying DER to premium power applications will be in matching the DER system characteristics to meet unique power quality and reliability requirements. For example resources installed to provide emergency power or as back-up to a UPS for extended outages will likely be limited in available fuel supply or by environment restrictions if placed into service as dispatchable resources or for extended peak shaving functions. On the other hand, a generator designed for part-time peak shaving or demand reduction will probably provide little value in protecting critical end-use equipment from momentary interruptions. To get the PQ value the system would probably have to be modified with additional interrupt protection, fast switching and some kind of short-term energy storage. 


\section{Synergies between DER and Premium Power Solutions}

In many ways on-site generation and storage equipment provide a natural enhancement to the power system reliability at the point of connection. Clearly generating nearer to the end-use equipment reduces exposures, losses and potential interactions with other end users when compared with the traditional central power generation. Power delivery from the central power plant via bulk transmission, sub-transmission and distribution exposes transmitted power to weather and other hazards, as well as increasing the number of cables and other power equipment required to complete the circuit.

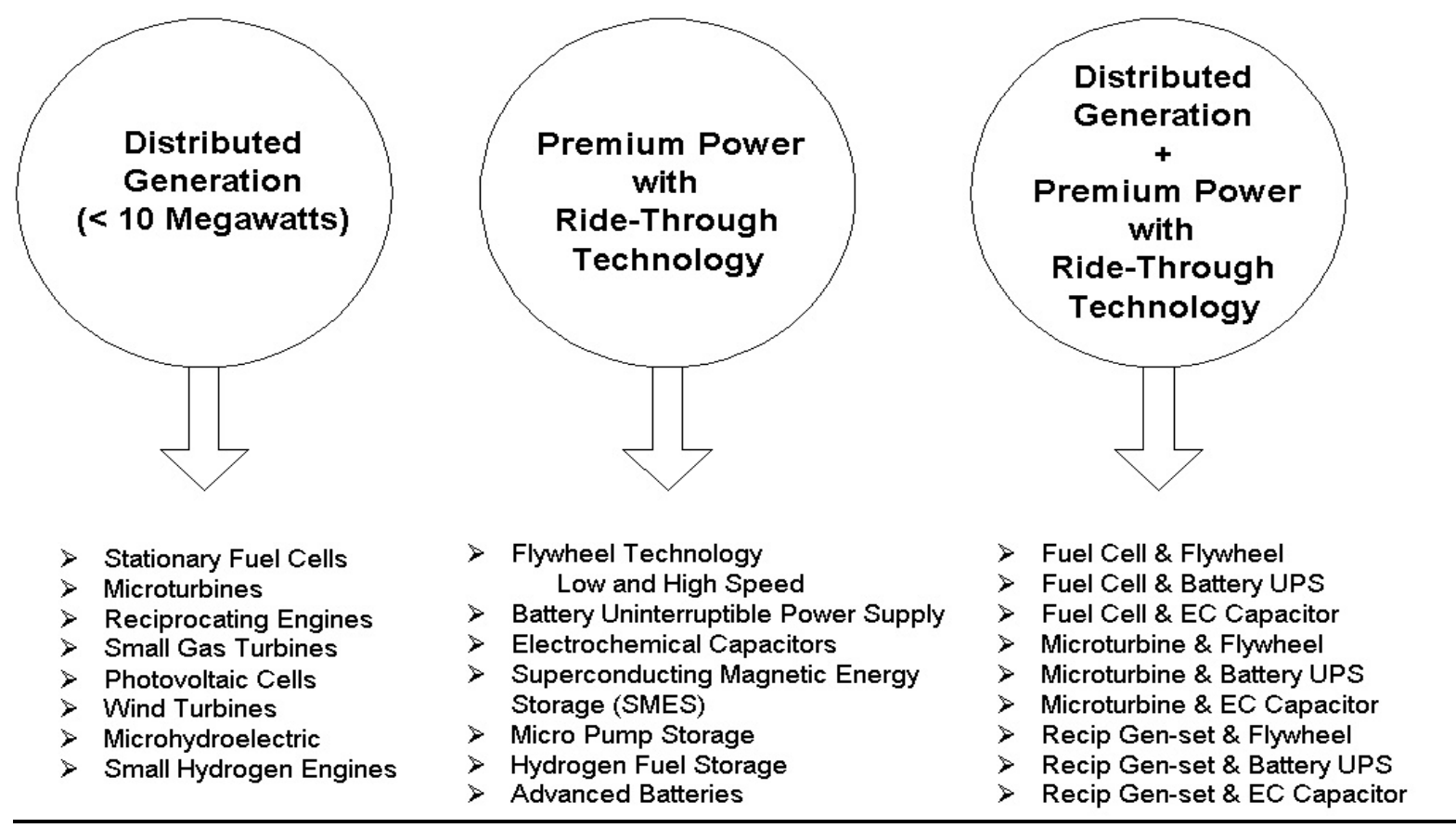

Figure 4-7

Spectrum of DER and Premium Power Equipment and Configurations

Figure 4-8 shows the various ways that power can be interrupted or quality can be diminished in the power delivery system by various exposures, potential hazards and miles of delivery that lay between the typical central power and the load centers. In contrast, distributed generation, while it must cope with the challenge of load following, does not contend with power delivery exposure and is therefore expected to have fewer external power disturbances.

It is a straightforward calculation to show that two power sources provide a higher reliability than one. As shown in Figure 4-9, two generators can be configured as primary and alternate power sources to enhance reliability. This can be demonstrated by an availability calculation. If the primary utility source is expected to have 3 failures causing a total of 4 hours downtime per year, its availability is 99.986 . The alternate on site generator source may be less reliable with 8 failures and a total of 30 hours downtime per year yielding an availability of 99.26. Together the two sources provide power source availability at this site of 99. 996. 

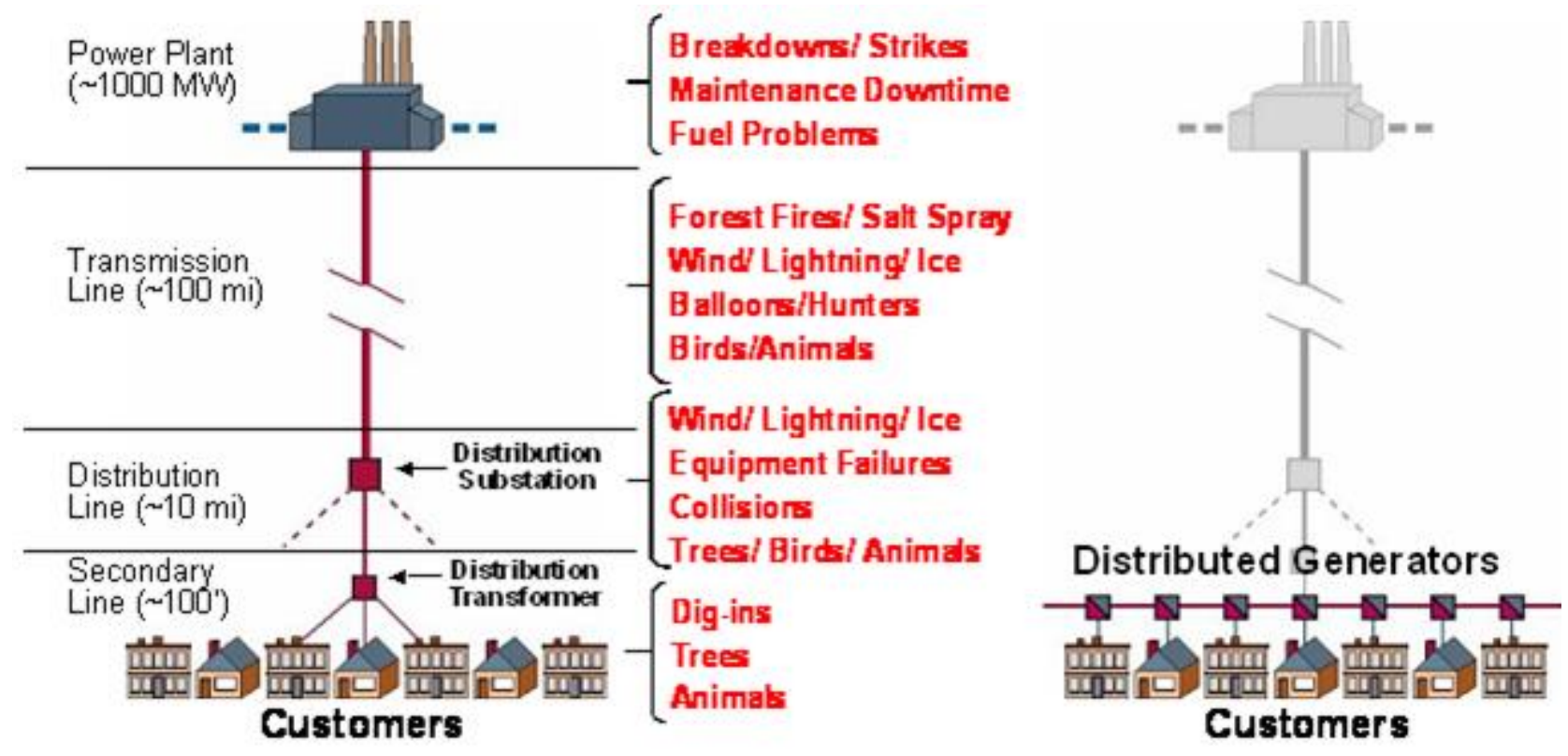

Figure 4-8

Various Exposures, Potential Hazards and Miles of Power Delivery Equipment Lay Between the Typical Central Power and Load Centers then Between DER and Load.

When the electric distribution power quality does not meet the needs of voltage sensitive enterprises, on-site back up generators, and in some cases energy storage systems, are likely to be cost justified. For high-tech commercial data centers, continuous-process manufacturing or precision industrial fabrication facilities the benefit is avoiding financial losses from production downtime, scrap, and equipment damage.

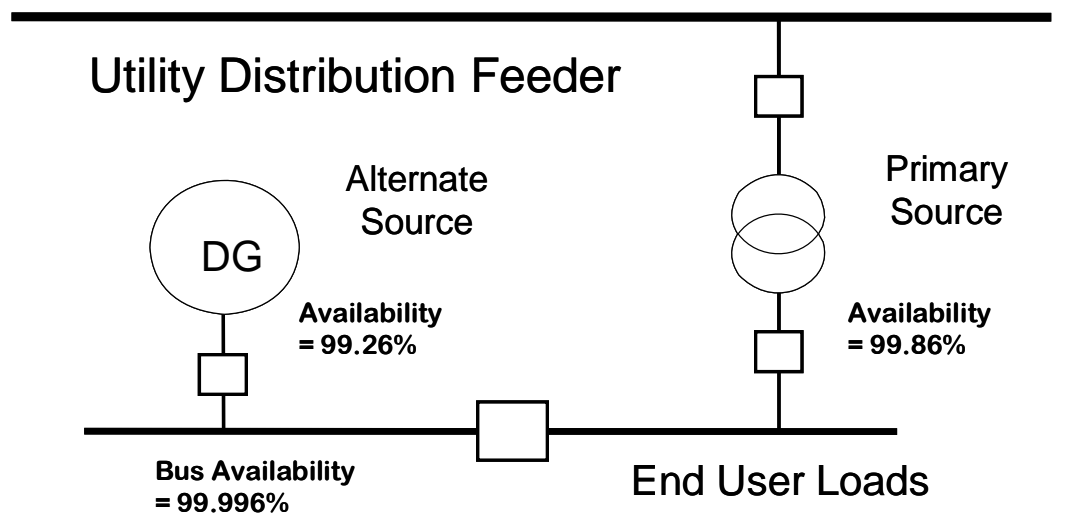

\section{Figure 4-9}

Addition of Alternate Generator Source Enhances Power Availability

This is especially true for plants that are operating near capacity, three shifts and seven days a week. In these cases downtime can mean losing customers to a competitor based on just-in-time delivery requirements. This high cost of unsatisfactory PQ in high-tech and other continuous 
process industries is illustrated by the semiconductor fabrication facility case. ${ }^{27}$ In this case, from the perspective of the end user, adding utility DER functionality is only a small incremental cost compared to the investment that is already justified based on power quality requirements of voltage sensitive processes.

\section{Expanding a DER System to Obtain Premium Power Benefits}

To add premium benefits to a DER system, the necessary performance parameters are "immediate isolation" from power problems such as system faults and "instant replacement energy” to support the critical load during any momentary disturbances or to bridge to an alternate power source. As shown in Figure 4-10, isolation can be provided by an electronic or static interrupter, and replacement energy is typically recovered from onboard storage.

Figure 4-10

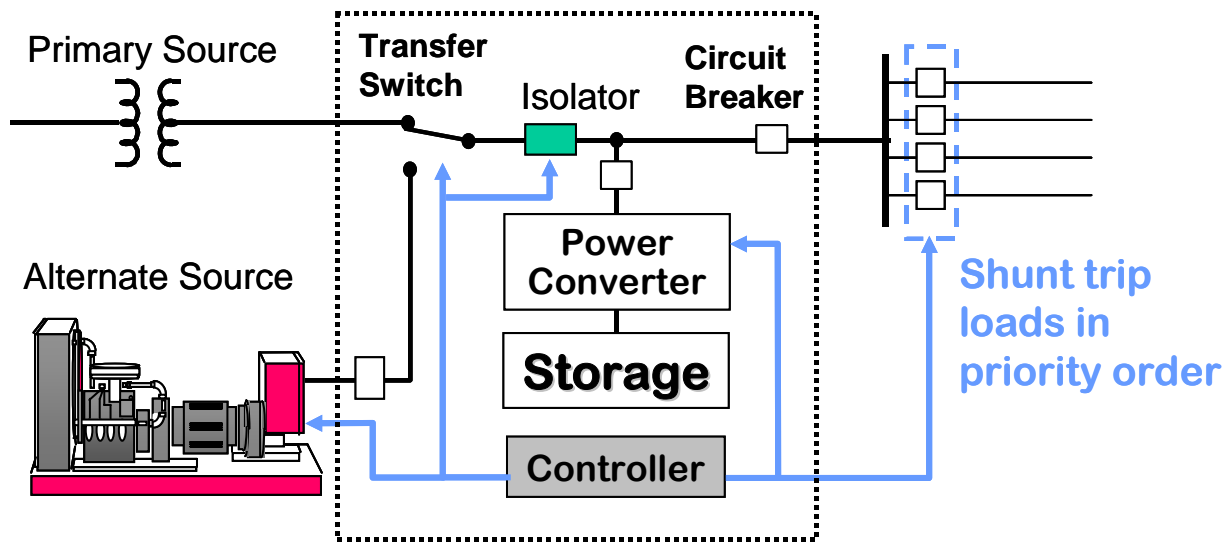

Typical auxiliary equipment required to convert a standby source to premium power.

Therefore premium power from DER can be provided by a fast response from energy storage to protect the load from momentary voltage variations. Other critical functions that are usually needed are conversion of the stored energy, control for synchronization and paralleling between systems, and soft transfer to the alternate power source. Also necessary is a sufficient quantity of energy storage capacity to ride thorough or bridge the time until normal power is restored.

For most premium power applications the main difference between the power system designed for DER functions and one that is designed to provide premium power is the on-board energy storage and the related switchgear and controls. System design must consider the unique details of each system, such as specific prime mover and interconnection characteristics of the alternate source. These characteristics will affect the design. For example, an inverter-connected prime mover is likely to be overload limited, some fuel cells have response delays inherent to the reformer, synchronous machines may bring unwanted dynamic interactions with the electric grid, and induction generators will be unable to operate stand-alone. The many different

configurations and types of available DER require that designs for these systems are site specific.

\footnotetext{
${ }^{27}$ A typical case assumes per annum utility PQ and reliability events of 2 long-term interruptions and 16 voltage sags (the average across all feeders monitored in the EPRI DPQ study). Economic losses for these events are assumed at \$3,500,000 and \$1,500,000 per event respectively.
} 


\section{Barriers to Combining DER and Premium Power Functions}

With a focus on end-user owned DER benefits, local interest in premium power is a strong driver for making investments in distributed generation and storage equipment. The more difficult question to answer has been whether these investment dollars can be combined for making the DER business case. This answer is clearly site-specific, and the DER-compatible segment may be limited compared to the entire digital economy. Several cases have been evaluated where premium power is very likely to enhance the business case for local generation. The main factors that limit combining premium power with DER functionality are:

- Technical requirements may not line up, such as mismatch in size, incompatibility in controls and connections, and potential conflicts in schedule. One telling statistic is that $90 \%$ of DER opportunities identified in commercial and industrial applications are greater than $100 \mathrm{~kW}$. This may be compared to the current market for premium power equipment, where $90 \%$ of the dollars spent in the last two years are for equipment of $100 \mathrm{~kW}$ or less.

- Regulatory or operational restrictions may be imposed for premium power equipment to provide DER functions. Probably the most common restrictions are related to using existing code-mandated generators, such as in hospitals or public buildings, for non-emergency functions. Although these are less applicable to high-tech digital enterprises. Restrictions may include resistance to non-emergency use prohibition by local authorities or environmental limits for operating diesel generators.

- Digital enterprise management concerns regarding financial and other risks related to operating local generation are common barriers. Many end users are reluctant to venture into business activities that are not their core business. They are concerned that utility agreements, DER equipment operating requirements, and other involvements will create potential conflicts with mainstream business.

Modifying an existing premium power system to include DER functions may be easily accomplished based on available equipment. However, as described in prior studies ${ }^{28}$, nearly all DER applications, including premium power solutions, face barriers for installation and operation. Even when premium power system equipment are well suited to provide DER functions, significant technical, regulatory and business reasons may prevent combining these functions into the same system. Some of the technical barriers have been discussed and include mismatch in the size of critical load compared to distributed-energy requirements. Also timing and required controls for operation for DER-related functions may conflict with premium power functions.

Perhaps even more of a barrier is when there are non-technical reasons that premium power systems are not allowed to operate as distributed resources. The more common regulatory and business barriers include:

1. Lack of environmental permits for needed operating hours in applications such as peak shaving or interruptible power contracts.

\footnotetext{
${ }^{28}$ Markets for Distributed Resources: Business Cases for DER Applications, EPRI TR-109234-V2, EPRI Palo, CA November 1997.
} 
2. Restrictions on non-emergency use of resources that are code required such as in public buildings, hospitals or communication facilities.

3. Resistance of operations managers to operate critical back up systems in non-critical situations, for example in data centers, air traffic control, or critical manufacturing processes.

4. Tenuous fuel supply (remote, low volume, low quality, etc.).

5. End-user aversion to utility control of user-owned resources.

6. Expected high frequency of interruptions and likelihood of conflicting needs when the DER resource is unavailable when needed for premium power operations.

7. Management policy to focus on core businesses and not to be involved with other responsibilities, such as DER operations and commitments with the local utility.

8. Lack of skilled or technical staff to represent the end user's interest results in a low "comfort factor” with operating DER.

9. End user is sophisticated and already makes significant use of on-site generation for cogeneration, standby power, etc. and doesn't want the utility involved.

10. Concern over the risk of investing and operating DER on premises.

It is because of these barriers that many systems may not qualify as "DER capable" even though the equipment employed is appropriate.

\subsubsection{Feasibility for Premium Power from DER}

Because most premium power resources are operated part time, and only when there is a problem with the local utility power, part time applications for DER are likely to be most compatible with premium power. The part-time DER business case options for end users is derived from requirements of the local utility such as demand reduction, peak shaving, and the opportunity of lower interruptible utility rates. These opportunities have received increased attention because of deregulation activities, as well as transmission congestions and a shortage of available power to serve the load in some parts of the country. This situation has created very location- or utilityspecific markets for grid support that can be derived from DER capabilities.

While the grid support capabilities of DER have value in many electric utility markets, they have not in and of themselves created a vibrant market for DER. Why is this case? The principal reason is that the economics of demand reduction, peak shaving, etc. have generally not been sufficient or predictable enough to justify the investment in DER, even on a part time basis. In terms of DER operation, the Spark Spread (difference in the cost of electricity versus natural gas or NG) needs to be considered. Obviously the higher the cost of electricity, the more attractive the DER economics based on NG use. These economics certainly have not been enough to justify installation of DER at a wide range of locations. However this business proposition becomes significantly more positive when additional end-use value is considered. There are many cases where improvement of reliability justifies DER.

\subsubsection{Feasibility for CHP in High-Technology Facilities}

\section{Production Facilities}

The applicability of DER technologies for high-tech production facilities - manufacturing and/or clean rooms - will be very site-dependent. As shown in Table 4-1, DER has the potential to:

- Improve facility reliability,

- Improve power quality of electric supply, 
- $\quad$ Reduce facility capital costs, and/or

- Reduce facility operating costs.

The economic analysis of the best means to assure reliability/power quality, and whether it is economically justified to add DER operating applications to the premium power system, is covered in Section 4.3.2. For reliable electric supply to critical processes, the facility can employ an uninterruptible power supply (UPS) and/or on-site back-up generation. The UPS (e.g., battery, flywheel, or capacitor) can handle short duration problems, with the back-up generator available to guard against longer term outages. Power quality can be assured through static equipment filters, isolation transformers, etc. - or by routinely operating the facility's critical loads off the UPS (i.e., operating the UPS in a grid-parallel mode). Transitioning from the UPS to an on-site generator may be handled in a variety of ways.

The key factor in choosing the back-up power supply or UPS is the length of outage or disturbance the facility feels it must guard against. The overwhelming majority of disturbances are less than a few minutes, and it is unlikely, but not unforeseeable, for a problem to last more than a few hours. Many facilities will size their UPS to carry 20 minutes to 2 hours of a facility's load. If deemed necessary, longer duration outages can be provided for by starting a back-up reciprocating engine. However, the facility must decide how much diesel or propane fuel to store for the emergency generator. Local codes and guidelines may specify the minimum fuel storage, but as was demonstrated in August 2003's Northeast blackout, extended outages of more than 24 hours are possible. EPRI surveys of transmission and of distribution reliability help give facility operators an indication of the typical magnitudes and durations of disturbances to expect, by region of the country.

Extraordinary events such as ice storms, hurricanes or tornadoes, or widespread damage to infrastructure from the 2001 terrorist attacks, are scenarios that argue for keeping a week's worth of fuel on hand. Where DER is normally operating in grid parallel mode to obtain economic DER benefits, natural gas-fired DER may be installed. In this case, the facility must also consider what support is needed for the fuel supply infrastructure; a widespread problem that depressurizes a natural gas pipeline could render useless the emergency generators it feeds.

One approach to specifying the fuel supply or energy storage capacity for back-up generation is to determine how much electricity would be needed to "gracefully" shut down (i.e., without damage to equipment or product) the process.

The decision of whether to operate the DER for capacity (e.g., using thermal energy storage) or operating cost (e.g., micro-turbines with waste heat utilization in an absorption chiller) savings is a fairly straightforward risk vs. reward evaluation.

\section{Concentrated Digital Loads (CDL)}

However, the growing load- and heat-densities associated with CDL, such as information processing, telecommunications, and Internet hub facilities, are leading to facilities where traditional equipment cooling and reliability designs based on alternating hot/cool aisles with 


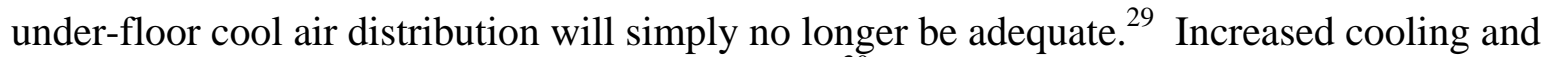
humidity control requirements (Section 3.3.2 and ${ }^{30}$ ) further exacerbate this.

This is a problem for both new and retrofit construction. CDL facilities must be designed to enable equipment changes (e.g., for maintenance, repair/replacement, and upgrade), reconfiguration and expansion of raised-floor data centers. ${ }^{31,32}$ Old cables and piping tend to be left in place under the raised floor, as removing them would disperse dust that would threaten the servers already installed. The resulting blockages severely impede the air flow and, with the expected operational problems or errors in configuring or re-configuring under-floor air flow baffles, maintaining filters, and the fluid dynamics of large pressurized plenums, etc., the “design” cool air flow is likely to be optimistic when compared to actual conditions. ${ }^{33,34}$

A typical result is shown in the computational fluid dynamics (CFD) simulation of Figure 4-11, where hotspots in unpredictable locations will lead to an unacceptable environment for some of the servers. Adding more CRAC units is not necessarily a solution. There is a limit to the space and power available for additional units, the hot spot may remain even with additional CRACs, and reconfiguring the air flow will likely just move the hot spot to a different group of servers. ${ }^{35}$ A self-contained spot cooler will increase dust circulation and add to the overall heat level of the room. The only viable alternative may be a supplemental liquid-based cooling unit, such as shown in Figure 4-12.

Liquid cooling, long considered anathema by data centers operators, is gaining acceptance by system and equipment designers. ${ }^{36}$ Use of liquid cooling will require some new design guidelines for the data rooms and/or use of electrically inert liquid coolants.

However, liquid coolant systems alone will not solve this problem. "Evaluating the available technologies indicates that no single technology provides a complete solution to this challenge. Data center designers will need to develop an understanding of all available technologies and create solutions that combine the strengths of multiple approaches. ${ }^{37}$

This has major implications for DER technologies, as use of liquid coolants opens the door for thermal energy storage, absorption chillers, and other DER technologies that can utilize the waste heat of the data centers' servers and the on-site generators. The potential applications of these DER technologies are:

\footnotetext{
${ }^{29}$ Nacke, Brad, “Power Densities Change Data Center Cooling,” Energy User News, pp 12 - 14, February 2004.

${ }^{30}$ Thermal Guidelines for Data Processing Environments, American Society of Heating, Refrigerating and Airconditioning Engineers, Atlanta, GA, 2004.

31 Alcardo, Dominic, “The Cost of Overbuilding,” Energy User News, pp 10 - 14, January 2003

${ }^{32}$ Gupta, Raj and Morris Toporek, “The Next Generation,” Consulting Specifying Engineer, July 2001 , pp 26 - 32.

33 Schmidt, Roger R., “Thermal Profile of a High-Density Data Center - Methodology to Thermally Characterize a Data Center,” ASHRAE Transactions, Volume 110, Part 2, 2004.

${ }^{34}$ Patankar, Suhas V. and Kailash C. Karki, “Distribution of Cooling Airflow in a Raised Floor Data Center,” ASHRAE Transactions, Volume 110, Part 2, 2004.

${ }^{35}$ Nacke, Brad, "Power Densities Change Data Center Cooling,” Energy User News, pp 12 - 14, February 2004

${ }^{36}$ Beaty, Donald L., “Liquid cooling - Friend or Foe,” ASHRAE Transactions, Volume 110, Part 2, 2004.

${ }^{37}$ Stahl, Lennart K., “Cooling of High Heat Density Rooms Today and in the Future,” ASHRAE Transactions, Volume 110, Part 1, 2004.
} 


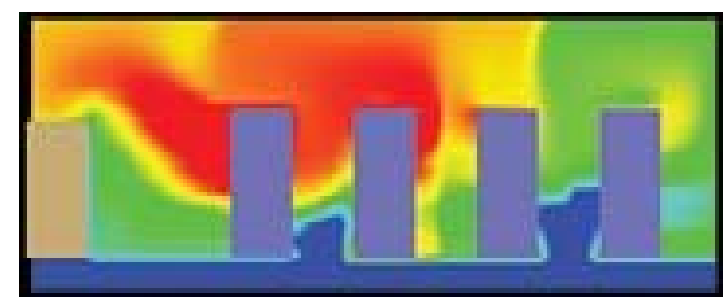

Figure 4-11

CFD image showing hot spot in raised-floor data center with no supplemental cooling Source ${ }^{35}$

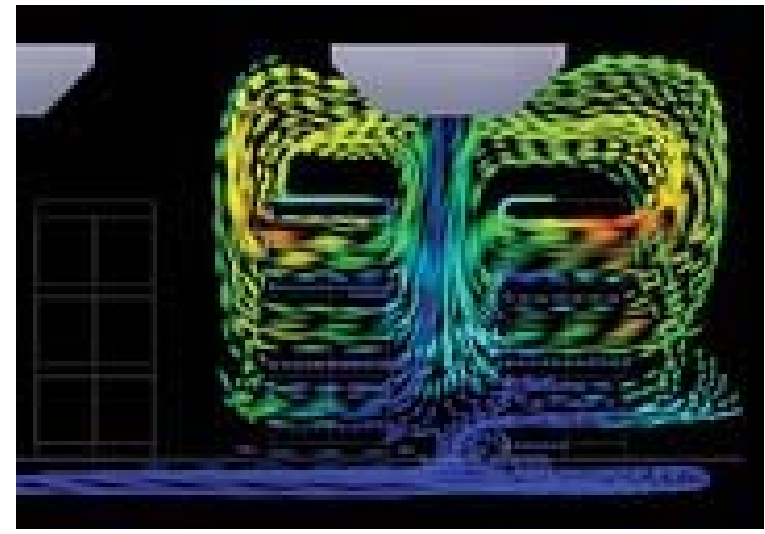

Figure 4-12

CFD image showing same data center with supplemental cooling Source ${ }^{35}$

- Operating economics

o Absorption chillers that use waste heat from servers and on-site generators for cooling will reduce the energy cost of cooling the facility. This technology may also be able to reduce the heat rejected into the datacom room, thus decreasing the cooling load.

o Thermal energy storage (TES) can shift chillers electricity use to off-peak periods, when electricity kWh prices are likely to be lower and when electricity kW demand does not count against the facility's peak demand charge.

- $\quad$ Facility capital cost

o Cooling may constitute 20 to $40 \%$ of a datacom's electrical requirement. Using TES as a source of emergency/backup cooling can reduce the capacity of emergency power generation needed. This may also reduce the amount of fuel that must be stored on-site for the emergency generators or extend the time the back-up systems can operate with a given amount of fuel.

o Using TES for cooling when one or more conventional CRAC units must be maintained or repaired will reduce the number of redundant CRAC units needed and may increase the space available for data units.

- $\quad$ Reliability

o As described above, supplemental rack-mounted or ceiling-mounted cooling units may be needed to eliminate hot spots. A liquid-based cooling unit, compatible with TES or absorption chillers, may be the best solution. 
o A well documented DER technology is the use of rejected heat to control operation of and regenerate a desiccant wheel. This will enable better humidity control, which improves reliability of electronic equipment. ${ }^{14}$

o Liquid-based cooling systems will decrease the amount of air flow over the electronic board needed to cool them, thus reducing equipment failures due to dust.

\subsubsection{Most Likely Scenarios of End-User Owned DER}

\section{Value Added From DER for Existing Life Safety Systems or Mission Critical Facilities}

In the case of digital enterprises, mission critical facilities, and those facilities mandated by law to have emergency or standby generation equipment, the incremental step of adding utility DER functions is usually not a large one. A web hosting or server farm center provides excellent examples of critical facilities that could, for economic necessity, take advantage of DER-capable technologies. Mitigating PQ and reliability phenomena also figure very strongly for digital enterprises, as they do for high-tech manufacturing such as semiconductor facilities. Achieving DER grid support benefits from these existing DER-capable installations at critical facilities offers a potential value to users and utilities.

\section{Power Quality Improvement Using DER Equipment as an Alternative to New Power Conditioning}

In many cases power-conditioning systems include elements of on-site generation and energy storage. For example popular short term UPS that bridge to onsite generators are very adaptable to operating as distributed resources. Usually the additional investment required is limited to modifying controls or additional switchgear to allow parallel operation with the utility system. In some cases electronic switching may be required to provide a fast interruption of the connection to the grid when faults or other disturbances occur. Depending on the size of the protected load a 10 or $20 \%$ incremental investment will allow both DER economic benefits, such as credits for peak shaving or low interruptible electric rates, as well as power conditioning protection of critical digital equipment.

In contrast some power conditioning solutions offer little or no opportunity for adding DER functionality. For example, static transfer switches (between two presumably independent utility feeders) may be economically viable compared to other alternatives when a second and independent feeder is already present, and utility capacity charges for the alternative feeder are very low. Another example is the dynamic voltage restorer (DVR), which is suitable for mitigating moderate sags in utility voltage. In this case there is no opportunity for using distributed generation or storage service because the DVR actually depends on the existing feeders, drawing voltage support for a low phase from the healthy phase. However, when the DVR technology is economically sized, it cannot mitigate very deep three-phase sags (below $30 \%$ of nominal), and will not protect from a power interruptions. As such, DVR is appropriate only for facilities that suffer moderate voltage sags, and not a significant number of costly power outages.

\section{Location-Specific Situations Where Grid Support Incentives are Available for On-Site DER}

On-site generation or electrical storage equipment can make economic sense absent other benefits if the local utility sees relatively high value for grid support and offers related

\footnotetext{
${ }^{14}$ Thermal Guidelines for Data Processing Environments, American Society of Heating, Refrigerating and Airconditioning Engineers, Atlanta, GA, 2004.
} 
incentives. These incentives are usually based on the need for location-specific enhancement of capacity, relief of occasional system peaks, or to provide ancillary services. The value can be quite high, up to a $30 \%$ reduction in the electricity bill for example. The value of utility incentives is perhaps best illustrated by examining a scenario where reliability, CHP, and other potential end-user benefits are not sufficient to cost-justify DER-capable technologies. ${ }^{38}$ Without significant benefits from CHP and enhancement of PQ and reliability, the economic picture for DER-capable technologies is not attractive. However, a grid support incentive of \$100 to \$200 per $\mathrm{kW}$ can make the investment cost-effective once all other benefits are considered.

\section{Existing Industrial and Commercial Facilities Valuing Heat Recovery and Savings in Energy Bill}

Economic justification of full-time operation of on-site generators almost always requires either very low fuel costs, significant additional benefits from using waste heat, or improving power quality and reliability where it is needed. The value of improved reliability in justifying DERcapable technologies is readily apparent in situations such as described above. Other end-user benefits, such as peak shaving or CHP, usually require extended operation of DER and, in some cases, use of on-site generation as the primary generation source, with or without the utility as backup. In such instances, the cost of fuel, the utility rate $(\$ / \mathrm{kWh})$, and the heat rate of the DER technology will dominate the economic analysis. Full-time operation of the on-site generation resource has the potential to offset a significant portion - estimated here at approximately 30\% of the facility's annual cooling costs by using waste heat from the DER to drive an absorption cooler. Use of utility power as primary source, and using on-site generation only intermittently, can significantly reduce the potential benefit from CHP.

\section{New Facilities Where Marginal Value is Realized From Both Heat Recovery and Back-up Generation}

This scenario applies to high-tech end-users seeking to mitigate sustained utility outages, and where CHP is not, by itself, cost effective, or is a secondary factor compared to reliability. The most economical solution can be a DER arrangement where the local utility is used for primary power, a combustion turbine or reciprocating engine is used for backup onsite generation or fulltime operation with heat recovery. In this case the backup generation might earn additional revenue via low interruptible rates or peaking value agreements from the local utility. The additional benefit of improved reliability based on the on-site generation may provide measurable economic justification to the investment. In cases where heat can be used on a fulltime basis, the most economical solution is a CHP arrangement. That is, primary power is supplied by an onsite combustion turbine or clean-burning reciprocating generator, with the local utility serving as backup. The possible limiting factors for this case will be restrictions on emissions and high fuel costs.

\footnotetext{
${ }^{38}$ A typical case assumes per annum utility PQ and reliability events of 1 long-term interruption and 20 voltage sags (reflecting the likelihood of such a facility being on a urban feeder). Economic losses for these events are estimated at $\$ 2,500$ and $\$ 100$ per event respectively. Equipment capital costs are reflected in a $20 \%$ carrying charge per annum.
} 


\section{End Users with Sensitive, Critical, or High-Cost-of-Outage Processes}

These end users are very likely to have already installed PQ and reliability enabling technologies. It is also very likely that these technologies will be a combination of DER-capable technologies including on-site generation and energy storage. Utilities seeking grid support from DER can approach these customers with incentives to provide DER benefits (such as load shedding, peak shaving, or specific ancillary services) back to the grid. A key factor is the likelihood that DER operations will not diminish existing power protection of critical loads. Also, the utility's taking on some aspects of the specification, maintenance and operation of the DER may be attractive especially for end users who do not normally employ engineers and technicians with the necessary power systems expertise.

\section{DER for Power Quality when Local Distribution Quality is Poor}

There have been many occasions in which the customer of a distribution utility is located in an area with poor power quality and/or operates highly sensitive process equipment. Thus a high premium can be placed on uninterruptible or higher quality power for his facility. A common way to solve such problems is with battery systems with back up diesel generators, which can provide reliable power up to several MW. This solution has the advantage of relatively low initial cost, but operation and maintenance of the system can be expensive, and the emissions and noise related to the generator can also be a nuisance.

Many different DER technologies can provide both back-up power and protection from grid disturbances. The most common is the use of energy storage to form a UPS system. The type of energy storage used must be suited for the situation. A solution based on a lead-acid battery may not be appropriate when the power reliability is so bad that the UPS is called to act several times a day; the battery may quickly deteriorate, and require an expensive replacement operation. A flywheel-based solution may be more appropriate in such cases. A combination of a flywheel and a conventional diesel generator may be able to provide the power quality required while reducing the O\&M costs associated with the generator.

\subsubsection{Future Designs for High Technology Facilities}

Because of the high cost of damages due to power outages or power quality problems for “digital” facilities, such facilities tend to stipulate a set of reliability and power quality requirements and then select equipment and systems designed to provide that level of premium power. Often this is done without regard to the capital and operating costs of the selected design, since the consequences of a service disruption are so severe.

Utility industry data on observed T\&D reliability and power quality incidents have proved extremely valuable in demonstrating the expected quality of service a utility can provide. These give guidelines to high-technology enterprises on the failures they should guard against. However, as recent extraordinary events - the August 2003 blackout, the September 2001 terrorist attacks and continuing Homeland Security warnings, the summer 2000 California blackouts, recent severe storms, etc. - have shown, it is not clear how much "insurance" is needed. It is clear that the "conventional" utility structure that relies on central generation cannot physically or economically provide the necessary reliability. Some level of distributed generation and energy storage are clearly required, and digital facility owners and operators are installing DER and UPS in growing numbers. 
In the concentrated digital load facilities, such as data and communications centers, the trend towards ever higher load densities and attendant heat generation has led to a re-examination of the necessary environmental conditions - thermal, humidity and dust-related. ${ }^{14}$ These more stringent design guidelines, the increasing thermal loads taxing the capability of conventional computer room air conditioning (CRAC) systems, and the higher electric load densities being served by a stressed and overloaded grid necessitate a new approach to designing and protecting high-tech facilities. A broader spectrum of distributed energy resources - thermal energy storage, waste heat utilization, and responsive load controls - in addition to power equipment, must be employed at the facility level to ensure continuity of service.

Thus, for technical and economic reasons, digital facilities must look beyond DER as solely a reliability provider; they must employ other distributed energy resources to better manage their thermal and electrical needs. There are no broadly applicable firm guides for applying specific DER technologies to individual digital facilities. However, there is a developing industry consensus that the facilities and their power supplies must be scalable and flexible. The industry must be scalable, because growth is inherent in the nature of digital industries and services, and flexible, because adaptability is essential for such industries to survive economically and technically.

To provide premium power and acceptable indoor environmental conditions in an economically and technically feasible manner calls for going beyond premium power requirements and incorporating DER functions in the value streams of the digital enterprises. The result is not just updating our conception of the structure of the $21^{\text {st }}$ Century utility, but also nature of the Customer-Utility Partnership of the $21^{\text {st }}$ Century. DER must be evaluated not as a stand-alone option, but as a grid-compatible technology. For design and protection of digital facilities, additional research, development and application is needed for individual DER and facility technologies and components:

- On-site generation, including reciprocating engines, micro-turbines, fuel cells, renewable sources (wind, solar, etc.) - Improved efficiencies, reduced emissions, better loadfollowing and regulating capabilities, improved inverter technologies.

- Uninterruptible power supplies, including battery, flywheel, capacitor, and other technologies.

- Adaptive protection systems to enable full everyday and emergency use of gridconnected DER.

- Waste heat utilization, including industrial co-generation and absorption chillers.

- Electric and thermal energy storage.

- Cooling systems and configurations for datacom rooms, server enclosures, individual circuit boards, and individual silicon chips.

- Liquid cooling technologies for digital facilities that incorporate designs for spill prevention and containment, use of electrically inert liquids, advanced phase change materials, etc.

- Improved air filtration and humidity control technologies.

- Refinement of premium power requirements for digital and mission-critical facilities.

\footnotetext{
14 Thermal Guidelines for Data Processing Environments, American Society of Heating, Refrigerating and Airconditioning Engineers, Atlanta, GA, 2004.
} 
But just as important is the need for R\&D to integrate these technologies and to integrate DER operations with the power grid. For example, the choice of an emergency generator cannot be properly and optimally made unless one also considers the economic and reliability benefits of incorporating its rejected heat to provide additional cooling for the facility and the possibility of using it to provide support - reserves or black start - to a stressed grid. This calls for advanced sensors and controls, improved facility simulation models incorporated with grid security assessment and dispatch procedures, and procedures to design and dispatch a micro-grid (or energy park).

\subsection{Utility-Owned DER for Digital Economy}

As shown in Figure 4-13, a variety of DER equipment in all types of end-users locations is envisioned for future distribution systems. However, on a site-by-site basis it may not always be easy to distinguish whether this type of equipment is primarily for distributed generation, for premium power, or installed as code-required emergency and standby power. The equipment may be essentially the same while the main functions and business purposes are different.

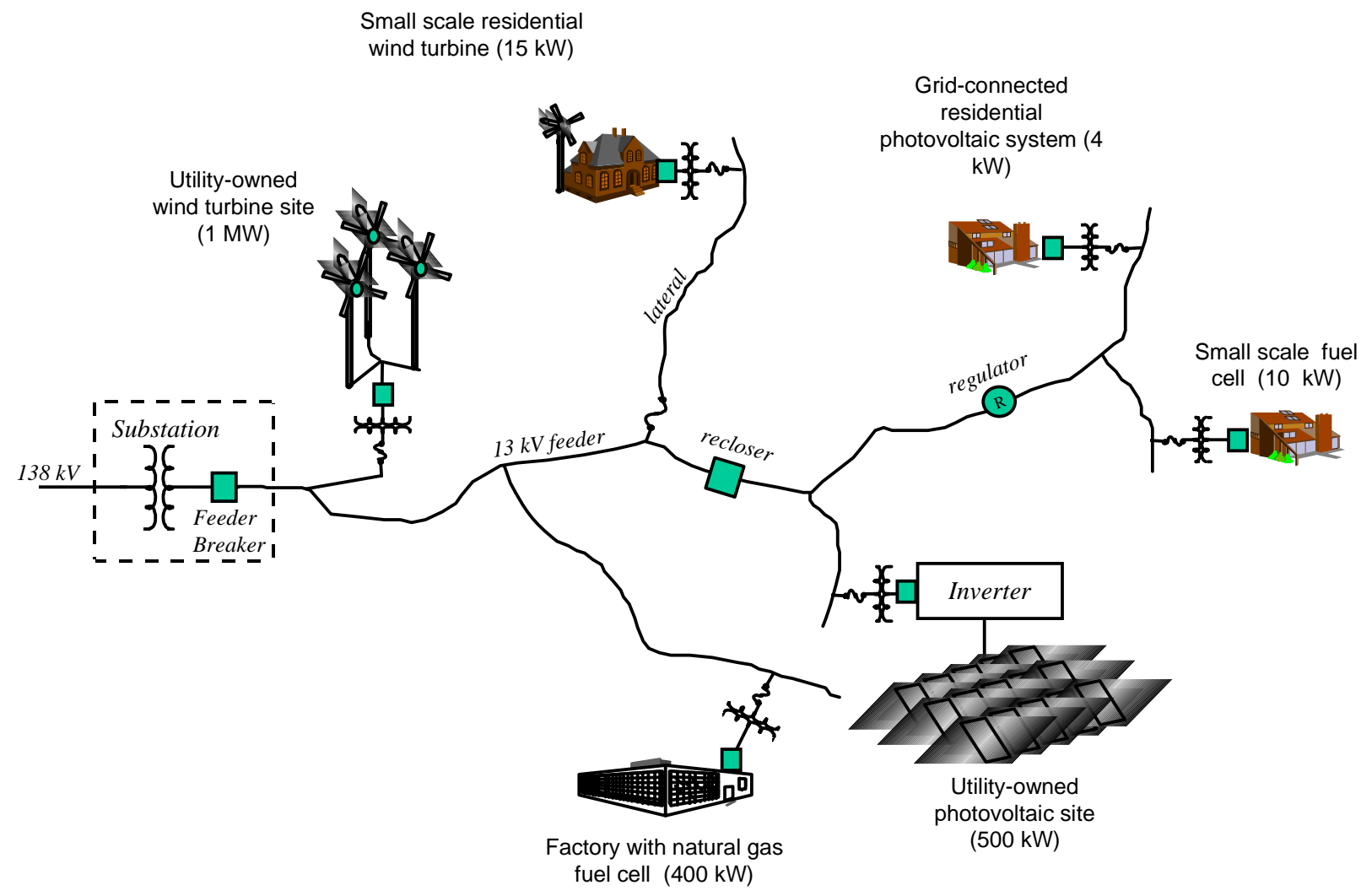

Figure 4-13

Distributed Resources Supplement Distribution System of the Future

Considering all the possible system configurations and operating modes, definitions for DER generally vary among different stakeholders. Some definitions focus on benefits to the end user and others emphasize benefits to the external power grid, or local utility. Energy storage, included in most DER definitions, is usually only providing a reliability benefit to the end user. 
Load management, emphasized as part of DER by some, is likely of more interest to utility system operators for demand reduction.

Usually business arrangements depend more on who owns the distributed resources, how the resources are operated, and where the costs and benefits are best assigned. In many practical cases equipment resources that were justified and paid for based on a single purpose use, such as emergency power, may be available for several functions. Therefore some costs and/or benefits that are not considered in the original investment should be identified in an incremental investment analysis. This suggests that it is the intended business, rather than the type of equipment, that best defines the DER business case.

Current interest in micro-grids is predicated on the basis that they offer significant benefits compared to traditional power system designs, which are based on central-station plants and the interconnected T\&D infrastructure required for delivery of power. This section takes a look at the potential benefits and drawbacks of micro-grids in an effort to determine the value of microgrid approaches with respect to conventional T\&D system approaches. In making this comparison, some key areas that are clearly important include:

- Cost

- Efficiency

- Reliability

- Potential for ancillary services

\subsubsection{Characteristics of Utility Supply Compared to DER}

The utility system is a strong source, which will typically have less than $5 \%$ impedance (at the point of common coupling on the kVA base of the DER) and will be very stable from a frequency perspective. It represents a vast interconnected network of thousands of megawatts of generation capacity, and any single distribution feeder load is tiny in comparison and has no significant impact on the bulk generation dispatch needs or operating efficiency. By comparison, the DER impedance is high (20\%), and the starting of large motors and other loads can create severe PQ problems. Typically, reliability of the utility system power is in the range of $99 \%$ to 99.999\% (national average is about 99.97\%). This compares to a single DER that is on the order of 94 to $97 \%$ available. DER reliability is improved by employing multiple units so that if one is down, the others can pick up the load. An "N-1" design, where one unit can be down and there is still sufficient capacity to serve the load, can be almost as reliable as a typical utility service.

Table 4-3 compares a 150-kVA transformer-fed utility service to a standalone synchronous generator type DER with a similar kVA rating. It also shows that the utility service is stiffer, more reliable, and better regulated for load-steps than a typical distributed generator operating as a standalone entity. In fact, it is conservative in that it compares a 150-kVA generator to a 150kVA utility service transformer. In many cases, the service transformer is greatly oversized relative to site load, so the utility system is even stiffer than indicated in the table. The only performance areas where the utility service has a performance disadvantage are with incoming deep voltage sags (due to the exposure of the power system) and in the efficiency of the generator if the DER is a co-generation unit (waste heat is recovered). 
Table 4-3

Performance Characteristics of a Standalone DER and a Utility Service Connection.

\begin{tabular}{|c|c|c|}
\hline Characteristic & $\begin{array}{c}\text { Standalone Generator } \\
\text { (150-kVA, Three- } \\
\text { Phase Unit) }\end{array}$ & $\begin{array}{c}\text { Utility System Service } \\
\text { (150-kVA, Three-Phase } \\
\text { Transformer and Service Drop) }\end{array}$ \\
\hline Source capacity & 150 kVA & 150 kVA \\
\hline Site peak load & 100 kVA & 100 kVA \\
\hline $\begin{array}{l}\text { Impedance (percent of source capacity } \\
\text { rating, } 150 \text { kVA) }\end{array}$ & $20 \%$ & $4 \%$ (includes service drop) \\
\hline $\begin{array}{l}\text { Fault level (per unit of site peak load } \\
\text { current, } 100 \mathrm{kVA} \text { ) }\end{array}$ & 7.5 & 37.5 \\
\hline Frequency dip during $100 \%$ step-load & $\begin{array}{l}\text { Can be more than } \\
10 \% .\end{array}$ & No change \\
\hline $\begin{array}{l}\text { Voltage drop due to } 20 \text {-HP motor start } \\
\text { (locked-rotor current }=5 \text { per unit) }\end{array}$ & $15-20 \%$ & $4 \%$ \\
\hline $\begin{array}{l}\text { Exposure to fault-related voltage sags } \\
\text { coming from utility system }\end{array}$ & None & $\begin{array}{l}1 \text { moderate to severe event per } \\
\text { week }\end{array}$ \\
\hline $\begin{array}{l}\text { Impact of load variation on generation } \\
\text { efficiency and economic dispatch }\end{array}$ & Strong impact & No impact \\
\hline Reliability (annual availability in percent) & $\begin{array}{l}97 \% \text { or less } \\
\text { (assumes a single } \\
\text { DER with no } \\
\text { redundancy) }\end{array}$ & $\begin{array}{l}99-99.999 \% \text { (average US value } \\
\text { is } 99.97 \% \text { and range represents } \\
\text { different T\&D system types and } \\
\text { conditions) }\end{array}$ \\
\hline $\begin{array}{l}\text { Typical effective power generation } \\
\text { efficiency }\end{array}$ & $\begin{array}{l}20-40 \% \text { (without } \\
\text { cogeneration) } 55-85 \% \\
\text { (with cogeneration) }\end{array}$ & $\begin{array}{l}35-55 \% \text { (Depends on mix of } \\
\text { utility generation resources; } \\
\text { range includes T\&D losses) }\end{array}$ \\
\hline
\end{tabular}

When DER is operated in parallel with the utility system, the positive attributes of both approaches can be realized. A properly interfaced grid-parallel DER can offer better PQ, reliability, and efficiency to the customer site than the standalone generator or the utility service alone. The key benefits are as follows:

- Voltage regulation: The low impedance of the utility service (typically less than 5\%) in combination with the DER means that load steps and motor starts have a far less perturbing impact on the facility voltage level than they would for a standalone generator with $20 \%$ impedance. Furthermore, the combined impedance of the DER and utility system is slightly lower than the utility system alone, enabling better voltage regulation response during loadsteps than with the utility system alone.

- Harmonic distortion: The lower impedance of the utility system with respect to harmonics in combination with the DER means that nonlinear loads result in far less voltage distortion than if a standalone generator had to drive them. The utility system combined with the DER 
may also result in less distortion than the utility system alone if the DER is not a significant source of harmonics

- Frequency regulation: The parallel utility connection should hold frequency to within $\pm 0.5 \mathrm{~Hz}$ of $60 \mathrm{~Hz}$ in all but the most unusual utility system conditions, whereas the standalone generator will be momentarily well outside $\pm 2 \mathrm{~Hz}$ of $60 \mathrm{~Hz}$ during large load fluctuations.

- Efficiency: Operation of the DER in parallel with the utility system will enable heat engine devices (internal combustion engines and combustion turbines) to operate at a point on their loading curve that saves 10 to $20 \%$ in fuel per kilowatt-hour produced compared to the standalone application. In cogeneration applications, the DER can also be sized and operated to more appropriately match the site heat needs, which will significantly improve efficiency.

- Reactive power: Operation of the DER in parallel with the utility system may allow the DER to focus purely on the site's real power consumption and not provide reactive support, depending on the interconnection requirements and agreement with local utility. Depending on the generator design, type, and loads at the site, this can lead to significant capacity cost savings for the DER.

- Reliability: A typical parallel utility connection can eliminate more than $99 \%$ of the potential power interruptions that an "N-0 designed" standalone DER installation would experience. Alternatively, it avoids the need to design for "N-1" or "N-2" and saves at least several hundred dollars per kilowatt in marginal standby capacity costs.

- Optimal sizing cost savings: The parallel connection with the utility system allows the DER integrator to design less capacity margin into the DER plant, thereby saving significantly on DER capacity costs.

Most or all of the above benefits apply to any type of distributed generation, including internal combustion engines and combustion turbine installations.

\subsubsection{Costs of Integrated DER Compared to Traditional T\&D Systems}

In comparing the cost of micro-grid systems to conventional T\&D systems, it is important to analyze the components that make up the cost of energy delivered via the traditional bulk power system and compare those to the costs of energy delivered via micro-grids. The cost elements of the traditional power system include the bulk generation, transmission, sub-transmission, distribution substation, primary feeder, and secondary system. For a micro-grid, the cost is the distributed generation cost (including all factors associated with this) added to the cost of the power system that makes up the micro-grid. If it is a low-voltage micro-grid, the only cost is basically that of the low-voltage wiring infrastructure with all of its controls and protectionthere is no high-voltage infrastructure. Figure 4-14 is an example showing a hypothetical comparison between a utility with a delivered energy cost of 10.5 cents per kWh (slightly above the national average) and a micro-grid at 10 cents per $\mathrm{kWh}$. Note that the cost of micro-grid generation assumes the recovery of waste heat; without this, it would be a few cents more expensive in this example. 


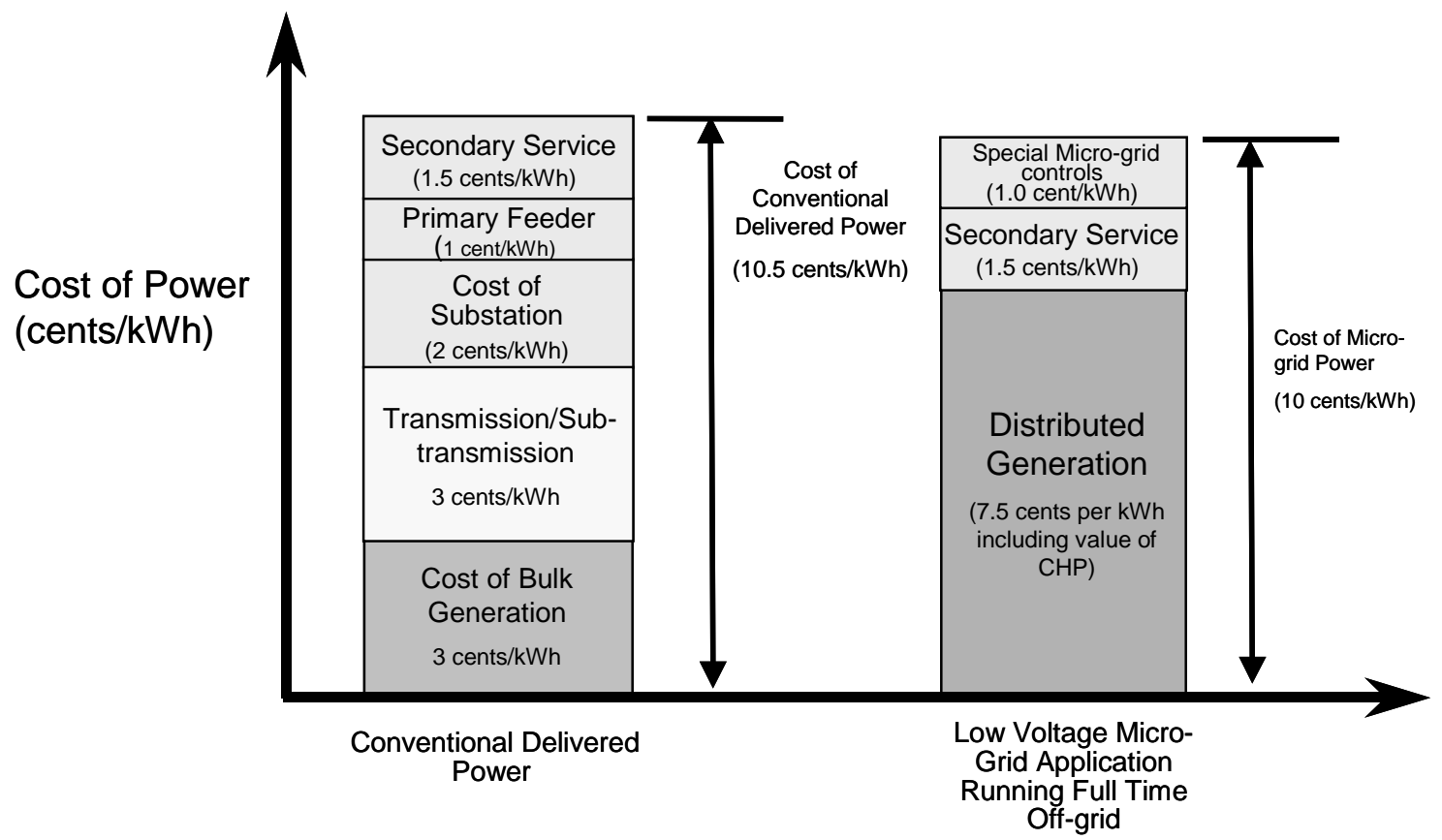

Figure 4-14

Hypothetical Comparison between the Costs of Conventionally Delivered Power and Costs of a Low-Voltage Micro-Grid Application

The example of Figure 4-14 intentionally contrasts a full-time micro-grid to conventionally delivered power. If we had attempted to contrast a part-time micro-grid (one that runs in parallel with the utility system some of the time), then some of the T\&D costs would need to be assigned to the micro-grid costs, and the analysis becomes much more complex. Also note that the cost structure of each utility company varies, so the breakdown of costs given in Figure 4-14 for conventional power are meant to be for illustration purposes only.

In our example of Figure 4-14, we used about 10 cents per kilowatt-hour for the cost of energy produced by the DER, and then we discounted that by another 2.5 cents/kWh to account for the value of the heat-recovery option. Therefore, the net cost of electricity production was 7.5 cent/kWh from the DER. This is a fairly reasonable assumption for a good CHP application with an internal combustion engine and with typical fuel prices. DER can be much more expensive than this if an emerging technology is employed, fuel costs are higher than average, or the machines are underutilized. For applications that do not have heat recovery and with some of the emerging technologies that are more expensive, costs can easily be higher than 15 cents per kilowatt-hour.

Table 4-4 summarizes current costs and expected future costs for some of the various DER technologies that are available. The costs shown include the range of expected fuel prices and capital cost variations based on the scale of the DER plant. There are economies of scale for the DER technologies, so larger units tend to have lower costs per kilowatt of capacity installed and the smaller ones the higher cost. The capital costs shown in Table 4-4 represent the bare-bones minimal installed costs for DER equipment from the largest size to the smallest size. If additional equipment or effort is needed for the project such as special switchgear, interface transformers, interconnection studies, fuel compressors, heat recovery units, or utility system modifications, 
they may add a considerable amount to the total system installed cost. This table represents only the DER cost and not the cost of any micro-grid distribution equipment.

Table 4-4

The Generator Is Currently the Major Cost Contributor in Micro-Grid Systems

\begin{tabular}{|c|c|c|c|c|c|}
\hline \multirow{2}{*}{ Generation Technology } & \multicolumn{2}{|c|}{$\begin{array}{c}\text { Present Cost } \\
\text { (2001) }\end{array}$} & \multicolumn{2}{c|}{$\begin{array}{c}\text { Predicted Future Cost in } \\
\text { Year 2010 }\end{array}$} & $\begin{array}{c}\text { Cogeneration } \\
\text { Potential }\end{array}$ \\
\cline { 2 - 6 } & $\begin{array}{c}\text { Capital Cost } \\
\text { Range (\$/kW) }\end{array}$ & $\begin{array}{c}\text { Cost of } \\
\text { Power } \\
\text { (cents/kW) }\end{array}$ & $\begin{array}{c}\text { Capital Cost } \\
\text { Range }(\$ / k W)\end{array}$ & $\begin{array}{c}\text { Cost of Power } \\
\text { (cents/kw) }\end{array}$ & Yes \\
\hline Internal Combustion Engine (ICE) & $300-900$ & $7-15$ & $300-700$ & $4-10$ & Yes \\
\hline $\begin{array}{c}\text { Conventional Combustion Turbine } \\
\text { (CT) 1-10 MW size range }\end{array}$ & $500-1,000$ & $5-15$ & $400-700$ & $4-10$ & Yes \\
\hline Microturbine (<500 kW) & $700-1,000$ & $9-15$ & $350-700$ & $7-10$ & No \\
\hline Photovoltaic & $5,000-8,000$ & $20-40$ & $2,000-3,000$ & $3-15$ & No \\
\hline Wind Turbine & $700-1200$ & $4-20$ & $500-1,000$ & $5-10$ & Yes \\
\hline
\end{tabular}

Given the costs of the distributed generation options, it is clear that many DER applications will not really be lower in cost than the lowest-cost utilities in the country. The lowest-cost retail utility power tends to be in the range of about 5 cents per kilowatt-hour, whereas the lowest cost DER cannot quite get this low even with heat recovery. The highest-cost conventional utility power is higher than 20 cents per kilowatt-hour in some island areas such as Hawaii, and DER is much more competitive in regions with high utility prices as long as fuel costs for the DER are still reasonable in those areas. Often, there is a tendency for areas with high utility electricity prices to also have high fuel prices, which tends to limit the competitiveness of DER solutions. The best areas in the country for DER are those that have high conventional power costs but low fuel costs. The average cost in the U.S. for conventional utility electricity is in the range of 8 to 9 cents per kilowatt-hour. If the DER cost plus the micro-grid infrastructure cost is lower than the utility cost, then a micro-grid makes sense on a pure cost perspective.

Figure 4-15 is an illustration of the cost distribution for conventional utility power overlaid on the cost distribution for distributed generation options. What is clear is that most DER scenarios are currently more expensive than most conventional utility situations. However, there are some applications where DER is lower in cost. Combined heat and power in regions with low fuel costs and high conventional power costs are the most likely candidates. DER may also be applied even when it costs more, simply because it improves reliability.

The costs shown in Table 4-4 are the distributed generation costs only and do not include the costs of the non-generation micro-grid infrastructure. The cost of the non-generation micro-grid infrastructure will vary widely due to the wide range of architectures that are possible. Some micro-grids are basic low-voltage systems, and others are networked high-voltage primary systems aimed at premium power markets. The cost added to generation will likely be in the 
range 2 cents per kilowatt-hour for the most basic low-voltage micro-grids to 10 cents per kilowatt-hour for very sophisticated networked primary micro-grids that have a variety of powerconditioning and power quality enhancement equipment. Certainly, the basic low-voltage system with no frills can be competitive in a number of scenarios with utility power. However, even the premium power micro-grid is competitive if its cost is compared to a premium power conventional distribution system or compared with the installation of numerous local UPS equipment at each load.

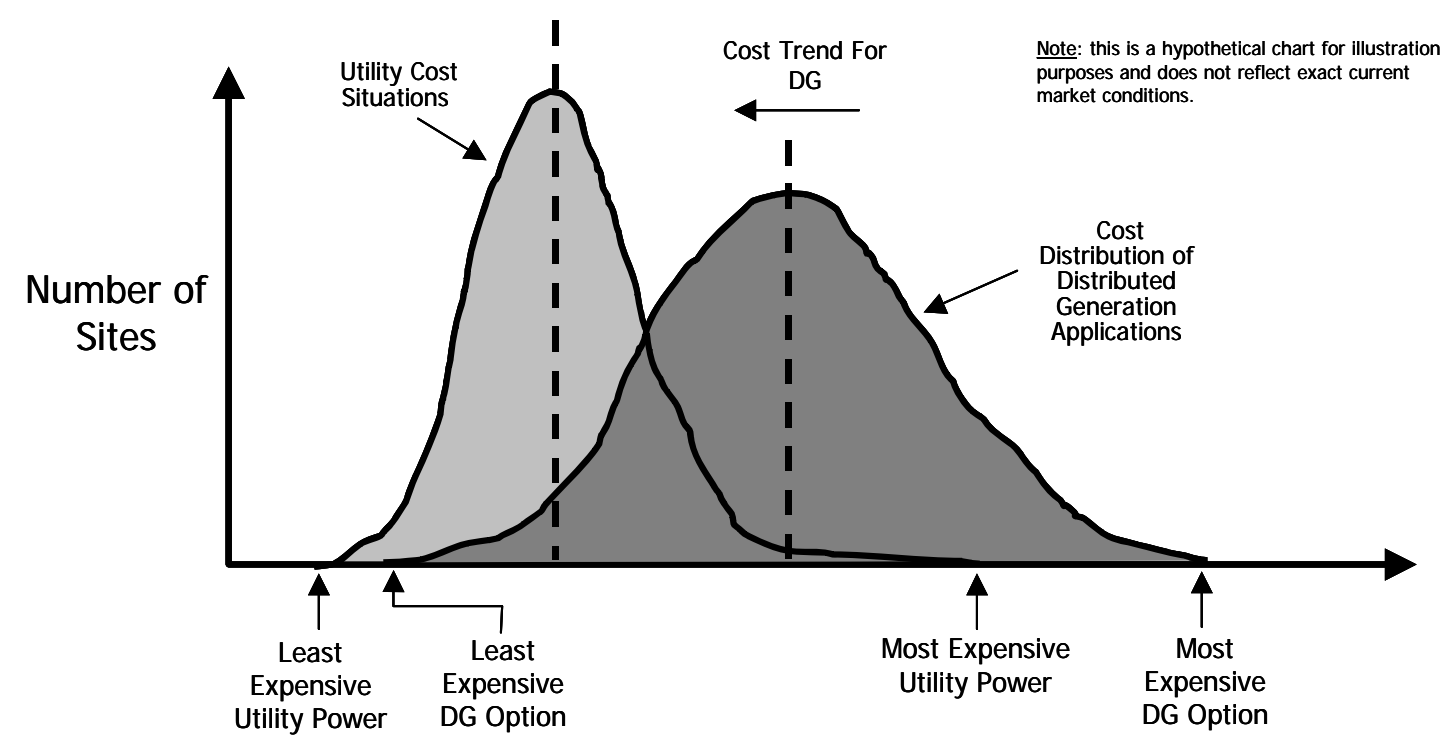

Cost

\section{Figure 4-15}

Illustration of Cost Distribution of Utility Energy Cost Scenarios Overlaid on Possible DER Cost Scenarios

Another cost factor to consider is that the electricity costs of Table 4-4 are based on ideal operating conditions for the distributed generators. If the DER is operated at light load, this will reduce the efficiency and increase the capitol investment per generated kilowatt-hour. Therefore, the cost of energy goes up. Generation plants have the lowest cost of production generally when they are operated at full load (at the highest possible capacity factor).

\subsubsection{DER in Lieu of a Line Extension}

There are applications for full-time micro-grids that stand-alone from the T\&D system and can make economic sense even when the cost is very high. One such application is the line extension deferment. Because the cost of building new primary distribution systems is in the range of $\$ 40,000$ to $\$ 100,000$ per mile (depending on the line design, terrain, and local labor costs), extending a line to serve a small load such as village or cluster of vacation homes can be more costly than building a micro-grid.

As an example, a micro-grid to serve 10 clustered vacation homes using a low-voltage configuration and ICE units could be completed for less than $\$ 100,000$. If the cluster of homes were located 3 miles from the nearest conventional distribution feeder, it probably would make more sense to build the micro-grid than to extend the distribution line- that is, assuming fuel can 
be delivered to the site and the ICE units and micro-grid can be operated with sufficient reliability to keep the customers happy.

\subsubsection{Most Likely Scenarios of Utility-Owned DER}

DER with demand side management can potentially reduce the loading on the transmission system, distribution system, and central station generators. The benefits of such reduced loading are called T\&D support benefits. Each watt of generation or demand side reduction that can be applied to reducing the peak power system demand reduces the need for capacity to transmit that watt from the central station to the end-use location where it would normally be consumed. Ideally, this can help the power system in the following ways:

- Defer need for new central station capacity,

- Defer need for new or upgraded T\&D infrastructure,

- Reduce power losses in T\&D infrastructure,

- Provide voltage support (Which will help reduce voltage drop on the system), and

- $\quad$ Release capacity on T\&D system (Which will help relieve transmission congestion).

Achieving these benefits is more difficult in practice than is often realized. Many of these benefits are only realized if peak system loading is reduced. Reducing loading at any time other than peak, while it still offers some benefits, won't offer the key capacity benefits that are so critical to establishing the highest T\&D support value. To be of true value, distributed generators and demand-side management approaches must be effectively dispatchable at the time of peak system loading. As an example, Figure 4-16 shows two daily demand cycles: one for a feeder with a peak load at around noontime and the other for a feeder that peaks in the early evening. Because the DER system operates during the period around noon, clearly the best feeder on which to apply this generator would be the feeder that peaks at noon. It would provide little support benefit from a capacity perspective for the evening peaking distribution feeder.

The reliability of the dispatch is extremely important. Many customer-owned generators that could be part of DER systems may have no reason to operate at times that are desirable for utility feeder support. In addition, periods of time may exist when the customer generation is unavailable for days or weeks because of a forced outage or scheduled, maintenance-related outage. When considering the actual amount of effective capacity relief that DER provides, planners must also plan for long forced outages and maintenance-related outages of DER. In many cases, for the capacity of the DER to really offer a potential for deferment of T\&D capacity, the customer-owned generators may need strong incentives to operate their generation at the time of peak feeder load and avoid maintenance outages during heavy loading seasons on the feeder such as summer or winter. Time-of-day electric tariffs or special contracts that encourage customers to operate DER at the time of peak system load are ways to achieve more reliable dispatch of customer-owned generation.

The value of deferred T\&D capacity depends on the economic scenario that applies at each specific utility company. Because companies each have different costs of building transmission and distribution infrastructure attributable to variations in terrain, labor costs, tax structure, cost of money, and cost of maintenance, a broad range of value is possible. For many utilities, the annualized value per kilowatt of T\&D deferment is in the range of \$50-200 per year depending 
on the cost structure of the utility company (This number is the total value of deferring $1 \mathrm{~kW}$ of distribution, transmission, and substation infrastructure). If DER capacity can be effectively applied to achieve a T\&D capacity deferral, then it is clear that this is a sizable benefit that can help justify the deployment of DER. Note that it alone can't offset the cost of DER but when added to other values such as the raw energy production and thermal output, together these can look very attractive.

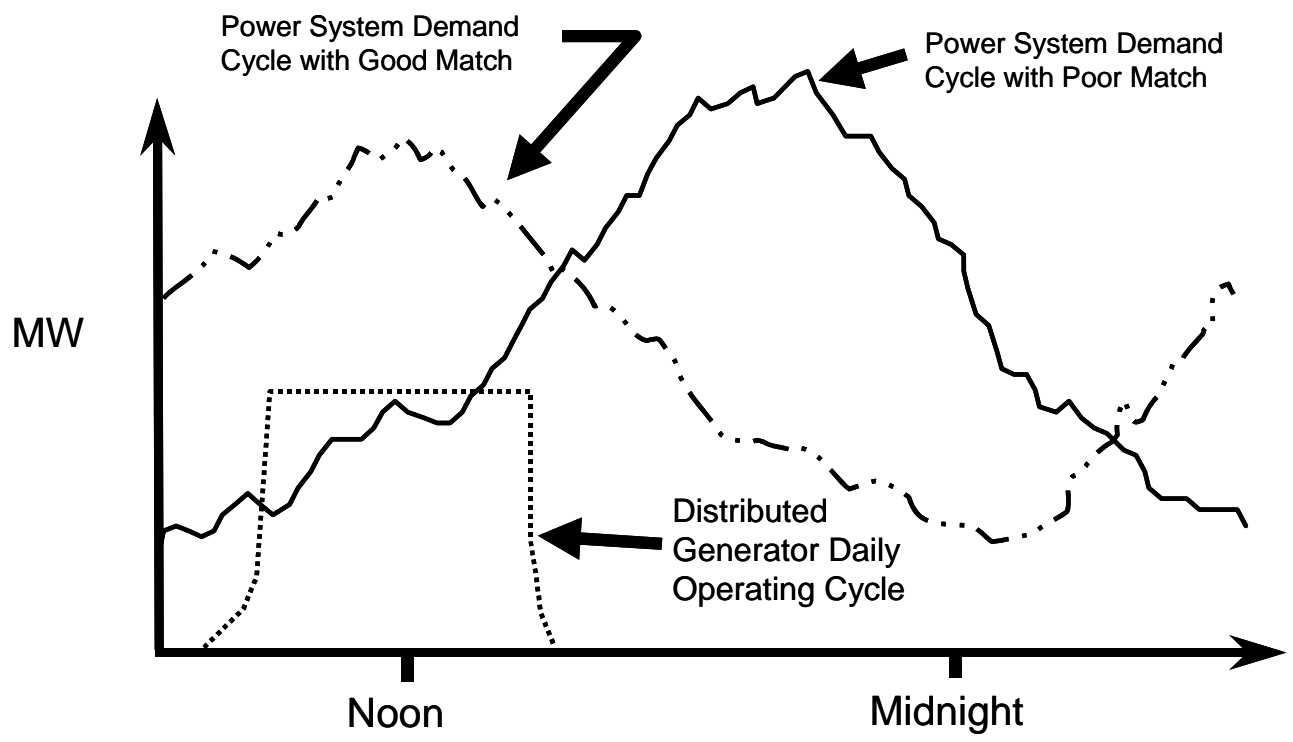

Figure 4-16

Distributed Generation Provides a Capacity Benefit Only if it is Available at the Time of Peak System Loading

\section{Distribution and Grid Support for Isolated- or Micro-Grids}

Isolated or islanded grid systems are those that operate without a connection to a large transmission grid or only via a very weak connection. This usually occurs in places such as small islands or remote towns that are geographically a significant distance from the transmission grid. The isolated grids do not import or export very much energy. Consequently they must be self sustaining, and able to quickly match generation with load. They cannot rely on the stiff transmission grid with many generation sources for frequency regulation. As a result, such grids usually have one or more generation units operating at less than full power to provide frequency control with output regulation up or down to match changes in system load.

Most isolated grids are small and individual generators are very large in relation to the size of the system, often making up $20-30 \%$ of the total generation. Thus the failure of a single unit could lead to failure of the grid. Consequently more reserves are required and the overall cost of operation is likely higher. Individual loads also form a bigger part of the total grid capacity, further increasing the susceptibility of the grid to disturbances. Controlling such a system can be a rather nervous business.

In such a case distributed resources, both generation and energy storage, can bring a number of benefits to the table. An appropriately-sized generator or energy storage system can perform frequency regulation and voltage support functions. The DER can also provide spinning reserve 
to the system. In the event of blackout, an energy storage system may even be able to provide black start services, provided it is located reasonably close to the generator it is helping to start.

\section{Peak Shaving for Substation or Distribution Investment Deferral}

Suppose the peak load in an area has grown beyond the rating of the substation transformer serving the area, while the average load remains well below the full rating of the substation. The utility faces a potentially expensive upgrade to meet a condition that may only exist for a few hours in the year. And, depending on the rate of load growth in the area, the problem may only be a temporary one that will resolve itself in a few years. The utility could consider the installation of DER for peak shaving as shown in Figure 4-17, which is often a cheaper way of serving the part-time overload and a better utilization of existing assets.

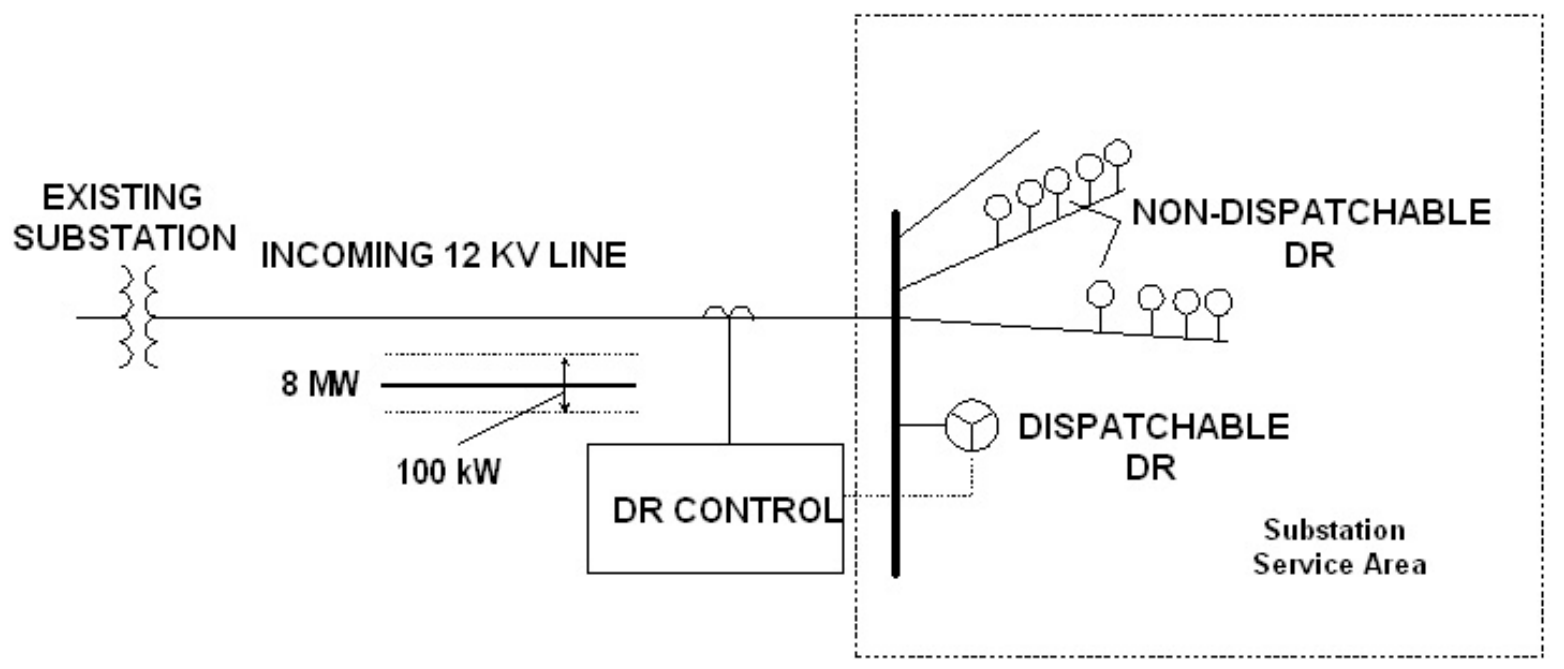

Figure 4-17

Dispatchable DER can Operate with Renewable DER to Regulate Loading

Unlike typical T\&D upgrades the DER solution can be modular, and is easier to add to or decrease in size as needed over time. Strategically placed DER may actually provide a leveraging effect where system capacity is increased more than the rating of the DER device. ${ }^{39}$ In transmission systems the incremental increase in ability to serve the load can to several times the rating of the DER. In distribution systems the increase is more in the range of 1 to 1.5 times, and is the result of additional reactive power support to maintain the required voltage under high loading conditions.

Whether generation or energy storage makes sense in this situation depends heavily on the rate at which the load is growing. Typically, the cost of an upgrade in $\$ / \mathrm{kW}$ is relatively low, but the overall capital cost is high because the number of $\mathrm{kW}$ is large, while the reverse is true for a DER peak shaving product. If the peak load is growing quickly, it would make more sense to go ahead and choose the upgrade to take advantage of the low $\$ / \mathrm{kW}$ cost. A slower growth in peak

\footnotetext{
${ }^{39}$ R.C. Dugan and S. K. Price, “Including Distributed Resources In Distribution Planning,” IEEE 2004 PSCE Conference Proceedings, New York, October, 2004.
} 
load would favor the cheaper initial cost of generation or energy storage solution, allowing the utility to defer large investments and take advantage of the time value of money.

Generally, DER peak shaving makes sense more often for deferral of substation or transmission assets than for distribution assets. This is because distribution assets tend to be much cheaper, and can often be applied piecemeal. ${ }^{40}$

\section{Distribution Support for Integration of Renewable Energy Resources}

Renewable energy sources such as wind turbines and solar photovoltaic power systems suffer from variability in output and a lack of dispatchability. Utility system operators have limited control over when power is produced, and how much is produced. If significant renewable capacity is connected to the grid, control of the system becomes difficult, since the generation often does not coincide with the load. Ideally, this should be corrected through aggregation and diversity in the transmission grid, which evens out differences. However, smoother effect may not be possible in areas with weak connections or no connections to a large grid system. Renewable sources connected directly to a distribution feeder will also have affects on other grid operational issues, such as voltage regulation and protection. This is important since a significant number of renewable power sources are connected in this way [3]. ${ }^{41}$

Dispatchable generators or energy storage systems can help the situation by leveling the power output of renewables, storing excess power when it is available and releasing it when it is required. The dispatchable DER can provide frequency regulation control in areas with little or no support from transmission, and can also provide voltage support through an appropriate power conditioning system. This application has been attempted in several locations. NEDO, a Japanese government agency, funded initial experiments examining the use of energy storage to stabilize wind turbine output, funded the development of a $4 \mathrm{MW}$ energy storage system to stabilize a wind farm in Hokkaido, Japan. King Island, a small island off the coast of Australia, has installed a vanadium redox-flow battery to serve the same purpose on their relatively small grid.

In addition to the main purpose, there are often additional value streams for the energy storage in any of these scenarios, depending on the technology selection, system design and location of the energy storage system. For example, the owner of a system designed for peak shaving should consider the sale of transmission-level ancillary services, such as frequency regulation control and spinning reserve, to further enhance the value of the system. In many cases, such sales will have minimum effect on the life of the unit while leading to a significantly better economic proposition.

\footnotetext{
${ }^{40}$ Strategic Role of Distributed Resources in Distribution Systems, Report \# TR114095 EPRI, Palo Alto, CA: 1999.

${ }^{41}$ Wind Power Integration Technology Assessment and Case Studies, Report \#1004806 EPRI, Palo Alto, CA: 2004.
} 


\section{Conclusions and Recommendations}

\subsection{Conclusions}

DER appears to provide a viable means for satisfying the electrical, thermal and reliability needs of the digital economy. It is expected to play an increasing role as distributed generation technologies improve. Today it is common practice for onsite generation vendors to provide integrated energy packages that are finding some applications in high-tech digital industries. These packages include onsite generation, integrated energy management controllers, power conditioning, heat recovery equipment and energy efficiency technologies; installed as part the power delivery and facility system. The concepts are not new but in recent years they have become increasingly sophisticated as the technology of DER and microprocessor based energy management controllers have improved.

Currently most on-site generation at in high-tech digital industries are dedicated to uninterruptible or back up power systems. However, to get the full value of these resources, thermal recovery and additional value streams will be needed. In the future DER for digital users will need to employ more diversity of generation sources and a much broader range of innovative heat recovery and power conditioning technologies. Getting to this next level will require improved distributed generation technologies, development of various supporting technologies in controls, power conditioning and heat recovery, and more field experience to develop and refine configurations needed to make these systems practical and cost effective for both commercial and industrial users.

There are obstacles to the implementation of DER for digital users. First, the cost of many onsite technologies is still too high to make economic sense. On a cost-of-energy basis, even lowcost DER technologies such as the internal combustion engine and turbine engine are usually competitive only in higher-cost utility power markets and only when CHP can be employed or reliability enhancement is needed. There are reliability and maintenance issues associated with the all the emerging on-site power technologies that are still in the early commercialization phase, and many control issues for integrating these systems have yet to be worked out. The regulatory and business questions revolving around the micro-grid also need to be resolvedquestions such as:

- Will digital industries want to broaden there businesses to include on-site power systems.

- What configuration will make business sense, micro-grid, multi energy, end-user or utility owned?

- Will wires companies be allowed to operate the micro-grid with its embedded generation?

- Can ancillary services, such as waste heat and reliability be sold and, if so, for what price?

These questions need to be answered before digital end users and utility companies can invest in DER, with a business plan that shows a recovery of the monetary and reliability benefits and a return on investment for installing and operating these systems.

In addition, there are still unresolved technical issues relating to utility system interconnection and the ability of multiple diverse generator types to operate as a coordinated and reliable system. New equipment to resolve these issues needs to be developed, and design experience 
needs to be obtained to establish the complete infrastructure needed to support development. The digital economy customer will also need to strongly believe in the potential savings and reliability improvements if they are to adopt the complexity of many DER systems.

\subsection{Recommendations for Future R\&D}

Based upon the preceding discussion, there are a number of areas of potential future research activities that can support the further development of DER for the digital economy. These addressed below.

\subsubsection{Interconnection for DER-Compatible Distribution-System Architecture, and Control Methodologies}

The industry has developed interconnection standards such as the IEEE 1547 for distributed generation that does not necessarily operate as a micro-grid. That work focused on the requirements for interconnection of DER to standard distribution systems, and much of it does not deal with the issues needed on micro-grid systems. The operation of distributed generation on micro-grid systems, such as architectures with dispersed multiple generation resources, will require significant changes in the controls, relay settings, grounding practices, and other technical interface requirements compared to those used for standard distribution systems. A project is recommended to evaluate and develop approaches for DER control and protection when DER is operated in micro-grids. The project should define the best methods to optimally dispatch generators, recover from system blackouts, control frequency and voltage, and handle electrical disturbances. Many of the recommendations would be based upon dynamic simulations of DER, representing various options for protection, voltage control, and frequency control.

\subsubsection{DER Compatible Distribution System Architecture}

Another key research element is to determine the ideal design and layout for a power-distribution system. Designs need to be developed that are compatible with micro-grid operation. These new designs will need to be much more like a transmission system with zone-based relaying and bidirectional capability. Design issues include the feeder configurations, types of protection devices and relaying needed, voltage-regulation equipment, grounding, and other design factors that are required to make micro-grids technically feasible. This part of the project would also include developing guidelines for primary and secondary power-system designs based on computer load-flow simulations that would identify the needed physical lengths of the primary circuits, spacing between generation plants, conductor sizes, and equipment ratings needed to facilitate proper system operation.

\subsubsection{Heat Recovery from Load Devices}

Loads can serve as a source of heat energy for water heating, space heating and other needs. While some products are available to recover heat from loads, it is clear that this is an area in which not much development has occurred and it may be very fertile ground for development of some new products and technologies that can increase efficiency. It is recommended that a research project be performed to identify the sources of waste heat energy in various types of loads and power delivery equipment and determine the methods and practicality of recovering heat from these devices. Some of the devices that are of interest include: 
- Servers and Routers

- Main-frame Computers and related Cooling Systems

- Facility Lighting and HVAC Systems

- Process Control Systems

- Power Conditioning Equipment

\subsubsection{Proof-of-Concept Designs, Modeling, and Lab Tests for DER based Premium Power}

Several low-voltage architectures for micro-grids were identified in this report that may be a radical departure from existing distribution systems but which have great promise to lower cost and improve power quality. These include both AC and DC designs. It is recommended that these be investigated with sufficient detail such that detailed designs for both AC and DC systems can be developed, including the required protection, grid layouts, types of loads, and load densities that can be served; spacing between connecting nodes and generators; and voltagedrop calculations.

\subsubsection{Detailed Economics DER}

Detailed case studies are recommended to evaluate the full lifecycle costs of micro-grids compared to conventional power-delivery systems. These studies should quantify the cost of all equipment needed and compare this cost with more traditional solutions. Case studies for several systems are recommended, including a micro-grid in lieu of a line extension, a substation-based micro-grid, a small residential cluster, and a power quality business park.

To evaluate the economics of DER applications like those discussed in this report, a project to perform very detailed case studies is recommended. These studies will quantify the cost of all equipment for the DER applications, look at its lifecycle cost and compare it with more traditional solutions. Case studies for three systems are recommended; residential, commercial office building and multi-energy park. These case studies can be used to help develop a formalized screening approach for DER applications.

\subsubsection{Power Equipment and Devices}

There are some physical devices that may be needed for successful micro-grid deployment. For example, sections 2 and 3 discussed a flow-blocking device that might be helpful at implementing the control and protection that is needed for DC and AC micro-grid designs, and there are many other useful devices that are worth investigating. These include:

- Micro-grid dynamic stabilizer with ultra-capacitor energy storage and other types of power conditioners

- DC and AC flow-blocking and sectionalizing devices

- Wide range DC-to-DC converters

- Static distribution transformers

- Self-synchronizing circuit interrupters and switchgear

- High-voltage DC interrupting devices 
- Whole-house inverter systems

- Secure high-speed and low-speed communication technologies such as power-line carrier and wireless-based devices suitable for linking micro-grid equipment

- Inverter control that will enable the DER to actively support the AC system voltage and frequency during electrical disturbances

- CHP and heat-recovery products that can add value to micro-grids

These and other devices could be investigated to determine their availability and/or the possibility for development if no suitable products are available. Studies could range from design analysis studies up to the development of prototype devices. Prototypes would be developed from scratch or by modifying existing products where appropriate. Research to focus on any of these areas to show the feasibility of products or systems or to develop specific prototype hardware would be useful to the industry to establish the base of necessary equipment for DER based systems. 